\title{
Hormonal responses in women as a function of physical exercise and training
}

Citation for published version (APA):

Keizer, H. A. (1983). Hormonal responses in women as a function of physical exercise and training. [Doctoral Thesis, Maastricht University]. Vrieseborch. https://doi.org/10.26481/dis.19830909hk

Document status and date:

Published: 01/01/1983

DOI:

10.26481/dis.19830909hk

Document Version:

Publisher's PDF, also known as Version of record

\section{Please check the document version of this publication:}

- A submitted manuscript is the version of the article upon submission and before peer-review. There can be important differences between the submitted version and the official published version of record.

People interested in the research are advised to contact the author for the final version of the publication, or visit the DOI to the publisher's website.

- The final author version and the galley proof are versions of the publication after peer review.

- The final published version features the final layout of the paper including the volume, issue and page numbers.

Link to publication

\footnotetext{
General rights rights.

- You may freely distribute the URL identifying the publication in the public portal. please follow below link for the End User Agreement:

www.umlib.nl/taverne-license

Take down policy

If you believe that this document breaches copyright please contact us at:

repository@maastrichtuniversity.nl

providing details and we will investigate your claim.
}

Copyright and moral rights for the publications made accessible in the public portal are retained by the authors and/or other copyright owners and it is a condition of accessing publications that users recognise and abide by the legal requirements associated with these

- Users may download and print one copy of any publication from the public portal for the purpose of private study or research.

- You may not further distribute the material or use it for any profit-making activity or commercial gain

If the publication is distributed under the terms of Article $25 \mathrm{fa}$ of the Dutch Copyright Act, indicated by the "Taverne" license above, 
Sportwetenschappelijke Onderzoekingen 4

HORMONAL RESPONSES IN WOMEN AS A FUNCTION OF PHYSICAL EXERCISE AND TRAINING 


\section{HORMONAL RESPONSES IN WOMEN AS A FUNCTION OF PHYSICAL EXERCISE AND TRAINING}

\section{PROEFSCHRIFT}

ter verkrijging van de graad van

Doctor in de Geneeskunde aan de

Rijksuniversiteit Limburg te Maastricht

op gezag van de Rector Magnificus

Prof. Dr. H. C. Hemker

volgens het beslluit van het College van Dekanen

in het openbaar te verdedigen in

de Aula van de Universiteit op

vrijdag 9 september 1983

des namiddags 16.00 uur

door

\section{HANS AD KEIZER}

geboren te Medemblik

\section{Dy}

Uitgeverij de Vrieseborch - Haarlem 
Promotores : Prof. Dr. R. S. Reneman, Rijksuniversiteit Limburg, Maastricht Prof. Dr. P. J. Brombacher, Rijksuniversiteit Limburg, Maastricht

Prof. Dr. J. de Haan, Rijksuniversiteit Limburg, Maastricht

Referenten : Prof. Dr. J.H. H. Thijssen, Rijksuniversiteit Utrecht Dr. J. L. H. Evers, afd. Gynaecologie en Verloskunde, St. Annadal Ziekenhuis, Maastricht

Het in dit proefschrift beschreven onderzoek werd mede mogelijk gemaakt door financiële steun van de Stichting Nationale Sporttotalisator, Den Haag, de Stichting Dr. Ir. J. H. van der Laar, Heerlen en Organon International BV, Oss.

(c) 1983 Hans Ad Keizer

Niets uit deze uitgave mag worden verveelvoudigd en/of openbaar gemaakt door middel van druk, fotokopie, microfilm of op welke andere wijze ook zonder voorafgaande schriftelijke toestemming van de uitgever.

BV Uitgewerij De Vrieseborch

Jacobijnestraat 5 - 2011 TG Haarlem

ISBN 9060761855 
Voor

11

Daniëlle

en Irmo. 


\section{CONIENTS}

\section{ABBREVIATIONS}

Chapter $\mathbb{1}$

INTRODUCTION

\section{Chapter II \\ SYNTHESIS, SECRETION, "TRANSPORT, CONUERSION AND DEGRADATION OF STEROIDS}

2.1 Intiraduction

2.2 Glandular sterolidogenesis

2.2.1 Dyarian steroidogenesis

2.2.1.1 Phases of the menstrual cycle

2.2.1.2 Changes in plasma sex homone levels during the nomal menstrual cycle

2.2.1.3 Sites of ovarian homone synthesis

2.2.1.4 Neuro-endocinine control of ovarian steroidogenesis 20

2.2.2 Regulation of adrenal steroidagenesis 21

2.3 Transport of steroid hormones $\quad 22$

2.4 Secretion, production, conversion and degradation of sex steroids

2.4.1 Introduction

2.4.2 Secretion rate $(S R)$, blood production rate $\left(P R_{B}\right)$ and

2.4.2.1 Estradial metabolic clearance rate (MCR) of sex steroids

2.4.2.2 Progesterone

2.4.2.3 Androgens

Chapter III

MATERIALS AND METHODS

3.1 Subjects $\quad 29$

3.2 Exercise protocols 33

3.2.1 General considerations 33

3.2.2 Erglometers

3.2.3 V0max tests $\quad 35$

3.2.4 Exercise protocols used in the studies 36

3.3 Experimental procedures 36

3.3.1 General procedures 36

$\begin{array}{lll}3.3 .2 & \text { Study I } & 37\end{array}$

3.3.3 Study II 38

3.3.4 Study III $\quad 39$

3.3.5 Study IV 40

3.3.6 Study Va en Wb 40

3.4 Analytical methods 42

3.4.1 Handing of blood samples 42 
3.4.2 Glucose and total protein 43

3.4.3 Lactate 43

3.4.4 Homone analyses 44

3.4.5 Free fraction of testosterone and estradiol 48

3.5 Data analysis 51

3.5.1 Criteria for maximal tests 51

3.5.2 Statistical analysis 53

Chapter IV

RESULTS

4.1 Maximal physical working capacity (MPWC) in relation to

4.2 Me phase of the menstrual cycle (study I)
4.2

exercise in untrained and trained women (study I and II) 56

4.2.1 Metabolic responses to exercise 57

4.2.2 Endocrine responses to exercise 60

4.2.3 The influence of a three month training period on hormonal and metabolic responses to exercise (study III) 79

4.2.3.1 Maximal physical working capacity (MPWC) 79

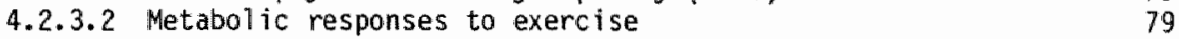

4.2.3.3 Endocrine responses to exercise 81

4.3 Gonadotropin and estradiol secretion patterns before and after prolonged physical exercise (study IV) 89

4.4 The influence of short-time physical exercise on the metabolic clearance rate of estradiol (study $\mathrm{Va}$ and $\mathrm{Vb}$ ) 96

Chapter W

DISCUSSION

5.1 Physical working capacity and metabolic responses in relation to the phase of the menstrual cycle (studies I and II)

5.2 Acute effects of physical exercise on plasma levels of sex hormones as a function of the level of physical fitness

(training)

5.2.1 Effect of a three month endurance tratining program on metabolic and hormonal responses to exercise (study III) 112

5.2.1.1 Maximal physical working capacity and metabolic responses to exercise

5.2.1.2 Endocrine responses to exercise after a period of endurance training

5.3 Changes in gonadotropin and estradiol secretion patterns (study III)

5.4 Possible mechanisms of the exercise-induced increments of plasma sex homones

5.4.1 The adrenal cortex as a possible source of enthanced plasma androgen levels

5.4.2 Exercise-induced changes in the MCR of estradiol 118

5.5 GENERAL DISCUSSION 
6.1 Summary and conclusions

6.2 Samenvatting en conclusies

\section{REFERENCES}

TABLES A1-A3

MAWDORD

CURRICULUM VITAE

Parts of the present thesis have already been published:

Bonen, A. and H.A. Keizer.

Athletic Menstrual Cycle irregularity (AMI) Endocrine response to exercise and training. Phys. Sportsmed. In press.

Keizer, H.A., Poortman, J. and G.S.J. Bunnik.

Influence of physical exercise on sex hormone metabolism.

J. Appl. Physiol. REEP 48: 765-769, 1980.

Kelzer, H.A., Poortman, J. and G.S.J. Bunnik.

Influence of physical exercise on sex hormone metabolism. In: Biochemistry of exercise IV-B Int. Series on Sport Scil., IIb (Eds: J. Poortman, G. Niset), University Park Press, Baltimore (1981), pp. 229-236.

Keizer, H.A., Van Schaik, F.H., De Beer, E.L., Schiereck, P. and G. van Heeswijk.

Exercise-induced changes in estradiol metabolism and their possible physiological meaning. Med. Sport 14: 125-140, Karger, Basel, 1981.

Keizer, H.A., Kuipers, H., Verstappen, F.T.J. and E. Janssen. Limitations of concentration measurements for evaluation of endocrime status of exercising women.

Can. J. Appl. Sport Sci. 7: 79-84, 1982. 


\section{ABBREVIATIONS}

$$
\begin{aligned}
& \text { ACTH = adrenocorticotropic hormone } \\
& \triangle 4-A=\text { androstenedione } \\
& \text { BBT = basal body temperature } \\
& \text { DHEA = denydroepiandrosterone } \\
& \text { DHEA-S = dehydroepiandrosterone sulfate } \\
& \mathrm{dpm} \quad=\text { desintegrations per minute } \\
& \mathrm{E}_{2} \quad=\text { estradiol } \\
& \text { GnRH = gonadotropin releasing homone } \\
& \mathrm{FSH}=\text { follicle stimulating homone } \\
& \text { IU = international unit } \\
& \mathrm{K}_{\text {ass }}=\text { affinity constant } \\
& \mathrm{LH} \quad=\text { Luteinizing hormone } \\
& M=\text { molar } \\
& \text { MCR = metabolic clearance rate } \\
& \text { mmol }=\text { millimol }\left(10^{-3} \mathrm{~mol}\right) \\
& \text { nmol = nanomol }\left(10^{-9} \mathrm{~mol}\right) \\
& \text { umol = micronol }\left(10^{-6} \mathrm{~mol}\right) \\
& \text { pmol }=\operatorname{picomol}\left(10^{-12} \mathrm{~mol}\right) \\
& \text { MPWC = maximal physical working capacity } \\
& \text { PRL = prolactin } \\
& \text { SHBG = sex homone binding globulin } \\
& \mathrm{T} \quad=\text { testosterone } \\
& \mathrm{TRH}=\text { thyrotropin releasing hormone } \\
& \mathrm{VO}_{2} \text { max }=\text { maximal oxygen uptake }
\end{aligned}
$$



CHAPTER 1

INTRODUCTION

It is only since the early seventies that women are allowed to compete in athletic activities associated with intense physical exercise. Until then it was thought that such activities as marathon running and crosscountry skiing were harmful to the female body although direct evidence for this idea was lacking. As a result of the growing interest to participate in such demanding types of exercise, the volume and intensity of the training of women increased tremendously, improving their performance level. Consequently the time devoted to training in elite class women athletes is not different from their male counterparts. Despite these alterations, there still remains a significant difference between the absolute performance of male and female athletes, probably due to hormanal, social and cultural factors. Al so the level of selection and competition might play a role (Harris, 1977; Wells, 1977).

Parallel to the increased participation in various types of athletic activities in women a growing scientific interest in responses to exercise can be observed. Especially the relation between physical exercise and the changes in plasma concentration of sex hormones - induced by the menstrual cycle itself or by physical exercise - receives more and more attention. Several reasons can be given for this growing scientific interest. Firstiy, the influence of the phase of the menstrual cycle on maximal physical performance and related physiological parameters is still controversial. Secondly, the exercise induced changes in sex hormone levels might be responsible for menstrual cycle disturbances.

- The phase of the menstrual cycle and physical performance.

It has been suggested that in women maximal athletic performance is dependent on the phase of the menstrual cycle, although conflicting results are reported about this relation. Several authors suggested a post-menstrual, pre-ovulatory performance optimum and a decreased maximal performance in the pre-menstrual or luteal phase (Millahn and Drecoll, 1960; Pahlke and Smitka, 1977; Schoene et al, 1981). Others showed an increased 
phystical performance in the luteal phase as compared to the follicular phase (Muller-limroth and Lohaus, 1963; Jurkowski et al, 1978). To complete the confuston several authors could n't find any effect of the phase of the menstrual cycle on maximat physical performance

(Drinkwater, 1973; Verstappen et al, 1981; Kuipers, 1983).

Maximal physical perfomance in prolonged physical exercise is not only dependent on the maximal oxygen uptake $\left(\dot{v} 0_{2} m a x\right)$ of a subject, but al so on the blood lactate response in relation to the workload and substrate turmover in skeletal muscle.

Since the blood concentrations of estradiol-17 $\left(E_{2}\right)$ and progesterone (P) shift markedly during the menstrual cycle their normal physiological alterations may possibly affect substrate utilization. In women this has been suggested by severall authors (Merimee et a1, 1969; Reinke et a1, 1972; Morrow et al, 1981). Such differences may become more apparent during exercise, when large alterations in substrate turn-over occur to meet the increased metabolic demands of skelletal muscle. The scarce data dealing with this topic are conflicting. Schwantiz and co-investigators (1978) reported a higher plasma glucose concentration in the luteal phase as compared to the follicullar phase in young women during a bicycle ergometer ride. On the other hand, Bonen and co-investigators (in press) could not find any effect at all of the phase of the menstrual cycle on the blood glucose response to exercise in young women.

Data on exercise-induced changes in blaod lactate in relation to the phase of the menstrual cycle are very scarce. Jurkowski and co-investigators (1978) reported a higher blood lactate content during submaximal and maximal exercise in the follicular phase of the menstrual cycle as compared to the luteal phase in nomally menstruating women. On the contrary Verstappen and co-investigators (1981) and Kuipers (1983) did not observe any difference between the phases of the cycle.

The experimental desigm of most of the afore mentioned studies i.e. the lack of data on the plasina concentration of ovarian steroid hormones and the wide variety of exercise protocols used, makes it impossible to draw definte conclusions regarding the relation between the phase of the menstrual cycle, the glucose and lactate responses and maximal athletic perfomance. If it is true that the phase of the menstrual cycle indeed can affect maximal physical performance and/or the response of physiological 
variables to exercise, it is tempting to speculate that the associated alterations in circulating sex-hormone lewels might be respons ble for this phenomenon.

- Exercise-induced changes in plasma sex hormone levels.

Recently it has been shown that physical exercise can be a powerful stimulus for increasing the circulating levels of sex hornones. For example, exercise induced increments of estradiol-178 ( $\left.E_{2}\right)$ and progesterone (P) have been observed in young untrained women (Jurkowski et al, 1978; Bonen et al, 1979). The magnitude of these increments seems to be dependent on the phase of the menstrual cycle in which the exercise was performed; it was reported to be most pronounced in the luteal phase (Juwkowski et al, 1978; Bonen et al, 1979). In contrast to trained women (see below) no data are available on changes in androgen concentration as a result of physical exercise in untrained women. Yet the influence of the phase of the menstrual cycle on androgen responses to exercise is unknown.

It is incompletely understood whether the hormonal responses to physical exercise are different in trained and untrained women. Bonen and co-investigators (1979) did not find an exercise-induced increase in plasma $E_{2}$ levels in women after a training period of three months. However, these findings seem to be in contrast with data from Schmitt and co-investigators (1981) who found distinct increments in plasma $E_{2}$ levels after a marathon run in trained women. The plasma testosterone (T) levels are reported to rise during exercise in trained women (Shangold et al, 1981; Baker et al, 1982). During exercise the concentration of some hormones, for example prolactin (PRL), was found to rise more pronounced in trained than in untrained women (Brisson et al, 1980; Shangold et al, 1981 ).

Detailed information about the possible onigin of the exercise-induced increments in plasma hormone concentration or the variability in the hormonal response to exercise in different phases of the menstrual cycle is not available due to the scanty number of investigations and the small number of subjects participating in these studies.

Interpretation of the afore mentioned data is difficult because the total plasma concentration of a hormone is the net result of production and metabolic clearance. The plasma $E_{2}$ concentration in young women for example results from secretion by the ovaries and to a minor extent by the adrenal 
cortex, perlpheral conversion of androgens and degradation which takes place in hepatic and extra-hepatic tissues. Thus, an enhanced plasma concentration can be attributed to increased glandular secretion, decreased degradation, Increased peripheral conwersion or combinations of these three mecharifsms.

An increased secretion rate of sex homones by the ovaries is likely to result from stimulation by the gonadotropins: the follicle stimulating hormone (FSH) and luteinizing homone (LH), which are secreted by the anterior pituitary gland. From the literature it is not clear whether the pituitary is indeed involved in the increased plasma cancentration of sex hormones during exercise, because $L H$ concentrations were reported to be unaffected (Jurkowski et al, 1978; Bonem et a1, 1979), increased (Bonen et al, in press) or decreased (Brisson et al, 1981) under these circumstances. In addition mo data are avallable about the effect of physical exercise on the episodic secretion pattern of gonadotropin releasing hormone (GnRH), LH and FSH.

For $T$ the situation is even more complicated, because in women a considerable part of the plasma concentration of this hormone is derived from adrenal secretion (Abraham, 1974). However, data on the adrenal contribution to the plasma concentration of androgen during exercise are lacking. Also the exercise-induced changes in degradation or conversion rate of ovarian and adrenal steroids have not been investigated until now.

Another complicating factor concerning the interpretation of changes in homone concentrations is that they do not necessarily represent the biological activity. The major part of the circulating plasma steroids is bound to specific proteins, which render them inactive (Pearlman et al, 1967; Kato and Horton, 1968; Vermeulen, 1973). The free fraction and/or the fraction that is bound to proteins with low binding affinity is responsible for the biological activity. Physical exercise does not only increase the concentration of sex homones, but al so body temperature. Consequentiy this might change the biological activity of hormones, because the dissociation rate is temperature dependent (Vermeulen and Verdonck, 1968; Vigersky et a7, 1979; Lata et al, 1980). In addition, a rise in free concentration tends to increase the degradation rate (Vermeulen and Ando, 1979).

In summary it appears from the afore mentioned studies that comprehensive knowledge of the homional responses to exercise in women is lacking. 
Yet, the underlying mechanisms for the exercise-induced increments in sex-hormone levels are incompletely understood. More detailed knowledge is of interest because:

- it is well recognized that the incidence of menstrual cycle disorders is significantly higher in athletes than in control-subjects (Dale et al, 1979; Speroff and Redwine, 1980; Baker et al, 1981).

- it is not known whether a decreased metabolic clearance rate or an increased ovarian and/or adrenal secretion rate is responsible for the observed increases in cinculating levels of sex homones.

The objectives of the present study were:

1 to evaluate the influence of the phase of the menstrual cycle, if any, on maximal physical performance and related physiological parameters.

2 to collect more detalled information about the hormonal responses to exercise in relation to the phase of the menstrual cycle in women with various levels of physical fitness. This aspect of the study was aimed at setting a valid hypothesis for the origin of the exercise-induced changes in sex hormone levels.

This may al so lead to a better insight into the reported menstrual cycle disturbances in women-athletes.

3 to differentiate between changes in degradation rate (measured as the metabolic clearance rate) and production rate as a possible cause of the exercise-induced increments in sex-hormone levels.

The effects of the phase of the menstrual cycle on physical performance was investilgated in three studies (I to III). In study I 19 untrained students volunteered, while in study 116 highly trained marathon runners participated. In study III the influence of a training period on maximal physical perfomance was evaluated in 8 previously umtrained women. In these studies also the hormonal responses to prolonged physical exercise were investigated.

The possible mechanisms of the increases in plasma hormone concentrations were investigated in study IV and $V$. In study IV, the post-exercise responses of gonadotropin and $E_{2}$ pulsatile secretion patterns were compared to the pre-exercise period in 7 women in the follicular phase of their menstrual cycle. In study $W$ the degradation rate of $\mathbb{E}_{2}$, measured as the metabolic clearance rate (MCR), in relation to the workload was investigated in 15 physical education students in the follicular phase of their menstrual 
woles.

The motivation of the cholce of various hormones measured in this investigation is given in chapter II. 
CHAPTER II

SYNTHESIS, SECRETION, TRANSPORT, CONVERSION AND DEGRADATION OF STEROIDS

\subsection{INTRODUCTION}

Throughout reproductive life the normal human ovary is capable of synthesizing estrogens, progestins, and androgens. However, the secretion rate and consequently the blood concentration of estrogens and progestins fluctuates markedly according to the phase of the menstrual cycle. On the ather hand, the plasma concentration of sex steroids does not simply reflect glandular (ovarian) and/or adrenal secretion. As discussed in chapter $I$, the plasma concentration is determined by production from different sources (ovaries and adrenals), peripheral conversion and degradation. This makes deductions about glandular secretion rates from single concentration measurements difficult, if not impossible.

Because the afore mentioned mechanisms are closely related and, in addition controlled by neuro-endocrine processes, a short description of the processes rellated to changes in plasma concentrations of steroids during the menstrual cycle can be considered to be appropriate. Therefore, these aspects will be discussed in the following sections.

\subsection{GLANDULAR STEROIDOGENESIS}

Al1 steraid hormones are basically of similar structure with relatively minor chemical differences. Nevertheless, these slight differences are responsible for a striking variation in bilologic activity. The sex steroids are divided into three main groups according to the number of carbon atoms. Corticoids and progestins are derived from a $\mathrm{C}-21$ skeleton, the pregnane nucleus. The $c-19$ series includes all the androgens and is based on the androstane nucleus, whereas the estrogens are derived from the estrane nucleus, a $\mathrm{C}-18$ skeleton. Cholesterol serves as a common precursor for the biosynthesis of the steroid skeleton of these steroids (fig 2.1). The rate limiting step in steroidogenesis is the conversion of cholesterol to preg- 
nenolone, which is stimulated in the ovary by $L H$ and in the adrenal cortex by adreno corticotropic hormane (ACTH). During steroidogenesis the number of carbon atons in cholesterol or any ather steroid molecule can be reduced, but never increased. In contrast to the adrenal gland which is capable of synthesizing all classes of steroids, the ovary is deficient of 21 hydroxylase and 11-beta-hydroxylase enzymes. Consequently the ovary is unable to produce glucocorticoids and mineralocorticoids. A simplified schene of the major biochemical pathways involyed in androgen and estrogen synthesis is depicted in fig 2.1 .

\subsubsection{Dvarian steroidogenesis.}

The human ovary is capable of synthesizing all three classes of sex steroids dependent on the phase of the menstrual cycle. The selection of specific biochemical pathways leading to synthesis of estrogens, androgens or progestins is not a chance event but a matter of cell types involved or, in ather words the stage of follicle development. Therefore, a short description of the different phases of the menstrual cycle, the development of the follicle in relation to blood-levels of sex hormones, sites of hormone production and regulation of these phenomena will be given.

\subsubsection{Phases of the menstrual cycle.}

The length of the menstrual cycle is the difference between two dates; the onset of the previous and the onset of the recent menstruation. The median length of the menstrual cycle in momen with a chronological age between 20 and 25 years (the age of the majority of the subjects who volunteered in the present study) is reported to be about 28 days, with 5 th and 95 th percentiles of 22 and 42 days respectively (Treloar et al, 1967; Vollman, 1977).

The menstrual cycle can be divided into two distinct phases:

- the follicular phase or the interval between the onset of bleeding and the ovulation. Its length can be extremely variable. In women (chronological age 20-30 yrs), the median length of the follicular phase is reported to be about 13 and 22 days in cycles with a length of 25 and 35 days, respectively (Wollman, 1977). In the early part of the follicular phase, the blood concentration of sex steroids is derived from a large pool of small follicles, but in the next part (mid and late follicular phase) it 


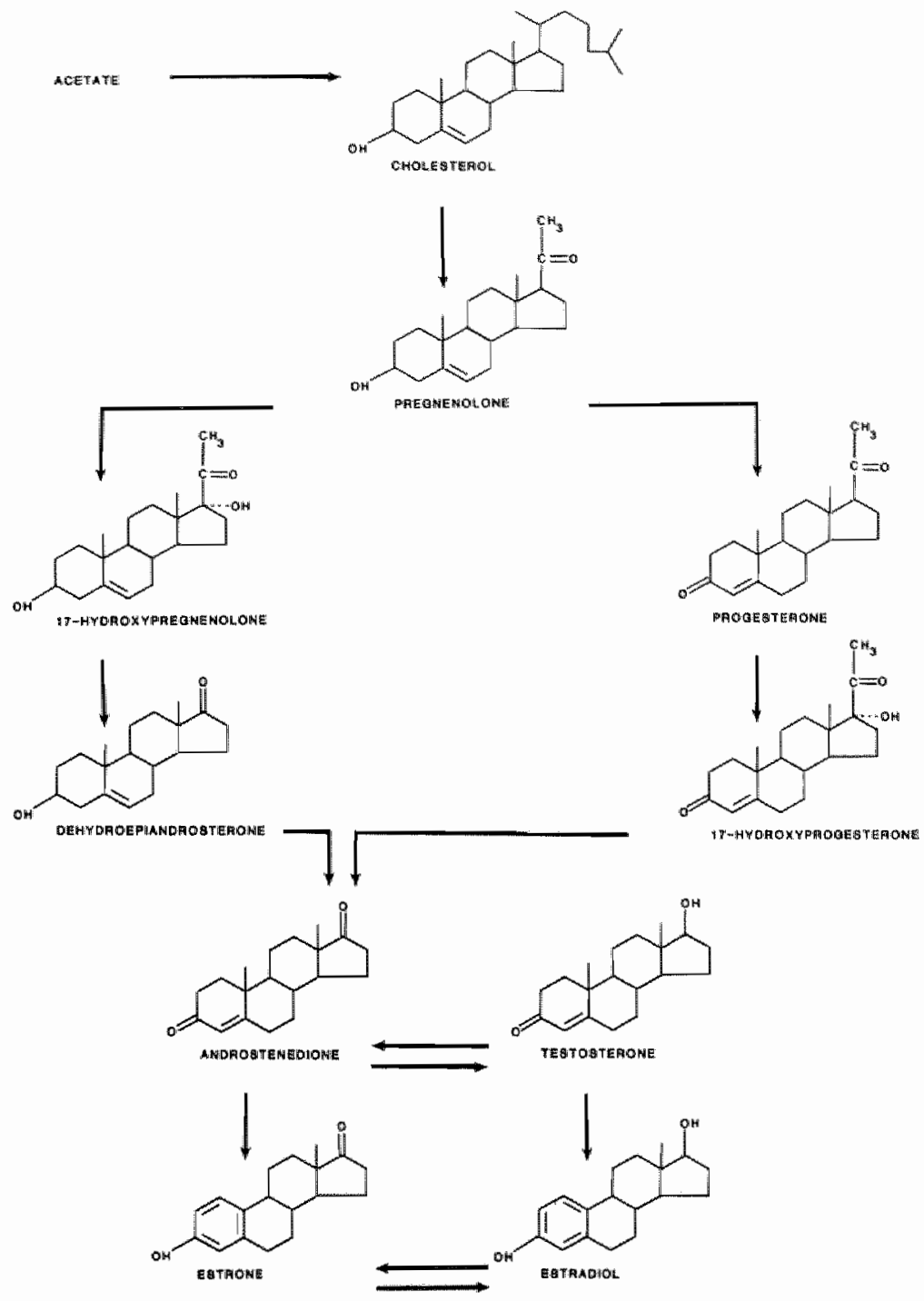

Figure 2.1

A simplifued scheme of the major biochemical pathways involved in the synthesis of sex hormones. 
is actually the dominant follicle that detemines the phase of the cycle by its hormone production and hence the blaod concentration.

- the luteal phase or the interval between ovulation and onset of the next menses. In the normal menstrual cycle its duration is remarkably constant, f.e. 12-14 days.

The ovulation itself is a very short event as revealed by ultrasonographical studies (Wetzels, 1983). Preceding the ovulation sone homonal changes occur, the most conspicuous being the LH surge, which takes place about 1 day before the ovulation.

The follicular and luteal phases can be subdivided into an early, mid and late phase.

The hormone concentrations in peripheral blood fluctuate with different frequencies. In principal three types of secretion patterns may be distinguished:

- law-frequency changes, which represent changes in the mean daily plasma hormone concentration during the menstrual cycle. These changes are called "trigintan" or "circatrigintan" (Williams, 1981) and reflect the well-known cyclic changes in plasma levels of sex steroids during the menstrual cycle (fig. 2.2).

- high-frequency changes, superimposed on the low-frequency changes. To date it is well recognized that many hormones including $L H, F S H, E_{2}$, PRL and $P$ are secreted in a characteristic pulsatile pattern (Yen et al, 1972 $a$ and b; Santen and Bardin, 1973; Korenman and Sherman, 1973; Lenton et a1, 1978; Lenton et al, 1979; Backstrom et al, 1982). These changes have been called "circhoval" since they repeat themselves approximately every hour (Knobil, 1974).

- changes of intermediate frequency, called "diurnal or circadian" because they recur every 24 hours. In women, diurnal changes are found for $L H$, FSH, $E_{2}$ and PRL (Backstrom et al, 1982).

In the next paragraphs these low, intermediate and high-frequency changes of the blood concentrations of ovarian and adrenal sex steroids and gonadotropins will be briefly discussed. 
2.2.1.2 Changes in plasma sex homone levels during the nomal menstrual cycle.

Gonadotropins

High frequency changes in plasma concentration of gonadotropins are due to changes in the episodic secretion pattern of gonadotropin releasing hormone (GnRH) (Yen et al, 1972 a and b; Santen and Bardin, 1973; Shaw, 1978). In women, the frequency and magnitude of the gonadotropin puises vary both between and within individuals (with the phase of the menstrual cycle). The frequency of the LH pulses has been reported to increase significantly from the early follicular to the late follicular phase of the cycle (from about one pulse per $2 \mathrm{~h}$ to $1 \frac{1}{2}-2$ per $2 \mathrm{~h}$ ). During the luteal phase this frequency is much lower than during any stage of the follicular phase (Yen et a1, 1972 a and b; Shaw et al, 1974; Shaw, 1978; Lenton et a1, 1979; Backstrom et al, 1982). The pattern of changes of the plasma FSH concentration has been reported to be very similar to that of LH throughout the menstrual cycle (Yen et al, 1972 a and b; Backstrom et al, 1982). The number of pulses of FSH increases from about one per 3 hours in the early follicular phase to about 1-2 per 2 hours in the mid and late follicular phases, while it drops to very low lewels in the luteal phase (Backstrom et al, 1982). It is believed that during spontaneous cycles the varying $L H$ and FSH levels result from complex positive and negative feedback actions of ovarian sex steroids on hypothalamic GnRH secretion and the pituitary cell responses to this homone (Shaw, 1978). The cyclic changes and normal values of plasma gonadotropin levels are depicted in fig. 2.2. From this graph it can be seen that the LH concentration rises slightly during the follicular phase, followed by a pronounced increase during the mid-cycle surge. Thereafter it declines sharply, followed by a slight decrease during the luteal phase. The mean FSH levels begin to rise in the late luteal phase, but show a gradual decrease during the follicular phase, followed by a modest mid-cycle peak, preceding ovulation. Thereafter a gradual decline is seen during the early and mid-luteal phases.

\section{Estradiol-17B $\left(E_{2}\right)$.}

In women the concentration of $E_{2}$ in peripheral blood fluctuates from hour to hour (Korenman and Sherman, 1973; Lenton et a1, 1978; Backstrom et 
a1, 1982). In most cases (about 80\%) the LH pulses are followed by a pronounced

Figure 2.2

Cyclic variations in

plasma duteininizing hormone $(\mathrm{LH})$, follicle stimulating hormone (FSH), progesterone $(P)$ and estradiol-17B $\left(E_{2}\right)$ during the menstrual cycle.

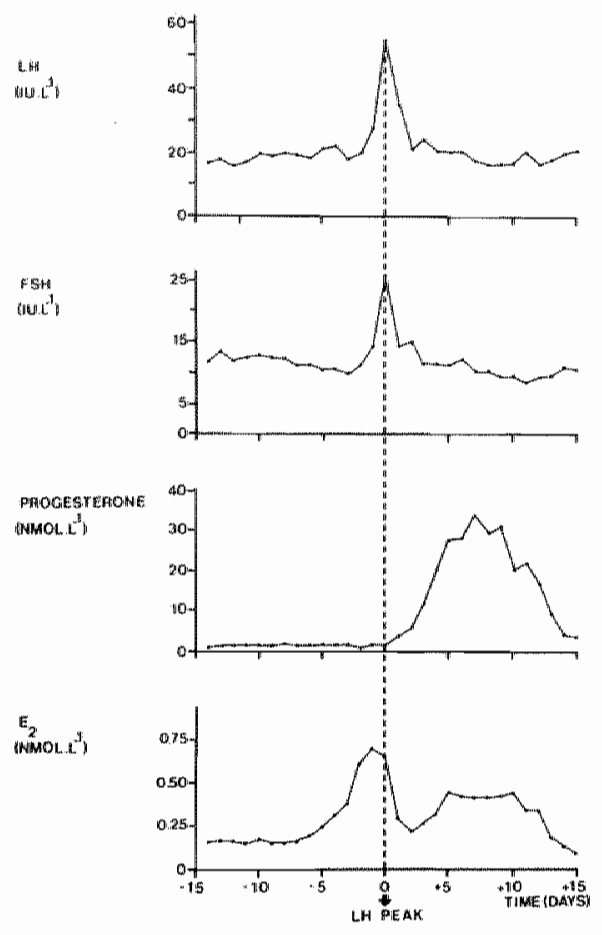

change in plasma $E_{2}$ concentration within 50 min (Backstrom et al, 1982). The magnitude and frequency of the $E_{2}$ pulses has been reported to fluctuate with the phase of the menstrual cycle; in the early follicular phase about three pulses per 6 hours could be observed, increasing to 4-6 pulses per 6 hours in the late follicular phase and decreasing to about 2 pulses per 6 hours in the midluteal phase (Lenton et al, 1978; Backstron et a1, 1982). The largest sample-to-sample variation (often more than 50\%) was found in women near midicycle (Lenton et al, 1978; Backstrom et al, 1982). During the day the mean plasma $\mathbb{E}_{2}$ concentration was highest between 8.00 and 9.00 a.m., whereafter it decreases (Lenton et al, 1978; Backstrom et al, 1982). 
The low frequency or cyclic changes in plasma levels follow a characteristic pattern, due to secretion of the dominant follicle and/or corpus luteurn. During the menses and the early follicular phase the $E_{2}$ concentration of the bload remains low (fig 2.2). In the mid-follicular phase the $E_{2}$ concentration graduallly increases, followed by a more rapid rise. The peak concentration in peripheral blood is reached in the late follicular phase, usually one day before the $L H$ concentration peak. Concomitantily with the rise in $L H$ the $E_{2}$ concentration decreases. Since ovulation occurs approximately 24-36 hours after the $L H$ peak, the drop in $E_{2}$ concentration precedes ovulation. During the luteal phase, the $E_{2}$ concentration rises again, reaching a maximum approximately 5-8 days after ovulation, i.e. in the mid-luteal phase. In the late luteal phase the $E_{2}$ concentration decreases sharply.

Progesterone $(P)$.

High frequency changes in plasma levels could only be abserved in the luteal phase of the menstrual cycle (Korenman and Sherman, 1973; Backstrom et al, 1982). Backstrom and co-investiglators (1982) found about 3 pulses per 6 hours with a relatively small amplitude. The low frequency changes and normall values of $\mathrm{plasma}$ progesterone levels during the menstrual cycle are depicted in figure 2.2. The small amounts of $P$ present in the circulating blood during menses and the follicular phase are mainly derived from extra-glandular conversion of adrenal pregnenolone and pregnenolone sulfate, and secretion of small amounts of $P$ by the adrenal cortex. At the beginning of the LH surge, the plasma $P$ concentration gradually increases, followed by a more pronounced increase during the luteal phase which para1 lels the increase in $E_{2}$. Peak concentrations are reached in the mid-luteal phase, whereupon the $P$ concentration decreases sharply in the late-luteal phase, if no conception had occurred.

Prolactin (PRL).

In women with a normal menstrual cycle high frequency (pulsatile) changes in prolactin concentration were described by several inwestigators (Ehara et al, 1973; Backstrom et al, 1982). The pulse frequency has been reported to increase from 1.5 per 6 hours in the early follicular phase, to 
2.5 per 6 hours in the Vate follicular phase (Backstrom et a1, 1982). In the luteal phase the number of pulses was found to decrease to about 1 pulse per 6 hours (Backstrom, 1982). During the day the mean prolactin level in the blood follows a diurnal pattern, being highest during sleep and decreasing within 1-3 hours thereafter (Williams, 1981). Throughout the cycle no consistent changes in circulating levels of prolactin have been found throughout the cycle by some investigators (McNeilly and Chard, 1974; Ehara et al, 1973; waffe et a1, 1973), whereas others found an increased plasma prolactin concentration in the late follicular phase with a modest peak during ovulation (Vekemans et al, 1977; Lenton et a1, 1979; Backstrom et $a 1,1982)$. In women the normal values of plasma prolactin levels are between 0.06 and $0.5 \mathrm{IU} . \mathrm{1}^{-1}$.

Testosterone $(T)$.

To date no pulsatilye changes in plasma androgen (including testosterone and androstenedione) concentration have been reported. In contrast, a diurnal secretion pattern of $T$ has been found; the highest values being recorded in the morning (Vermeulen, 1973).

The plasma $T$ concentration has been reported to be fairly constant during the menstrual cycle (Williams, 1981), albeit that a gradual increase of plasma $T$ concentration was found during the follicular phase with a rather sharp peak paralleling the LH peak, followed by a gradual decline during the luteal phase (Abraham, 1974; Apter et al, 1978). Plasma $T$ is derived from various sources (table 2.1); about 50\% arises from glandular secretion, while the remainder arises from peripheral conversion. Abraham (1974) showed that from the glandular $T$ production $40-66 \%$ is derived from the adrenal cortex, and about $33 \%$ from the ovary, both in the follicular and luteal phase of the menstrual cycle. About $50 \%$ of plasma $T$ is derived from conversion of androstenedione $(\Delta 4-A)$ in various tissues (Horton and Tait, 1966; Longcope et al, 1976; Frisch et al, 1980). The normal values of plasma testosterone levels during the menstrual cycle are depicted in table 2.2.

Androsteneditione $(\triangle 4-A)$.

No hilgh frequency changes or episodic secretion pattern of $\triangle 4-A$ has been described, but low frequency changes were reported during the menstru- 
a) cycle (Williams, 1981; Judd and Yen, 1973). A minimun concentration is reached directly after menses, which is followed by an increase during the follicular phase. About $70 \%$ higher levels are reached during the late follicular phase. Parallel with the LH peak a more pronounced increase in $\Delta 4$ has been observed, whereafter the plasma concentration decreases.

A considerable part (table 2.1) of the plasma $\Delta 4-A$ concentration is derived from the adrenal gland (Abraham, 1974). Adrenal $44-A$ secretion exhibits a diurnal pattern with a peak in the morning and a minimum in the late evening. There seems to be no variation in adrenal secretion during the menstrual cycle (Abraham, 1974). Normal values for plasma $\Delta 4-A$ concentrations are given in table 2.2.

Tabel 2.1

Relative contribution (\%) of ovarian and adrenal secretion and peripheral conversion to the blood production rate of T, $\triangle 4-A$ and DHEA-S during a normal menstrual cycle. (according to data from Abraham, 1974; Farber et a 1, 1977; De Jong, 1982).

$\begin{array}{llll}\text { OVARY } & \text { Adrenal Peripheral } \\ \text { folli- } & \text { "ovula- Tuteal } & \text { cortex } & \text { conversion } \\ \text { cular tion" } & & \end{array}$

\begin{tabular}{lrrrrr}
\hline$T$ & $10 \%$ & $20 \%$ & $10 \%$ & $20-30 \%$ & $50 \%$ \\
$\triangle 4-A$ & $20 \%$ & $65 \%$ & $55 \%$ & $30-55 \%$ & $5 \%$ \\
DHEA-S & $2 \%$ & & $2 \%$ & $98 \%$ & $0 \%$
\end{tabular}

Dehydroepiandrosterone sulfate (DHEA-S).

Conflicting results have been reported about the variation of plasma DHEA-S during the menstrual cycle. Several authors did not show any distinct effect of the phase of the menstrual cycle on plasma DHEA-S levels (Abraham, 1973; Williams, 1981), whereas others showed significantly higher DHEA-S levels near mid-cycle (Cattaneo et al, 1975; Abraham, 1974). The latter is somewhat curious because DHEA-S is almost exclusively derived from the adrenal cortex (Abraham, 1974).

The plasma concentration of DHEA-S shows a wide, interindividual variation. The mean concentration was reported to be $4.1 \mu \mathrm{mol} .1^{-1}$ with a range of 2-9 $\mu \mathrm{mol} .1^{-1}$ (Buster and Abraham, 1972; Metcalf, 1976). In addition it 
has been shown that the circulating levels of DHEA-s decrease with age (Drucker arid Dawid, 1980; De Peretti and Forest, 1978).

Table 2.2.

Reference values (mean and standard deviations) of androstenedione ( $\Delta 4-A$ ), dehydroepiandrosterone sulphate (DHEA-S) and testosterone (T) in plasma of nomal women, in the follfcular, owulatory and luteal phases of the menstrual cycle. (According to data from Faiman et al 1976 and Hollanders, 1981).

PHASE OF THE CYCLE

Homone Follicular ovulatory Luteal

\begin{tabular}{|c|c|c|c|}
\hline$\frac{\Delta^{4}-A}{\left(n m o 1.7^{-1}\right)}$ & $\begin{array}{r}5.9 \\
\pm 1.9\end{array}$ & $\begin{array}{r}6.6 \\
\pm 2.7\end{array}$ & $\begin{array}{r}6.0 \\
+2.2\end{array}$ \\
\hline $\begin{array}{l}\text { DHEA-S } \\
(\text { umal. }-1)\end{array}$ & $\begin{array}{r}6.7 \\
\pm 2.5\end{array}$ & $\begin{array}{r}7.5 \\
\pm 2.5\end{array}$ & $\begin{array}{r}7.8 \\
\pm 3.6\end{array}$ \\
\hline$\left(\right.$ nnol. $\left.1^{-1}\right)$ & $\begin{array}{r}1.2 \\
\pm 0.3\end{array}$ & $\begin{array}{r}1.4 \\
\pm 0.4\end{array}$ & $\begin{array}{r}1.0 \\
\pm 0.4\end{array}$ \\
\hline
\end{tabular}

\subsubsection{Sites of ovarian hormone synthesis.}

As mentioned before, the plasma concentration of several sex hommones and gonadotropins changes markediy from hour to hour and during the normal menstrual cycle. In women measurement of sex steroid concentrations in blood, simultaneously sampled in a peripheral vein and a vein draining the owary, revealed that the ovary containing the dominant follicle is responsible for the $r i s e$ in peripheral $E_{2}$ and $P$ levels (Mikhail, 1970; Baird and Fraser, 1975; McNatty et al, 1976). This is supported by other investigathons showing that excision of the owary containing the dominant folliclle or the corpus luteum results in a rapid decline in serum $E_{2}$ and $P$ levels (Aedo et al, 1980 a and b). Besides, in women with a normal menstrual cycle, estrogen pre-treatment affects gonadotropin release by the pituitary gland (Shaw et al, 1975; Shaw, 1978). This further suggests that the ovary containing the dominant follicle or the corpus luteum coordinates the sex steroid homone synthesis in relation to hypothalamic and pituitary cen- 
tres. Although a detalled description of the mechanisms involved in ovarian steroidogenesis is far beyond the scope of this thesis, the most important processes leading to follicle maturation and hence appropriate steroid synthesis during the follicular and luteal phases of the menstrual cycle, will be briefly sumnarized here.

Follicle growth and steroidogenes is in the follicular phase.

The human ovary contains follicles in several stages of development. According to the developmental stage three main groups of follicles can be distinguished:

- the small, non-growing follicle (also called the primordial or primary follicle), in which the oocyte and its surrounding cells are at rest.

- the pre-antral follicle (also called the secondary follicle) in which the oocyte and its surrounding (granulosa) cells grow and differentiate, thus forming one or more layers around the oocyte. At this stage, the zona pellucida forms and a theca layer differentiates. Fluid begins to collect between the granulosa cells, at last forming the fluid filled cavity: the antrum.

- the antral follicle (also called the tertiary or Graafian follicle) in which the oocyte has terminated its growth, while the surrounding cells contimue to differentiate. This follicle containes a full grown oocyte, many granulosa cells, a fluid filled antrum and outside the basement membrane a well developed theca layer.

The initiation of follicular growth is a continuous process, which is independent of gonadotropin influence. Even without pituitary support, the primary follicle can reach the next stage of development, it becomes a secondary or pre-antral follicle. Although the stimulus for this initiation of follicular growth is unclear, the further development of the secondary follicle is greatily dependent on both gonadatropins and ovarian steroidogenesis. From now on, the secondary or pre-antral follicle begins to concentrate FSH in its developing antrum. This is important because particularly FSH is necessary for further development of the follicle in the early follicular phase. In this phase differences in antral fluid concentration of FSH can be found between the follicles, as was shown in experiments with human ovarian tissue in vitro (McNatty and Sawers, 1975; McNatty, 1978; McNatty et a1, 1979). From these experiments it appeared that FSH induces 
the following events in human gramulosa cells:

- an increase in mitotic activity and hence proliferation of granulosa cells.

- an increase in symthesis of arcmatizing enzymes.

- stimulation of FSH receptor synthesis.

- stimilation of LH receptor synthesis.

These FSH stimulated events are of particular impartance because thecai cells are supposed to synthesize androgens (mainly $\triangle 4-A$ and to a lesser extend TH. These cells, however, cannot aromatize the $C-19$ steroids to estrogens. After synthesis $\Delta 4-A$ and $T$ diffuse through the basement membrane into the FSH-stimulated granulosa cells, where they can be aromatized to estrogens (Channing, 1969; Moon et al, 1978; McNatty et al, 1979). However, the role of the androgens at this stage of follicular development is complex. At relatively low concentrations andragens enhance their own aromatization, but at higher levels the capacity for aromatization is overwhelmed and consequently the follicle becomes androgenic and ultimately atretic (McNatty et al, 1979; Hillier et al, 1980). Therefore, the follicle which is best capable of concentrating FSH and responding to this hormone will survive and eventually ovulate. Consequently the concentration of estrogens increases in the antral fluid of this follicle, while that of androgens and PRL decreases (the follicle becomes more "estrogenic"). This process will take place at the beginning of the mid-follicular phase of the menstrual cycle, the follicle is at its next stage of development and is called a tertiary or antral follicle.

The rising $E_{2}$ concentration in both the follicle and the peripheral blood is important for two reasons:

- it maimtalns follicular growth and enzyme induction, independent of FSH

- it inhibits FSH release which will hamper further developsent of the non-dominant follicle. In the antral fluid of these follicles high concentrations of androgens and PRL are found before they become atretic.

If in the late-follicular phase, just before ovulation, the production of $E_{2}$ in the follicle becones so high that the plasma concentration exceeds 0.7 nmol. $1^{-1}$ for a period of at least $50 \mathrm{hrs}$ (Young and Jaffe, 1976), the hypothalamus will respond with an outpouring of gonadotropin releasing hormone (GnRH), resulting in the $L H$ surge. This will also lead to inhibition of granulosa cell mitosis as has been shown in experiments with human 
ovarian tissue in vitro (Delforge et al, 1972, McNatty and Sawers, 1975), the resumption of oocyte maturation (McNatty, 1978; Hillier et al, 1980), and initiation of granulosa cell luteinization (Baird et al, 1975). Simultaneously with the mid-cyclic LH-rise an increase in FSH concentration of the blood can be observed. The functional importance of this FSH surge is thought to be a further induction of $\mathrm{LH}$ receptors in the follicle. To produce a normal corpus luteum, the rising concentration of $P$ in the late follicular phase seems to play an additional, facillitating role in the regulation of the LH mid-cycle surge (Shaw, 1975; Shaw, 1978).

Steroidogenesis in the luteal phase.

After rupture of the follicle and release of the ovum, the granulosa cells increase in size and a characteristic vacuolization associated with the accumulation of a yellow pigment, lutein, appears. During the early 1 uteal phase (the first 3 days after ovulation) the granulosa cells enlarge and become more vascularized. From now on the predominant pathway of steroidogenesis in the corpus 7 uteum is the delta-4 pathway, which means that not only estrogens and androgens, but also $P$ is synthesized. Recently the importance of the vascularization for $P$ synthesis was investigated by Carr and co-investigators (1982). They suggested that the rate of $P$ secretion is determined by two factors:

- stimulation of cholesterol side-chain cleavage by cAMP-requiring mechanisms. This occurs throughout the ovarian cycle as a consequence of the action of FSH and LH.

- availability of adequate quantities of cholesterol as a precursor. A considerable amount of cholesterol has to be derived from the low density lipoproteins (LDL) in the blood. Unt $i l$ the corpus luteum is vascularized, the granulosa cells are not exposed to adequate quantities of LDL.

Eight to 9 days after ovulation, the peak of vascularization has been reached. This is associated with high synthesis rates of all three classes of steroids. In this period plasma gonadotropin levels reach the lowest values. In the late luteal phase (10-12 days after the ovulation) the corpus luteum reaches a phase of regression, resulting in a sharp decline in steroidogenesis. The factors contributing to this regression are incompletely understood, but from experiments with rhesus monkeys (Karsch et al, 1973; Karsch and Sutton, 1976; Stouffer et a1, 1977) and isolated human 
luteal cells (Williams et al, 1981) there is considerable evidence that high estrogen levells may initiate luteolysis, which is further mediated by an increased prostaglandin $F\left(P G_{2} a\right.$ ) synthesis (Auletta et al, 1978; Fritz and speroff, 1982).

\subsubsection{Neuro-endocrine control of ovarian steroidogenesis.}

The changes in homonal levels are regulated by feedback mechanisms. In the early follicular phase there is a negative inhibitory effect on gonadotropin release initiated by the relatively low levels of $E_{2}(0.1-0.2$ nimol. $1^{-1}$ ). It should be noticed that this negative feedback is not only detemined by the absolute level of $E_{2}$, but also by the time of exposure and the sensitivity of the individual. The site of action of $\mathbb{E}_{2}$ in this negative feedback appears to be at the hypothalamic and pituitary level. At the level of the hypothalamus, $E_{2}$ decreases $G$ RRH secretion (Nillius and Wide, 1970), while at the level of the pituitary the inhibitory effect is exerted by a decreased sensitivity to GnRH (Shaw, 1978).

If $E_{2}$ synthesis has reached such high levels that the plasma $E_{2}$ concentration rises over 0.7 nmol. $1^{-1}$ and this concentration is maintained for approximately $50 \mathrm{hrs}$ a positive feedback on gonadotropin release developes (Hohlweg and Junkman, 1932; Nillius and Wide, 1971; Leyendecker et al, 1972; Monroe et al, 1972; Yen and Tsai, 1972; Shaw, 1975 a and b; Young and Jaffe, 1976; Shaw, 1978). A positive feedback is onlly noticed in the estrogen primed hypothalamus-pituitary (Shaw, 1978).

Progesterone may al so have negative or positive feedback effects on the hypothalamus-pituitary axis. The negative feedback action of $P$ might be responsible for the short duration of mid-cycle gonadotropin surge (Shaw, 1978). Its positive feedback action has been thought to facilitate the mid-cyclic FSH surge but aglain only in estrogen primed subjects (Shaw et al, 1975).

Summarizing the mechanisms leading to steroidogenesis it is obvious that $E_{2}$ plays a key role in this process. The role of this homone is essential in the following events:

- in response to the decline in $\mathrm{E}_{2}$ concentration in the late-luteal phase the FSH concentration will rise, which initiates the beginning of the next cycle. 
- estradiol acts synergistically with FSH in maintaining follicular sensitivity to FSH by inducing FSH receptors.

- estradiol induces LH receptors in granulosa cells, and hence acts synergistically" with FSH.

- estradiol induces and maintains the mitotic and biosynthetic activity of granulosa cells.

- ovulation is triggered by the LH surge, which in turn is triggered by the rapid rise in plasma $E_{2}$ concentration (positive feedback on the hypothalamic-pituitary axis).

- regression of the corpus luteum is initiated by its own estradiol production.

\subsubsection{Regulation of adrenal steroidogenesis.}

Adrenal steroidogenesis is stimulated by ACTH, circulating cyclic AMP (CAMP) and possibly PRL (Parker et al, 1978; Forest, 1978; Trager, 1977; Nel son, 1980). Of these factors ACTH is far out the most important one. About $90 \%$ of the ACTH originates from the anterior pituitary gland and about 10\% from the lobus posterior and the eminentia medianis (Nelson, 1980). ACTH exerts glandular and extra-glandular effects. The glandular effect is mainly mediated by stimulation of the adrenal adenylate cyclase. Consequently the intracellular CAMP concentration rises and this triggers the conversion of cholesterol to pregnenolone (fig. 2.1.). The other glandular effects of ACTH involve accumulation of cholesterol within the adrenals, stimulation of the activity of pregnenolone synthetase (Caron et al, 1975) and other enzymes that are active in converting pregnenolone to other steroids. ACTH already stimulates the adenylate cyclase in the membranes of the adrenal cell of the rat in concentrations of $1.5 \cdot 10^{-8} \mathrm{M}$ (Ontjes, 1980). Within minutes after ACTH stimulation the CAMP content of the adrenal cells is increased with a maximum after 3 minutes. This rapidly activates one or more protein kinases (Ontjes, 1980), resulting in a very rapid activation of steroidogenesis. Within 3 minutes after the ACTH peak, sterold secretion will rise and wane over a period of 10 minutes or more.

The extra-glandular effects of ACTH involve a rapid activation of tissue lipase, resulting in an increase in plasma non-esterified fatty acid (NEFA) concentration and the induction of a pronounced increase in sulfatase activity in ovarian tissue (Dominguez et al, 1975). The secretion of 
ACTM by the anterfor pituitary gland is largely governed by the hypothalamus by means of a releasing homone, the corticotropin releasing factor (CRF). The regulation of CRF and ACTH secretion is controlled by three factors:

- the plasma corticosteroid concentration, which acts at the level of the pituitary. A rise in cortisol level diminishes ACTH secretion.

- a "biological clock". The ACTH secretion follows a diurnal pattern with a maximum just after awakening and a minirnum in the evening. The biological clock works through the central nervous system.

- stress (mental and/or physical). This factor also works through the central neryous system.

It depends on the actual situation which factor is most important. In periods of great physical stress, this factor overrules the biological clock, while in prolanged physical exercise the rising cortisol levels are not able to suppress ACTH secretion.

\subsection{TRANSPORT OF STEROID HORMONES}

In the human blood only a small fraction of the total concentration of unconjugated sex steroids exists in the free form. The major portion is specifically bound with high affinity to plasma proteins such as sex hormone binding globulin (SHBG) and with low affinity to albumin. These proteins serve the following purposes (Traeger, 1977):

- protection of the circulating hormones against inactivation by enzymes in blood and perfused organs. Consequently the half-life time will be lengthened.

- formation of a "buffer-compartment" from which the steroid dissociates relatively easy, if necessary. This buffer is also able to neutralize an acute rise in steroid concentration.

- modulation of the intracellular activity of the steroid by competition between the extracellular carrier (mainly albumin) and the intracellular receptor for the steroid.

Between SHBG and albumin marked differences exist in binding affinity for the various sex steroids (table 2.3). 
Table 2.3

Association constants ( $K$ ass) of sex hormone binding globulin (SHBG) and albunin for several steroid homones (according to data from Vemeulen et al, 1973 and Dunn et al, 1981).

Steroid

$$
\begin{array}{cr}
K_{\text {ass }} \text { SHBG } & \text { Kass albumin } \\
\left(10^{6} \mathrm{M}^{-1}\right) & \left(10^{4} \mathrm{M}^{-1}\right)
\end{array}
$$

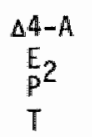

29
680
8,8
1600

An additional difference is that albumin has an almost unlimited steroidbinding capacity due to its high concentration (about 19000 times higher than that of SHBG). Besides, it has multiple binding sites per molecule in contrast to SHBG which has only one binding site per molecule. These differences in binding affinity and capacity of plasma proteins for sex steroids make that im non-pregnant monen about $37 \%$ of the total $E_{2}$ concentration circulates in complex with SHBG, while about $60 \%$ circulates in complex with albumin. For $\mathrm{T}$ these values are $66 \%$ and $30 \%$, respectively. Consequentiy, only a very small fraction of the tatal plasma cancentration of sex steroids cilrculates in the free form. Only this fraction is considered to be biologically active (Pearlman et al, 1967; Tavernetti et al, 1967; Kato and Horton, 1968; Vermeulen and Verdonck, 1968; Vermeulen et al, 1973).

The mean percentage of free $E_{2}$ and $T$ was reported to be constant throughout the menstrual cycle (Wu et al, 1976). The percentages measured by severall inwestigators range from $1.5-2.6 \%$ (Hammond et a1, 1980; Dunn et al, 1981; Moll et a1, 1981) for $E_{2}$ and $1-1.9 \%$ for $T$ (Hamnond et a1, 1980; Dunn et a1, 1981).

The free percentage of for example $E_{2}$ may be elevated either by a decrease in SHBG concentration or an increase in competing steroids or other substances that interact directly or indirectly with SHBG or albumin. Body temperature will also play an important role in the association of sex steroids with plasma proteins since the $K_{\text {ass }}$ is dependent on temperature (Vermeulen and Verdonck, 1968; Lata et al, 1980; Vigersky et, a 1, 1979). This will result in a higher percentage of unbound and non-specifically 
bounil sterolds with increased blood temperature. However, Vigersky and co-irvestigators (1979) showed that the dissociation rates of $E_{2}$ and $T$ from plasma were markedly different.

From the work of Latal and associates (1980) it became apparent that the $K_{\text {ass }}$ of the steroid binding proteins is insensitive to chanaes in $\mathrm{pH}$ in the phys lalogical range $(6.8-7.4)$.

\subsection{SECRETION, PRODUCTION, CONVERSION AND DEGRADATION OF SEX STEROIDS}

\subsubsection{Introduction}

As mentioned in the preceding paragraphs interpretation of the plasma concentration of sex steraids is complicated by the fact that it is derived from several sources i.e. glandular synthesis and peripheral conversion. Besides, these processes are counteracted by the degradation, that occurs in splanchnic and extra-splanchnic tissue. Thus, some concepts (Tait, 1963; Gurpide, 1975) had to be introduced to differentiate between these processes, which all contribute to the actual plasma concentration. These concepts include secretory rate $(S R)$, blood production rate $\left(P R_{B}\right)$ and metabolic clearance rate (MCR), which are defined as follows:

- the secretory rate of a homone $A$ (SRA) is the amount of A released by an endocrine gland into the circulation per unit time.

- the blood production rate $\left(\mathrm{PR}_{B}\right)$ of a homone $A$, is the total rate at which $A$ enters de nowo into the circulation per unit time (Tait, 1963; Gurpide, 1975). When a hormone is derived exclusively from glandular secretion, the $S R$ and $P_{B}$ are the same. When the hormone also originates from peripheral conversion, $\mathbb{P R}_{B}$ will be higher than $S R$.

- the MCR of a hormone equalls the volume of plasma irreversibly cleared from a hormone per unit time. The MCR usually measured is the overall MCR, which can be considered to be the sum of all organ MCR's.

In the next paragraphs the literature about steroid hormone secretion, blood production and conversion will be briefly reviewed. 
2.4.2 Secretion Rate (SR), Blood production rate $\left(P R_{B}\right)$ and Metaboll ic Clearance Rate (MCR) of sex steroids

\subsubsection{Estradiol.}

Secretion Rate (SR)

In women, the major part (95\%) of the circulating $E_{2}$ in the blood originates from ovarian secretion as revealed by both indirect techniques (isotope dilution technique, Baird and Fraser, 1974) and direct sampling of ovarian venous blood (Abraham and Chamakjian, 1973; Aedo et al, 1980). The $\mathrm{SR}$ of $\mathrm{E}_{2}$ ranges from 0.26 to 1.5 and from 3 to $0,92 \mu \mathrm{mol} /$ day in the early follicular and the luteal phase of the menstrual cycle, respectively (Tagatz and Gurpide, 1973).

Blood production rate $\left(P R_{B}\right)$

The $P R_{B}$ of $E_{2}$ almost equals the $S R$. It was found to be $0.3 \mu \mathrm{mol} /$ day in the early follicular phase and to increase to $1.63-3.45 \mu \mathrm{mol} /$ day in the late follicular phase and to decrease somewhat $(0.99 \mu$ mol/day $)$ in the mid-Tuteal phase.

The difference between $S R$ and $P R_{B}$ can be explained by the fact that several tissues, including adipose tissue, skeletal muscle and bone marrow, are able to convert androgens to estrogens. Longcope and co-investigators (1978) calcullated that muscle accounts for 25-30\% and adipose tissue for 10-15\% of the total extra-gonadal aromatization of androgens to estrogens. In addition about $3 \%$ of the estrone $\left(E_{1}\right)$ entering the circulation of skeletal muscle is converted to $E_{2}$ in this tissue, whille adipose tissue converts about $2 \%$ of $E_{1}$ to $E_{2}$ (Longcope et al, 1976).

Metabolic Clearance Rate (MCR)

In women, the overall MCR of $E_{2}$ was reported to vary between 1025 and 1350 1.plasma/day (Longcope et al, 1963; Hembree et al, 1969). The spanchnic bed is the major site of metabolism for estrogens, progestins and androgens. However, due to marked differences in affinity for plasma proteins the magnitude of the splanchnic clearance varies considerably from steroid to steroid. Experiments in dogs have shown that $\mathbb{E}_{2}$ is metabolized for almost $90 \%$ in splanchnic tissue (Collins et al, 1970). The extra- 
splanchnic metabolism of $E_{2}$ mainly occurs in skeletal muscle and adipose tissue. Longcope and co-investigators (1976) have shown that in men both tissues account for about $10 \%$ of the overall metabolism of $E_{2}$.

\subsubsection{Progesterone.}

Secretion Rate (SR)

During the follicular phase of the menstrual cycle almost all $p$ is derived from adrenal secretion (Traeger, 1977), while in the luteal phase significant amounts of this steroid are secreted by the corpus luteum. The $S R$ by the ovaries is reported to be 3.5 to $7 \mu$ mol/day in the follicular phase, and 70-105 umol/day during the luteal phase (Tagatz and Gurpide, $1973)$.

Blood Production Rate $\left(P R_{B}\right)$

In normally cycling women the $P R_{B}$ of $P$ ranges from in the average 9 $\mu \mathrm{mol} /$ day in the follicular phase to in the average $110 \mu \mathrm{mol} /$ day in the luteal phase of the menstrual cycle (Tagatz and Gurpide, 1973). The close agreement of $P R_{B}$ and $S R$ reveals that there is no peripheral conversion of other steroids to $P$.

Metabolic Clearance Rate (MCR)

The MCR of $P$ was reported to vary between 1800 and $25001 . p l a s m a / d a y$ (Tagatz and Gurpide, 1973; Little et a7, 1975). Besides the splanchnic metabol ism, which accounts for approximately $40 \%$ of the overall metabolism, extensive metabolism occurs in several other organs, including brain and uterus (Little et al, 1975). In experiments with ${ }^{14} \mathrm{C}$-progesterone it has been shown (Lin et al, 1978) that bovine muscle and adipose tissue are also able to metabolize $P$ in considerable amounts. This suggests that in man muscle and adipose tissue are also involved in P metabolism.

\subsubsection{Andragens.}

Secretion Rate (SR)

In the early follicular phase $\triangle 4-A$ and DHEA are the major androgen products of the ovaries which are secreted mainly by stromal tissue. 
Accumulation of stromal $t$ issue, which nomally occurs at mid-cycle, results in an additional rise in $S R$ of $\triangle 4-A$ and $T$. (Judd and Yen, 1973; Abraham, 1974; Vemeulen and Verdonck, 1976). Im women, the SR of $T$ is not known, but assuming that about $50 \%$ of the circulating $T$ arises from peripheral conversion from prehomones, the SR can be calculated to be about $0.35-0.45$ umollday for both ovaries and adrenals.

The SR of $\triangle 4-A$ by both ovaries ranges from 2.8 to 5.6 umol/day, whille the SR of DHEA-S by the adrenal cortex is about 18 umol/day (Gurpide et al, 1963; McDonald et al, 1965; Van de Wiele et al, 1963; Poortman et al, 1973).

Blood Production Rate $\left(P R_{B}\right)$

The $P R_{B}$ of $\triangle 4-A$ and $T$ is relatively constant during the menstrual cyclle ( 10 and 1 umol/day, respectively). Virtually all (95\%) of the plasma $\Delta 4-A$ concentration arises from glandular secretion (Bardin and Lipsett, 1967; Horton and Tait, 1966; Kirschner and Bardin, 1972; Kirschner and Jacobs, 1971; Poortman, 1974). This means that the $P_{B}$ of $\Delta 4-A$, which was calculated to be 5.2-6.4 mol/day (Poortman et al, 1973; Tagatz and Gurpide, 1973), almost equals the SR of both the adrenal cortex and the ovary.

For $T$ the $P R_{B}$ is derived from adrenal and ovarian secretion (both accounting for approximately $50 \%$ of the $P R_{B}$ ) and peripheral conversion mainlly from $\triangle 4-A$ and to a lesser extent from DHEA (Bardin and Lipsett, $1967)$.

Metabolic Clearance Rate (MCR)

The overall MCR of $\triangle 4-A$ and $T$ im women is reported to be 2000 and 700 1.plasma/day respectively (Baird et a1, 1969; Horton et a1, 1966; Poortman et a1. 1973). Due to the extremely high affinity for albumin the MCR of DHEA-S is very low. It is estimated to be 10-15 1.plasma/day (Longcope et al, 1972).

Both $\triangle 4-A$ and $T$ are metabolized extensively outside the splanchnic bed. Longcope and co-investigators (1976) showed that skeletal muscle and adipose tissue contributes to the averall conversion of $\Delta 4-A$ to $T$ with $10-15 \%$ and 5-10\%, respectively. Muscle appears to contribute to the overall metabolism of $\triangle 4-A$ and $T$ by $5-12 \%$ and adipose tissue by $2-7 \%$. 
In the light of the afore mentioned in the present study the following hormones mere measured in blood plasma: $E_{2}, P, L H, F S H, T, \triangle 4-A$, DHEA-S, PRL, ACTH and in addition the free $E_{2}$ and $T$ concentration. $A, D H E A-S$ and ACTH were measured to get more insight into the probable involvement of the adrenal cortex as a source of plasma androgens. Besides, we were interested in the relation between exercise plasma PRL and DHEA-S levels, because hyperprolactinemia with or without concomitant increased DHEA-S levels have been associated with secundary amenorrhoea Vermeulen et al, 1977; David and Drucker, 1979; Fachinetti et al, 1979; Lobo et al, 1980; Lake Polan and Behman, 1981). It is not known whether the ovarian secretion rate enhanced or the degradation rate of sex steroids is decreased during exercise. Ovarian secretion is stimulated by the gonadotropins (especially $\mathbf{L H}$ ), hence the measurement of $L H$ and FSH during exercise provides insight into the involvement of the pituitary. In addition, the changes in episodic secretion pattern in gonadotropins and $E_{2}$ during and after physical exercise, if any, was investigated.

In human volunteers, measurement of the degradation rate is only possible with indirect techniques such as the isotope dilution technique. Therefore, this technique was used to monitor the degradation rate of $E_{2}$ (measured as the MCR) during exercise to provide us more insight into this possible mechanism. 
CHAPTER III

MATERIALS AND METHODS

\subsection{SUBJECTS}

Fourty seven healthy women agreed to participate in five different studies (see below). The nature and intent of the studies were carefully explained to each individual before they gawe their written consent. The subjects met the following qualifications:

1. their menstrual cycle had to be normal for at least 1 year prior to the study as revealed from the menses data. A normal menstrual cycle length was considered to be $28 \pm 4$ days. Ovulation was detected by the basal body temperature (BBT) method and the measurement of plasma $\mathbb{P}$ levels at rest. We considered a subject to be in the luteal phase if the plasma P levels at rest exceeded 10 nmol. $1^{-1}$ since Wetzels (1983) showed that ovulation always occurred when this level had been reached.

2. no gynaecological disorders as assessed by a trained gynaecologist.

3. normal liver and renal functions.

4. no use of drugs that could interfere with the menstrual cycle for at least 6 months prior to the study.

The subjects participating in study I and III ( $n=19)$ were untrained students. From this group two dropped out because their veins did not allow repeated blood sampling, while a third subject became amenorrhoic for several months. The remainder of the group $(n=16)$ participated in study I. Tabel 3.1 summarizes their physical characteristics and $\mathrm{V}_{2} 2^{\text {max }}$ values. A11 women of this group were nulliparous. From this group eight subjects (1002, $1008,1010,1011,1012,1015,1017$ and 1021) were retested after a three month period of endurance training (study III). 
Table 3.1

Age, thysical characterisics, matmal physical working capacity (APWC) and maxinal oxygen uptake (16omax) of the subjects participating in study $I$ and 11 when entering the study.

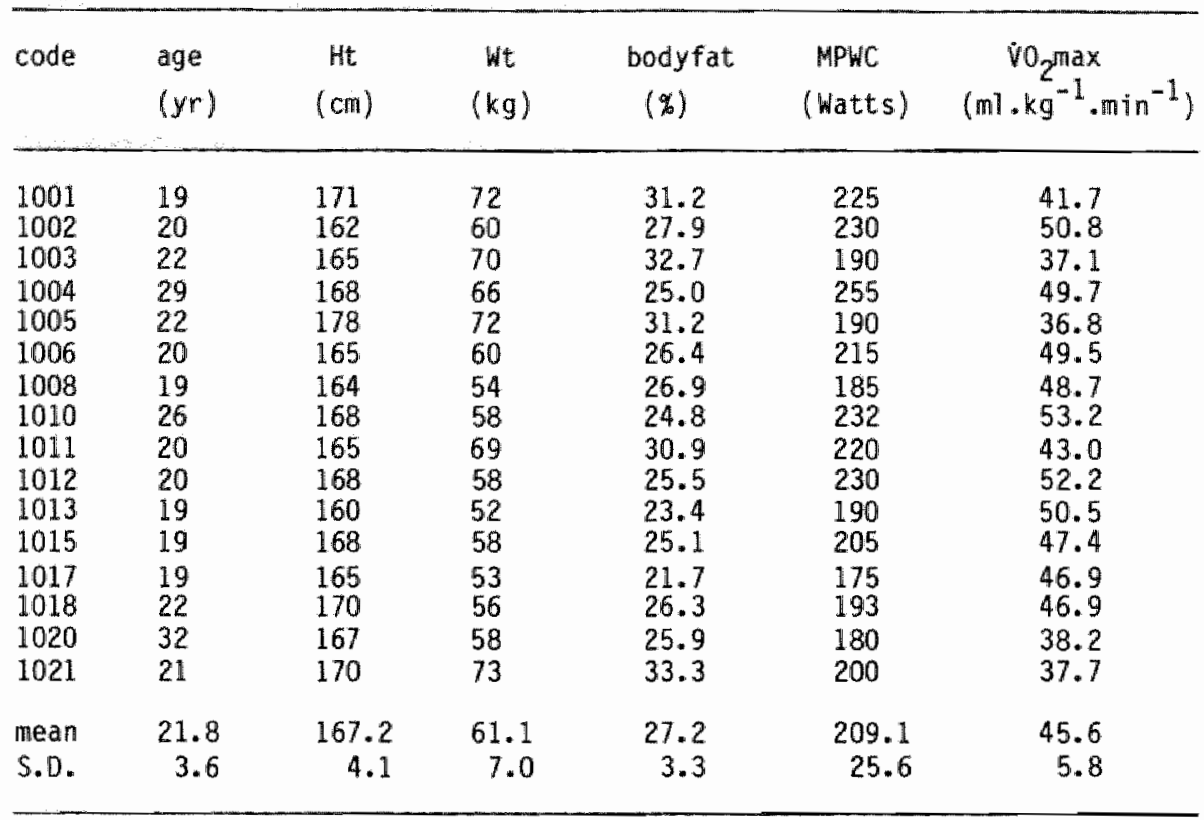

The subjects participating in study II $(n=6)$ were highly trained marathon runners. Their performances varied between $2 \mathrm{hr} 54 \mathrm{~min}$ and $3 \mathrm{hr} 05 \mathrm{~min}$ for the marathon. Training age and training volume (i.e. > 6 yrs, 100-140 km/week) were comparable. They participated in study $\mathbb{1}$. Table 3.2 sumarizes their physical characteristics and $v_{2}$ max walues. Three out of 6 were multiparous, the ather three were nulliparous. 
Table 3.2

Age, physical characteristics, maximal physical performance (MPWC) and maximal axygen uptake $\left(\mathrm{VO}_{2} \mathrm{max}\right)$ of the subjects participating in study 11 .

\begin{tabular}{|c|c|c|c|c|c|c|}
\hline code & $\begin{array}{l}\text { age } \\
(y r)\end{array}$ & $\begin{array}{c}\mathrm{H} \\
(\mathrm{cm})\end{array}$ & $\begin{array}{c}W \\
(\mathrm{~kg})\end{array}$ & $\begin{array}{c}\text { bodyfiat } \\
(x)\end{array}$ & $\begin{array}{c}\text { MPWC } \\
(\mathrm{km} / \mathrm{hr})\end{array}$ & $\begin{array}{c}\text { Vo.max } \\
\left(\mathrm{ml} \cdot \mathrm{kg}^{-1} \cdot \mathrm{min}^{-1}\right)\end{array}$ \\
\hline $\begin{array}{l}1302 \\
1303 \\
1304 \\
1305 \\
1307 \\
1309\end{array}$ & $\begin{array}{l}39 \\
32 \\
39 \\
39 \\
36 \\
31\end{array}$ & $\begin{array}{l}165 \\
167 \\
154 \\
163 \\
168 \\
170\end{array}$ & $\begin{array}{l}58.0 \\
52.0 \\
45.2 \\
56.4 \\
57.1 \\
55.2\end{array}$ & $\begin{array}{l}13.4 \\
12.2 \\
11.0 \\
13.6 \\
14.5 \\
11.8\end{array}$ & $\begin{array}{l}18.0 \\
18.0 \\
18.0 \\
17.0 \\
18.0 \\
18.5\end{array}$ & $\begin{array}{l}57.2 \\
59.2 \\
58.0 \\
52.3 \\
64.8 \\
64.1\end{array}$ \\
\hline $\begin{array}{l}\text { mean } \\
\text { S.D. }\end{array}$ & $\begin{array}{r}36.0 \\
3.4\end{array}$ & $\begin{array}{r}164.5 \\
5.2\end{array}$ & $\begin{array}{r}54.0 \\
4.4\end{array}$ & $\begin{array}{r}12.8 \\
1.2\end{array}$ & $\begin{array}{r}17.9 \\
0.5\end{array}$ & $\begin{array}{r}59.3 \\
4.2\end{array}$ \\
\hline
\end{tabular}

The subjects participating in study IV $(n=7)$ were untralined students. This study was done in cooperation with Dr. A. Bonen (School of Physical Education, Dalhousie University, Halifax, Nova Scotia, Canada). Three Canadian subjects received exactly the same exercise treatment as the dutch giris. The protacol and handling of blood samples were thoroughly discussed and apparantly the same. Al1 radio-immuno-assays were done in Mastricht. Table 3.2 sumarizes the physical characteristics and $v_{2}$ max values of the subjects participating in this study. 
Table 3.3

Age, physical characteristics, maximal physical working capacity (MPWC) and maximall oxygen uptake $\left(V 0_{2}\right.$ max) $)$ of the subjects participating in study IV.

\begin{tabular}{|c|c|c|c|c|c|c|}
\hline code & $\begin{array}{l}\text { age } \\
(y r)\end{array}$ & $\begin{array}{c}H \\
(\mathrm{~cm})\end{array}$ & $\begin{array}{c}k \\
(\mathrm{~kg})\end{array}$ & $\begin{array}{c}\text { bodyfat } \\
(\%)\end{array}$ & $\begin{array}{l}\text { MPWC } \\
\text { (Watts) }\end{array}$ & $\begin{array}{c}\operatorname{Vo}_{2} \max \\
\left(\mathrm{ml} \cdot \mathrm{kg}^{-1} \cdot \mathrm{min}^{-1}\right)\end{array}$ \\
\hline $\begin{array}{l}1002 \\
1006 \\
1010 \\
1012 \\
1022 \\
1023 \\
1024\end{array}$ & $\begin{array}{l}20 \\
20 \\
26 \\
20 \\
24 \\
23 \\
22\end{array}$ & $\begin{array}{l}162 \\
165 \\
168 \\
168 \\
165 \\
166 \\
164\end{array}$ & $\begin{array}{l}60 \\
60 \\
58 \\
58 \\
62.3 \\
56.4 \\
60.5\end{array}$ & $\begin{array}{l}27.9 \\
26.4 \\
24.8 \\
25.5 \\
24.8 \\
25.0 \\
26.2\end{array}$ & $\begin{array}{l}230 \\
215 \\
232 \\
230 \\
260 \\
230 \\
215\end{array}$ & $\begin{array}{l}50.8 \\
49.5 \\
53.2 \\
52.2 \\
57.3 \\
53.8 \\
46.6\end{array}$ \\
\hline $\begin{array}{l}\text { Mean } \\
\text { S.D. }\end{array}$ & $\begin{array}{r}22.1 \\
2.3\end{array}$ & $\begin{array}{r}165.4 \\
2.2\end{array}$ & $\begin{array}{r}59.3 \\
2.1\end{array}$ & $\begin{array}{r}25.8 \\
1.1\end{array}$ & $\begin{array}{r}230.3 \\
15.0\end{array}$ & $\begin{array}{r}51.9 \\
3.4\end{array}$ \\
\hline
\end{tabular}

The subjects participating in study $V_{a}(n=9)$ were physical education students. All subjects of this group were nulliparous. Their physical characteristics and $\dot{\mathrm{V}}_{2} \max$ walues are given in table 3.4 .

Table 3.4

Age, physical characteristics, maximal physical working capacity (MPWC) and maximal oxygen uptake of the subjects participating in study Va.

\begin{tabular}{lcccccc}
\hline code & $\begin{array}{c}\text { age } \\
(\mathrm{yr})\end{array}$ & $\begin{array}{c}\mathrm{H} \\
(\mathrm{cm})\end{array}$ & $(\mathrm{kg})$ & $\begin{array}{c}\text { bodyfat } \\
(\%)\end{array}$ & $\begin{array}{c}\text { MPWC } \\
(\text { Watts })\end{array}$ & $\begin{array}{c}\mathrm{Vo}_{2} \mathrm{max} \\
\left(\mathrm{mi} \cdot \mathrm{kg}^{-1} \cdot \mathrm{min}^{-1}\right)\end{array}$ \\
\hline 1201 & 23 & 178 & 76.4 & 33.1 & 256 & 46.7 \\
1202 & 22 & 170 & 60.3 & 30.6 & 212 & 4.7 \\
1204 & 20 & 178 & 66.1 & 33.0 & 193 & 46.1 \\
1206 & 20 & 158 & 63.2 & 28.1 & 225 & 53.5 \\
1207 & 23 & 168 & 74.2 & 27.4 & 250 & 50.5 \\
1211 & 25 & 167 & 59.0 & 24.4 & 200 & 44.6 \\
1214 & 20 & 165 & 54.1 & 24.3 & 225 & 53.4 \\
1215 & 26 & 163 & 52.0 & 22.5 & 215 & 46.7 \\
1218 & 21 & 173 & 68.8 & 31.0 & 262 & 49.8 \\
mean & 22.2 & 168.9 & 63.8 & 28.3 & 226.6 & 48.4 \\
5.0. & 22.1 & 6.3 & 7.9 & 3.7 & 24.6 & 3.3 \\
\hline
\end{tabular}


The subjects participating in study vb were physicall education students $(n=3)$ and trained runners $(n=3)$. Their physical characteristics and $\mathrm{V}_{2}$ max values are given in table 3.5 .

Table 3.5

Age, physical characteristics, maximal working capacity (MPWC) and naximal oxygen uptake $\left(\mathrm{VO}_{2} \mathrm{max}\right)$ of the subjects participating in study $\mathrm{Vb}$.

\begin{tabular}{|c|c|c|c|c|c|c|}
\hline code & $\begin{array}{r}\text { age } \\
(y r)\end{array}$ & $\begin{array}{l}H \\
(\mathrm{~cm})\end{array}$ & $\stackrel{W}{(\mathrm{~kg})}$ & $\begin{array}{c}\text { bodyfat } \\
(\text { (q) }\end{array}$ & $\begin{array}{l}\text { MPHC } \\
\text { (Watts) }\end{array}$ & $\begin{array}{c}\mathrm{VO}_{2} \max \\
\left(\mathrm{ml} \cdot \mathrm{kg}^{-1} \cdot \mathrm{min}^{-1}\right)\end{array}$ \\
\hline $\begin{array}{l}1221 \\
1222 \\
1223 \\
1224 \\
1225 \\
1226\end{array}$ & $\begin{array}{l}21 \\
21 \\
20 \\
22 \\
20 \\
20\end{array}$ & $\begin{array}{l}161 \\
169 \\
167 \\
172 \\
172 \\
172\end{array}$ & $\begin{array}{l}70.3 \\
55.0 \\
63.2 \\
52.7 \\
52.5 \\
52.5\end{array}$ & $\begin{array}{l}27.0 \\
18.0 \\
28.0 \\
15.8 \\
19.0 \\
17.0\end{array}$ & $\begin{array}{l}210 \\
210 \\
200 \\
240 \\
240 \\
250\end{array}$ & $\begin{array}{l}43.6 \\
46.0 \\
36.5 \\
57.1 \\
52.0 \\
60.0\end{array}$ \\
\hline $\begin{array}{l}\text { mean } \\
\text { S.D. }\end{array}$ & $\begin{array}{r}20.7 \\
0.8\end{array}$ & $\begin{array}{r}168.8 \\
4.4\end{array}$ & $\begin{array}{r}58.5 \\
7.0\end{array}$ & $\begin{array}{r}21.0 \\
5.6\end{array}$ & $\begin{array}{c}225 \\
20.7\end{array}$ & $\begin{array}{r}49.2 \\
8.8\end{array}$ \\
\hline
\end{tabular}

A1though the characteristics of the subjects participating in study II were different from those of the participants in the other studies, as far as age and parity are concerned, a better selection was not possible because it was very difficult to find female marathon runners, with a training volume of $100 \mathrm{~km}$ per week or more, who did not experience any menstrual irregularity (i.e. a variability between the length of the menstrual cycle of less than 8 days).

\subsection{EXERCISE PROTOCOLS}

\subsubsection{General considerations}

For evaluation of differences in hormonal and metabolic responses to various types of exercise in trained and untrained wonen, the exercise protocols used in this investigation had to be comparable, both in intensity and duration. To meet this qualification three criteria had to be fullfilled: 
- the type of energy expenditure for muscle contraction had to be similar. Therefore, we have chosen for an exercise intensity below the vol ${ }_{2}^{\text {max }}$ Hevel.

- the workloads were selected in such a way that the metabolic response to exercise was expected to be comparable, despite interindividual differences in physical fitness. This criterion could be fullfilled best if the workloads were expressed as a percentage of the workload at which the maximum oxygen uptake ( $\dot{V}_{2} \max$ ) was attaimed (Ästrand and Rodahl, 1977; Hollmann and Hettinger, 1981).

- the duration of each workload had to be sufficiently long to achieve a physiologicall steady-state. This means that it had to be at least 6 min. In addition it was recognized that the exercise protocols should be comparable with those used in some recent studies in this field (Jurkowski et al, 1978; Bonen et al, 1979). Although this is difficult to achieve completely, a good compromise seemed to be an exercise intensity of at least $60 \%$ $\mathrm{VO}_{2}$ max and a duration of the workloads of $15 \mathrm{~min}$. Based upon these assumptions the exercise-protocals used in this investigation can be subdivided into protocols to monitor the hormonal response to short-term exercise ( $>6$, $<15 \mathrm{~min}$ ) and protocols to monitor the hormonal response to prolonged exercise ( $30 \mathrm{~min}$ ). The influence of prolonged physical exercise on hormonal responses was investigated in study I to IV, the influence of shortterm physical exercise on hormonal responses was investigated in study $V$.

\subsubsection{Ergometers}

Two types of ergometers were used for several reasons. Although we intended to use the treadmill as an ergometer in all studies, a pilot study with several untrained subjects, using the same protocol as the marathon runners, (i.e. incremental speed changes only) revealed that they were not able to run for a period longer than $5-10 \mathrm{~min}$. Therefore, a bicycle ergoneter was used in all studies, except for the one in marathon runners. In these athletes the exercise performance was thought to be assessed most adequately on a treadmill because of their high-intensity long distance running for years which in addition is known to result in specific adaptations of the body (Astrand and Rodah1, 1977; Verstappen et al, 1982). A bicycle ergometer has the following advantages: 
- standardization of external workload is easy with a bicycle ergometer.

- the bicycle is a commonly used transport vehicle in The Netherlands. Therefore, most subjects are skilled in bicycling.

The bicycle ergometer (Lode NV, Groningen, The Netherlands) was electrically braked. The external workload was independent of revolution rate in the range from $60-90$ revolutions/min.

In study II a motor-driven treadmill (Quinton 18-50, Seattle, Washington, U.S.A) was used.

\section{2 .3 vo $_{2}$ max tests}

To estimate the workload to be used in each experiment an incremental bicycle ergometer (all studies except for II) or treadmill (study II) test preceded the experiments. During this test respiratory data were recorded continuously from which the oxygen uptake was calculated.

In study II (marathon runners) an incremental Vo $_{2}$ max test preceded each experiment (thus twice in a menstrual cycle), because changes in the training program might alter their test performance. In the other studies, where untrained subjects volunteered, only minor differences in maximal physical performance could be expected and hence the $\mathrm{V}_{2}$ max test was performed only before the first experiment.

The bicycle ergometer test consisted of a load of 100 Watt for the first $5 \mathrm{~min}$, followed by increments of 50 watt ewery $2 \frac{1}{2}$ min until the subject was exerted. The maximal physical working capacity (MPWC) from which the workloads for the experimental protocol were estimated, was calculated as follows:

$$
M P W C=W o u t+t / 150 \times \Delta W
$$

where, Wout $=$ the last workload (in Watts) which the subject completed for $2 \frac{1}{4} \mathrm{in}, \mathrm{t}=$ the time (in seconds) which the subject could sustain the highest workload and $\Delta W=$ the final load increment.

In the treadmill test the runners performed at a speed of $12 \mathrm{~km} / \mathrm{hr}$ for $10 \mathrm{~min}$, follawed by an increase in speed of $2 \mathrm{~km} / \mathrm{hr}$ every $2 \mathrm{~min}$, until the subject was exerted. The slope was kept at $0^{\circ}$. The workloads to be used during the experimental days calculated in a similar way as in the bicycle ergometer test. From these tests it appeared that in all cases the 
Wor $2^{\text {max }}$ was attained at the highest workload. Hence in the following sections the intensity of the workloads will be expressed as a percentage of the $10_{2}$ max.

\subsubsection{Exercisie protocols used in the studies}

In study I, III and IV a load of 60\% Vomax for $15 \mathrm{~min}$, was followed by an fincrease of $10 \% \mathrm{VO}_{2} \mathrm{max}$ each $15 \mathrm{~min}$ unt il the subject had to give up. In study 11 (marathon runners) a workload of $60 \%$ v0 max was followed by a run with a workload of $85 \% \mathrm{~V}_{2}$ max for one hour. In study Va a workload of $70 \%$ Wo $2^{\text {max }}$ for 10 min was followed by a workload of $100 \%$ vo max until the subject was exerted, while in study Wb a workload of $70 \% 60$ max was follow ay a recovery period at $25 \% \mathrm{VO}_{2}$ max for $30 \mathrm{~min}$.

Study I-IV were done in the exercise laboratory (Department of Physiology) of the University of Limburg (Mastricht. The Netherlands), while study $V$ was performed in the exercise liaboratory of the Department of Physiology of the University of Utrecht (Utrecht, The Netherlands).

\subsection{EXPERIMENTAL PROCEDURES}

\subsubsection{General procedures}

On the experimental days, the subjects came to the laboratory in the morning of the 7 th - 10th day of their menstrual cycle. The subjects who participated in study I, II or III also performed in the luteal phase of their menstrual cycle (between the $20 t h$ - 25th day). All exercise tests were performed between 8.15 and $10.30 \mathrm{a} . \mathrm{m}$. If the subjects had to exercise twice in a menstrual cycle (as in study I, II and III) both exercise tests were performed at the same time of the day (difference less than 15 min).

After dressing in a sport-suit, a tefion catheter (18-gauge, quick cath., Travenol Laboratories, Deerfield, 111., U.S.A.) was inserted into an antecubital vein, which was kept patent by a slowly dripping infusion of saline. After a rest period in a chair of 30 (study I, II, III) or 120 inin (study IV and $V$ ) ) the subjects began to exercise. Blood was collected twice at rest ( 15 and 2 min prior to the exercise bout).

During exercilse several blood samples were collected. In each case blood was obtained without interrupting the exercise. All exercise samples were 
corrected for hemoconcentration by measurement of total protein, which was compared with the mean of the two concentrations at rest. The details of the various experiments are described in the following sections.

\subsubsection{Study I}

The aim of this part of the study was to collect data about hormonal responses to prolonged incremental physical exercise in both the follicular and luteal phase of the menstrual cycle in 16 untrained women. In addition, the influence of the phase of the menstrual cycle on maximal physical performance (MPWC) was evaluated. The physical characteristics of these subjects are given in table 3.1. They reported to the laboratory between 8.15 and $9.30 \mathrm{a} . \mathrm{m}$. after an overnight fast.

After a 30 minutes rest period, the subjects started the bicycle ergometer test at $60 \% \mathrm{vo}_{2} \max$ for $15 \mathrm{~min}$. Thereafter the workload was increased by $10 \% \mathrm{VO}_{2}$ max every 15 minutes until the subject was exerted. Blood was collected every 15 min through the indwelling catheter. In these samples the plasma concentration of lactate, glucose, total protein, E $2, P, T, \Delta 4-$ $A$, DHEA-S, PRL, ACTH, LH and FSH were determined. The free $E_{2}$ and free $T$ fractions were detemined in the plasma samples at rest, and those obtained at the end of the exercise bout.

The whole procedure is depicted schematically in figure 3.1 . 


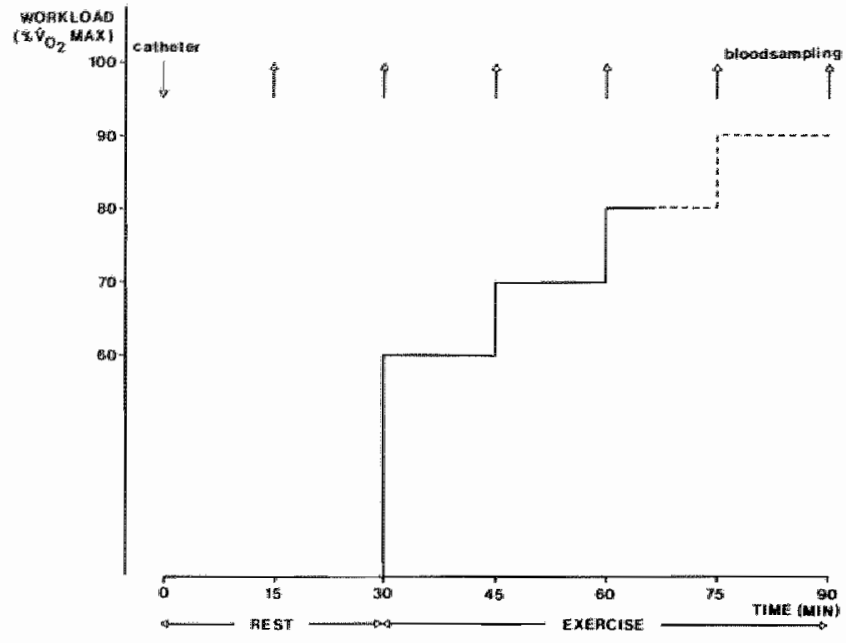

Figure 3.1

Schematic representation of the experimental procedures in study $I$ and $I I I$.

\subsubsection{Study II}

The aim of this part of the study was to collect data about hormonal responses to prolonged physical exercise in highly trained marathon runners both in the follicular and luteal phase of their menstrual cycle. Additionally, the influence of the phase of the menstrual cycle on MPWC was eva1uated. The physical characteristics of the subjects participating in this study are given in table 3.2. All subjects reported to the laboratory between 9.00 and $9.30 \mathrm{a} . \mathrm{m}$. after a light breakfast (ca. $350 \mathrm{kcal}$ ) taken 2 hrs before the experiment. This was done because in a previous experiment the subjects complained about symptoms of hypoglycemia at the end of a long treadilill run. 
After a 30 min rest period the subjects ran on a treadmill for $75 \mathrm{~min}$. The exercise test consisted of a warming-up period of $15 \mathrm{~min}$ at $60 \% \mathrm{~V}_{2} \max$, followed by a continuous run for one hour at about $85 \% \mathrm{VO}_{2}$ max. Blood was obtained every $15 \mathrm{~min}$ through the indwelling catheter without interrupting the run. In these samples the plasma concentrations of lactate, glucose, totall protein, $\mathbb{E}_{2}, P, T, \triangle 4-A, D H E A-S, P R L, A C T H, L H$ and as well as the $F S H$, free $E_{2}$ and free fractions at rest and after the exercise $T$ were determined.

The whole experimental procedure is depicted schematically in fig. 3.2 .

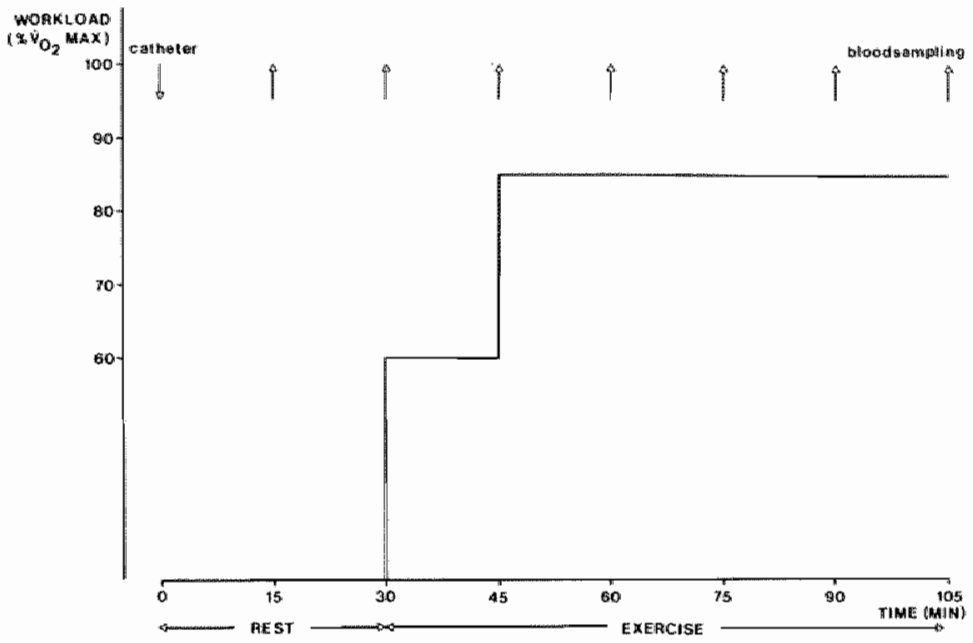

Figure 3.2

Schematic representation of the experimental procedures in study II.

\subsubsection{Study $\mathbb{I} 11$}

The aim of this part of the study was to evaluate the influence of a short period ( 3 month) of endurance training on metabolic and homonal responses to exercise in previously untrained women. Additionally, the influence of the phase of the menstrual cycle on MPWC was evaluated. For this purpose 8 of the subjects (1002, 1008, 1010, 1011, 10112, 1015, 1017 
and 1021), participating in study 1 , volunteered in this part of the study* The physhcal characteristics of these subjects are given in table 3 a. 1 .

The training program consisted of running and cycling 3-4 times per week. The training wolume was increased progiressively during a period of 3 months from about 25 min to $50-60$ min per training unit. The training consisted of interkal and continuous ruming and/or cycling. The absolute intensity of the exercise was adapted to heart rate, which was not allowed to fall under 160 beats/min. After this training period each subject was retested in the follicular and luteal phase of her menstrual cycle. The absolute worklaad was reajusted according to the changes in MPMC, the rellative warkload, however, was the same as in the pre-training tests. The whole experimental procedure was identicai to the one in study $I$.

\section{3 .5 Study IV}

The aim of this part of the study was to collect data about changes in the pulsatile pattern of gonadotropin release before, during and after physical exercise.

For this purpose 7 subjects participated in this study. In the follicular phase (between the 7 th and 10 th day of their menstrual cycle) they performed the same exercise protocal as described in study I. To monitor changes in the pulsatile pattern of gonadotropins and $\mathbb{E}_{2}$ the exercise was preceded and followed by a rest period of 2 hours. Blood (about $3 \mathrm{ml}$ ) was obtained every 15 min during the whole experimental period. The exercise protocal was indentical to that of study 1 .

\subsection{6 study $\mathrm{Va}$ and $\mathrm{Vb}$}

The aim of these parts of the study was to determine if a decreased degradation rate, measured as the metabilic clearance rate, might be responsible for increments in $E_{2}$ concentration of the bload. For this purpose 9 subjects participated in study $\mathrm{Va}$, whereas 6 subjects participated in study $\mathrm{Vb}$. Their physical characteristics are given in table 3.4 and table 3.5, respectively.

The MCR of $E_{2}$ in each subject was stiudied in the follicular phase, 7-10 days after the beginning of the menses, using the constant infusion technique (MacDonald et al, 1969) as described by Poortman and colleagues 
(1973). The subjects came to the laboratory at $8.15 \mathrm{a} . \mathrm{m}$ and after insertion of the catheter a resting blood sample was obtained. Immediately after the collection of blood, a priming dose of $8 \mu \mathrm{Cl},{ }^{3} \mathrm{H}$-labeled estradiol in $10 \mathrm{ml}$ of $5 \%$ ethanol in saline was injected into the arm vein. The contim nuous infusion was started $30 \mathrm{~min}$ after the priming dose. The radioactive solution (approx. $24 \mu \mathrm{Ci}$ in $30 \mathrm{ml}$ of $5 \%$ ethanol in saline) was infused into the right antecubital vein at a constant rate, using an infusion pump (Braun, Melsingen, Germany).

Another catheter was inserted into an antecubital vein of the opposite arm, which was used for the collection of blood samples. To avold influences on MCR due to differences in body position (erect vs supine) the subject was seated on the bicycle ergoneter without cycling for $20 \mathrm{~min}$ before the start of the exercise test (i.e. from 75 min to 95 min after the priming dose). Approximately 135 min after the priming dose the subject started to pedal. Two exercise tests (study $V_{a}$ and $V b$ ) were used:

- in the first test (study Va) 9 subjects (group 4) performed at a load of $70 \% \mathrm{~V}_{2}$ max during $10 \mathrm{~min}$, followed by a load of $100 \% \mathrm{~V}_{2}$ max till exhaustion.

- in the second test (study $v b$ ) 6 subjects (group 5) performed during 10 min a $70 \% \mathrm{~V}_{2} \max$ followed by a recovery period of $30 \mathrm{~min}$ at a load of $25 \% \mathrm{VO}_{2} \max$.

In both studies blood $(10-12 \mathrm{ml})$ was obtained through the catheter in the left am vein at the same time intervals as in study IV. The first two samples, obtained $15 \mathrm{~min}$ and just before the exercise tests, were taken to establish whether a steady-state level of the tracer was reached. In study Va blood was collected during exercise at the end of the 70 and $100 \% \mathrm{~V}_{2}$ max period, while in study $\mathrm{Vb}$ blood was collected each $5 \mathrm{~min}$, and al so during the recovery period. The whole experimental procedure for study $w_{b}$ is depicted in fig. 3.3 . 


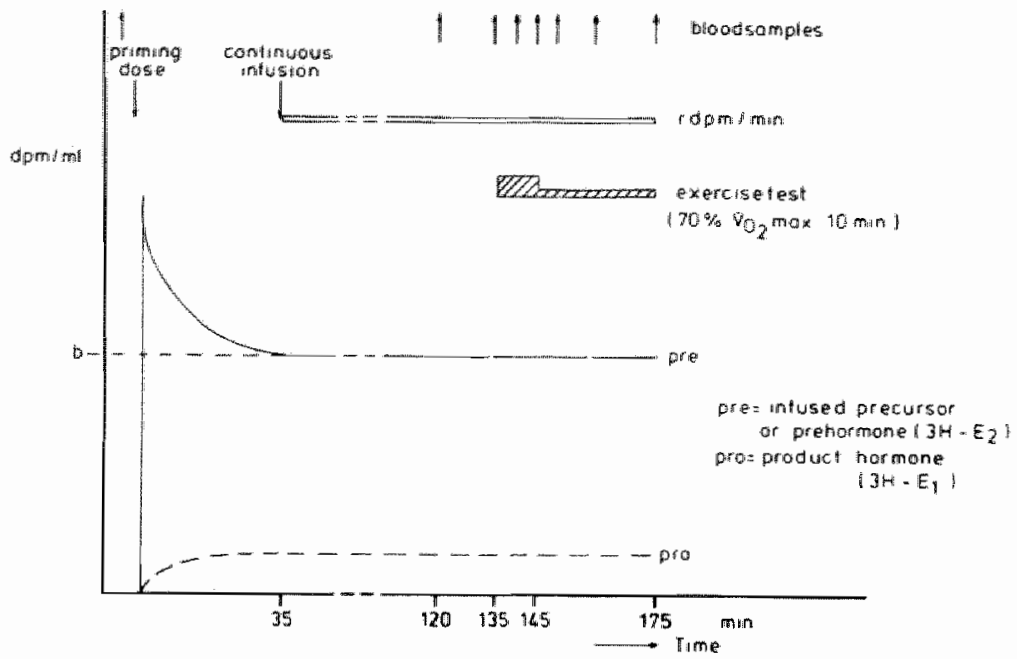

Fig. 3.3 Time schedule and schematic representation of radioactive steroids in blood during the infusion experiment of study vb.

\subsection{ANALYTICAL METHODS}

\subsubsection{Handling of blood samples}

Blood samples $(12 \mathrm{ml})$ were drawn through the indwelling catheter in 10 mil disposable syringes. About $1 \mathrm{ml}$ (study $\mathrm{I}$ to $\mathrm{IV}$ ) was allowed to clot in a glass tube. To accelerate the blood clotting, some glass pearls were present in the tube, which was gently turned for several times and placed in an tce bath. Immediately after the exercise test the bload was centrifuged $\left(2000 \mathrm{~g}, 10 \mathrm{~min}, 4^{\circ} \mathrm{C}\right.$ ) and thereafter serum was collected. Two hundred microliters of serum were irmediately analyzed for glucose and total protein.

The major part of each blood sample (about $10 \mathrm{ml}$ ) was collected in a heparinized glass tube, which was stored in an ice bath. Immediately after 
each experiment the blaod was centrifuged $\left(2000 \mathrm{~g}, 10 \mathrm{~min}, 4^{\circ} \mathrm{C}\right)$, the plasma divided in $0.5 \mathrm{ml}$ portions and stored at $-20^{\circ} \mathrm{C}$ for subsequent analysis. All deteminations, except thase for the clearance studies were done im duplicate.

\subsubsection{Glucose and tatal protein}

Serum glucose and total protein were analyzed by centrifugal analysis (Cobas Bia, Hoffmann La Roche, Basel, Switzerland). Glucose was detemined by the hexokinase method. The principle is as follows:

Glucose + ATP hexokinase glucose-6-phosphate + ADP.

G1 ucose-6i-P+NADP G6P-DH gluconate-6-P+NADPH $+\mathrm{H}^{+}$.

The NADPH concentration equals the gilucose concentration and was measured spectrophotometrically $(340 \mathrm{~mm})$. The intra and inter assay coefficients of variation were calculated to be $1.2 \%$ and $3.5 \%$, respectively.

Total protein was determined by the biuret method. The biuret reagent was obtalined from Hoffman La Roche $\mathrm{mr}$. 1010083 ( $\mathrm{K}$-Na tartrate $200 \mathrm{mmol} / \mathrm{L}$, $\mathrm{CuSO}_{4} 120 \mathrm{mmol} / \mathrm{L}, \mathrm{KJ} 100 \mathrm{mmol} / \mathrm{L}, \mathrm{NaOH} 2 \mathrm{mmol}$ ). The intra and inter assay coefficients of variation were calculated to be $0.9 \%$ and $1.5 \%$, respectively.

\subsubsection{Lactate}

Lactate in blood plasma was determined with an electro-chemical-enzymatic method as described by Racine (1975). The principle is based on the highly specific oxidation of lactate to pyruvate in the presence of the enzynite cytochrome $b_{2}$ and hexacyanoferrate-(III) according to:

Lactate $+2 \mathrm{Fe}(\mathrm{CN}) 6^{-3} \stackrel{\text { cyt. }}{\longrightarrow}$ pyruvate $+2 \mathrm{Fe}(\mathrm{CN}) 6^{-4}+2 \mathrm{H}^{+}$.

The hexacyanoferrate-(II) produced in this reaction is reoxydized electrochemically at a Pt-electrode:

2. $\mathrm{Fe}(\mathrm{CN}) 6^{-4} \rightarrow 2 \mathrm{Fe}(\mathrm{CN}) 6^{-3}+2 \mathrm{e}^{-}$ 
The current measured is related to the lactate concentration in the soluton. For this purpose a semi-atomatic lactate analyser llactate analyser 640. Kontron, Zurich, Switserland) was used.

The intrasusay coefficient of variation for low $\left(2\right.$ monol. $\left.1^{-1}\right)$ and high (15 mino $.1^{-1}$ ) lactate concentrations was calculated to be $8 \%$ and $1.5 \%$, respectively.

\subsubsection{Hormone analys is}

The hormone analysies were performed in the clinical laboratory of the "Sint Annadal" Hospital, Maastricht. Al1 hormone measurements were done by commercial radioimuno-assays (RIA), as specified ifm detall below. In general the following definitions were used:

\section{Accuracy}

All standards used in the hormone analyses were assayed against Medical Research Council (MRC) standard preparations.

\section{Precísion}

The intra-assay (within) and inter-assay (between) coefficients of variation were determined to estimate the variability of the assays. The intraassay coefficients of variation $\left(V_{C_{i}}\right)$ were calculated from the duplicates. The between-run coefficients of variation $\left(v c_{b}\right)$ were computed from three separate series of standards with low, medium and high hormone concentrations.

3. Mimimal detectable concentration (mdc)

The sensitivity of the assays was expressed as the minimal detectable concentration which is defined as the detectable concentration of at least twice the standard deviation of the zero value.

\section{Specificity}

The specificity of the assays was expressed as the cross-reactivity, defined as the ratio between the mass of the hormone analyzed and the mass of the respective substance at $50 \%$ inhibition of binding of the homone tracer.

The specifications of the RIA's used in this investigation are partly 
sumarized in table 3.6 , and partly described below.

Estradiol $\left(E_{2}\right)$

Cross-reactivity.

Substance

estradiol

estrone

estriol

progesterone and testosterone

Precision.

\begin{tabular}{llr}
$n$ & $\begin{array}{c}\bar{x} \pm S D \\
\left(\mathrm{nmol} .1^{-1}\right)\end{array}$ & $\begin{array}{r}V C_{6} \\
(\%)\end{array}$ \\
\hdashline- & $0.34 \pm 0.02$ & 7.3 \\
15 & $1.25 \pm 0.12$ & 9.7 \\
15 & $2.32 \pm 0.24$ & 10.3
\end{tabular}

(8)

100

2

$<0.1$

The intra-assay coefficient of variation was calculated to be $4.1 \%$.

(Luteinizing Hormone) LH

Cross-reactivity

Substance

LH

FSH

$\frac{(\%)}{100}$

TSH

1.9

4.0

HCG

100

Precision.

n

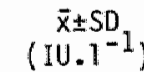

$--$

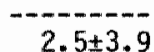

$15 \quad 26.0 \pm 2.5$

$15 \quad 38.4 \pm 2.2$

$15 \quad 108.0 \pm 8.3$

$V C_{b}$
$(\%)$

15.5

8.7

5.7

7.7

The intra-assay coefficients of variation were calculated to be $5.0 \%$. Follicle Stimulating Hormone (FSH)

Cross-reactivity

Substance

FSH

$\frac{(\%)}{100}$

$\mathrm{LH}$

0.13

TSH

0.25 
Prectiston.

$\begin{array}{lll} & \bar{x} \pm S D_{1} & \text { VC } \\ & \left(10.1^{-1}\right) & (\%) \\ -- & -2 .-2.5 & -5.3 \\ 14 & 7.9 \pm 0.5 & 7.8 \\ 14 & 14.7 \pm 1.14 & 7.8\end{array}$

The intra-assay coefficients of variation were calculated to be $4.3 \%$.

Progesterone $(P)$

Cross-reactivity

Substance

Progesterone

11- $\beta$-hydroxy-Progesterone

5 -a-di hydroprogesterone

5-B-dihydroprogesterone

Pregnenolone, cortisol, etc.

Preciston.

$\begin{array}{lcl}n & \bar{x} \pm \text { SD } & v C_{5} \\ & \left(\text { nmol. }^{-1}\right) & (\%) \\ 12 & 3.15 \pm 0.28 & 8.8 \\ 12 & 12.40 \pm 1.09 & 8.8 \\ 12 & 49.90 \pm 3.57 & 7.2\end{array}$

$\frac{(x)}{100}$

75

8.8

7.1

$<1.0$

The intra-run coefficient of variation was calculated to be $4.2 \%$.

Prolactin (PRL)

Cross-reactivity

No detectable reactivity with TSH, FSH, LH, HGG and ACTH.

Precision.

$\begin{array}{lll}\mathrm{n} & \bar{x} \pm \mathrm{SD} & V C_{6} \\ & \left(\mathrm{IU} .1^{-1}\right) & (\%) \\ 18 & 0.11 \pm 0.01 & 9.2 \\ 18 & 0.45 \pm 0.03 & 6.7 \\ 18 & 0.92 \pm 0.05 & 6.2\end{array}$

The intra-run coefficient of variation was calculated to be $3.7 \%$.

Testosterone (T)

Cross-reactivity

Substance

Testosterone

dihydrotestosterone

5 - $\beta$-androstan-3- $\alpha, 17 \beta-d i o 1$

11-Hydroxy-testosterone

5- $\alpha$-androstan-3- $\alpha, 17 \beta-d i o l$

5-a-androstan-3- $\beta, 17 \beta-d i 01$

Androsterone

$(\%)$

100

22

3.8

3.3

2.4

2.7

2.1 
Precistion.

$\begin{array}{lrl}n & \bar{x} \pm 50 & V C^{-1} \\ & \left(\text { nmol } .1^{-1}\right) & (\%) \\ 10 & 2.5 \pm 0.22 & 8.8 \\ 14 & 5.8 \pm 0.37 & 6.3 \\ 10 & 20.4 \pm 1.17 & 5.7\end{array}$

The intra-run coefficients of variation were calculated to be $4.5 \%$.

Androstenedione $(\Delta 4-A)$

Cross-reactivity

Substance

$\Delta 4$-androstenedione

Androsterone

Adrenosterone

$\frac{(8)}{100}$

11.6

2.7

2.1

Dehydroepiandrosterone

Precision.

$\begin{array}{llr}n & \begin{array}{c}\bar{x} \pm S D \\ (n m o l .1\end{array} & V C_{b} \\ 14 & 1.61 \pm 0.23 & 14.2 \\ 14 & 3.82 \pm 0.16 & 4.2 \\ 14 & 5.78 \pm 0.19 & 3.2\end{array}$

The intra-run coefficient of variation was calculated to be $4.1 \%$.

Dehydroepiandrosterone sulphate (DHEA-S)

Cross-reactivity

Substance

DHEA-S

DHEA

44-androstenedione

$\frac{(q)}{100}$

78

3.3

Precision.
n $\overline{\mathrm{x}} \pm$ SD
25
3. $10 \pm 0.26$
$\mathrm{VC}_{\mathrm{b}} \mathrm{.}$
8
$4.72 \pm 0.58$
12.4

The intra-assay coefficient of variation $\left(V C_{j}\right)$ was calculated to be $4.7 \%$. Adrenocorticotropic hormone (ACTH)

Cross-reactivity.

The only known reactive substances are human and porcine $\operatorname{ACTH}^{1-39}$ and human ACTH $1-24$.

Precisilion.

$\begin{array}{lcl}\mathrm{n} & \overline{\mathrm{x}} \pm \mathrm{SD} & v \mathrm{C}_{\mathrm{b}} \\ & \left(\mathrm{pmol} \cdot 1^{-1}\right) & \left(\mathrm{w}^{-1}\right) \\ 14 & 10.7 \pm 1.26 & 11.8 \\ 14 & 52.0 \pm 5.2 & 9.9\end{array}$


The intra-run coefficient of variation $\left(V C_{j}\right)$ was calculated to be $5.0 \%$.

\subsubsection{Free fraction of testosterone and estradiol}

separation of free from protein bound testosterone and estradiol in undiluted plasma was done by centrifugal ultrafiltration, using a commercial avallable filtration system (IUPS-1 with YMT filter, Amicon corp. Danvers, Mass. USA). The method is as follows. Radio-actively labelled estradiol $\left[2,4,6,7-3_{\mathrm{H}}(\mathrm{N})\right]$ estradiol $17-8$ sp act $91 \mathrm{Ci} \cdot$ mol. $]^{-1},[1,2,6,7-$ $\left.3_{H}(N)\right]$ testosterone, sp act $93.9 \mathrm{Ci}$.mmol. $7^{-1}$ and glucose, $\mathrm{D}-\left(\mathrm{U}_{-}{ }^{14} \mathrm{C}\right)$ glucose. sp act 257 mCi.mmo $1^{-1}$ were obtained from Amersham Int. (UK). Radiochemical purity was checked before use by thin llayer chromatography (TLC) $\left(E_{2}\right.$ and $\left.T\right)$ and paper chromatography $\left({ }^{14} \mathrm{C}-\mathrm{gl}\right.$ ucose). Working solutions of ${ }^{14} \mathrm{C}$-glucose were made up in distilled water immediately before use. If necessary, purification was done on sephadex $\mathrm{LH}-20$ chromatography columns using hexane (bp $67^{\circ} \mathrm{C}$, analytical grade) and chloroform (analytical grade) as the elution solvents $1-2$ days before use.

\section{Methodology}

Plasma samples were centrifuged a second time after thawing and any precipitate was discarded. Aliquots of ${ }^{3} \mathrm{H}$-steroid in ethanol $\left(10^{6} \mathrm{dpm}\right)$ were evaporated in glass tubes under nitrogen and $20 \times 10^{3} \mathrm{dpm}{ }^{14} \mathrm{C}$ glucose in $5 \mu \mathrm{I}$ of distilled water was added to each tube. Plasma samples (250 microl) were transferred into these tubes, briefly blended on a Vortex mixer, and incubated for 30 min under an atmosphere of $95 \% \mathrm{O}_{2}: 5 \% \quad \mathrm{CO}_{2}$ at the desired temperature $\left(37\right.$ or $39,5^{\circ} \mathrm{C}$ ) and for an additional $30 \mathrm{~min}$ at room temperature. Aliquots (200 microl) of the incubations where then pipetted onto the YMT membrane of the MPS-1 system and placed for another $10 \mathrm{~min}$ in a prewarmed rotor of an ultracentrifuge (Beckman L8-70, with 60-TI angle rotor). The centrifugation angle was $35^{\circ}$. Centrifugation occurred at $1000 \mathrm{~g}$ at the desired temperature $\left( \pm 0.2^{\circ} \mathrm{C}\right)$ for $10 \mathrm{~min}$. After centrifugation $50 \mu \mathrm{l}$ from both the ultrafiltrate and the plasma was pipetted into scintillation vials. Scintillation liquid $(3 \mathrm{ml}$ of Picofluor) was added to the vials, which capped, blended on a vortex mixer and counted in a liquid scintillation spectrophotometer (Packard Tricarb 3390) adjusted for the simultaneous measurement of ${ }^{3} \mathrm{H}$ and ${ }^{14} \mathrm{C}$. The precision of counting $<1.0 \%$ (coefficient of variation of counts per min) for ${ }^{3} \mathrm{H}$ and ${ }^{14} \mathrm{C}$. The intra and inter run coefficient of variation were obtained from repeated $(n=10)$ runs of 
series $(n=32)$ of the same plasma and were callculated to be $7.3 \%$ and $10 \%$, respectively.

Calculation of the percentage of free steroid

Because ${ }^{14} \mathrm{C}$-glucose is not bound to plasma proteins or the dialysis membrame, the ratio's between ${ }^{3} \mathrm{H}$-steroid and ${ }^{14} \mathrm{C}$-glucose on either side of the dialysis membrane can be used to evaluate the relative concentration of labelled steroids and glucose irrespective of volume. After corrections for background counts and ${ }^{14} \mathrm{C}$ to ${ }^{3} \mathrm{H}$ spill-over in the counting system, the percentage of free steroid could be calculated as follows:

free steroid $=$

$$
{ }^{3} \mathrm{H} \text {-steroid (dpm) }{ }^{3} \mathrm{H} \text {-steroid dpm }
$$

$$
\begin{aligned}
& \overline{{ }^{14} \mathrm{C} \text { glucose }(d p m)} \div \overline{{ }^{14} \mathrm{C}-g l u \operatorname{cose}(d p m)} \\
& \text { ultrafiltrate plasma }
\end{aligned}
$$

Metabolic clearance rate studies ( $\mathrm{Va}$ and $\mathrm{Vb}$ )

The MCR of $E_{2}$ was calculated by a modification of the constant infusion technique as described by Poortman et al (1973). With this method a tracer amount of ${ }^{3} \mathrm{H}-\mathrm{E}_{2}$ was infused.

After extensive purification of plasma extracts for estimation of radiochemical homogenity the MCR could be calculated. Correction for procedural losses was done by gas liquid chromatagraphy (GLC). The details of the method are as follows.

\section{Materials}

Labelled estradiol, $\left[2,4,6,7-{ }^{3} H(N)\right]$ estradiol $-17 \beta,[$ TRK 322, SA]

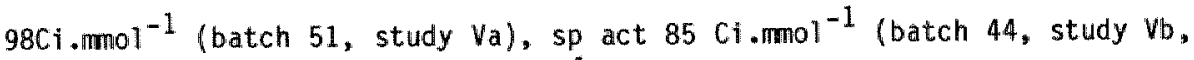
subj. 1-3) and sp act $104 \mathrm{Ci}^{\mathrm{m} . \mathrm{mmol}^{-1}}$ (batch 46, study Vb, subj. 4-6) was obtained from The Radiochemical Centre (Amersham, UKK). The non-radio-active steroids $\left(E_{2}\right.$ and $\left.E_{1}\right)$ were obtained from Makor chemicals, Ramat-Gan, Israel and Organon, Oss, The Metherlands. Purity of labelled steraids was checked by TLC performed on $20 \times 20 \mathrm{~cm}$ Merck precoated silica gel GF-254 glass plates.

All solvents for extraction of plasma samples and for chromatography 
Were of analytlcal grade and redistllled before use. Gas Liquid Chromatography (GLC) was performed on a Pye gas chromatograph (model 104) with automatic solid injection and a Perkin Elmer gas chromatograph (model P-17) using $1 \%$ XE-60 packing and a hydrogen flame ionization detector. Acetylattion and saponification of the sterolds were done as described by Bush (1961)

Anal ytical procedures.

The analytical procedures were as follows: $200 \mu$ gram $E_{1}$ and $E_{2}$ were dissolwed in $0.2 \mathrm{ml}$ ethanol and the plasma sample added, which was diluted with an equal volume distilled water. Extraction occured with diethylether $(3 \times 20 \mathrm{ml})$, thereafter the ether extract was collected and evaporated to dryness. The residue was dissolved in $1 \mathrm{ml}$ ethanol and after addition of 25 mil toluene a phenolic separation according to Brown (1955) was performed. The water phase (with $E_{3}$ ) was discarded and the organic phase (after the $\mathrm{pH}$ was brought at 8.8$)$ was extracted with diethyl-ether $(2 \times 30 \mathrm{~m} 1)$. After washing with $5 \mathrm{ml}$ distilled water the etherphase was collected and evaporated. The residue was dissolved in methanol and subjected to TLC (toluenemethanol $9: 1(\mathrm{v} / \mathrm{v})$.

After localization of the $E_{1}$ and $E_{2}$ band, the silicagel was collected, inactivated with a drop of distilled water and eluated $(3 x)$ with tolueneethanol $(9: 1, v / v)$. The extracts were evaporated to dryness under a stream of nitrogen. The residue was dissolved in 5 drops of pyridine, vartexed, whereafter 10 drops of acetic anhydride were added. The air in the tube was removed by a stream of nitrogen, whereafter it was stoppered. Acetylation of $E_{1}$ and $E_{2}$ occurred at room temperature in darkness. It was shown that for complete acetylation 18 hrs was sufficient. After acetylation the tubes were ewaporated to dryness under a stream of nitrogen, the residue dissolved in some drops of ethanol and again subjected to TLC. As a control 100 $\mu$ gram of crystalline $E_{2}$-diacetate and $E_{1}$-acetate were dissolved in ethanol and also subjected to TLC. After detection of the $E_{1}$-acetate and $E_{2}$-diacetate bands the silicagel was removed, eluated with ethylacetate (3x) and evaporated to dryeness under $N_{2}$. The residues then were dissolved in ethylacetate $(1 \mathrm{ml})$ and from this solution $0.4 \mathrm{ml}$ was subjected to LSC and 0.2 Inl to GLC. The GLC was done to quantitate procedural losses.

To further evaluate the effectiveness of the procedures a deacetylation 
step was performed. For this purpose the remainder of the acetates $(0.4 \mathrm{ml})$ was evaporated to dryeness under $\mathrm{N}_{2}$. Deacetylation occured in a solution of $0.4 \mathrm{ml} \mathrm{NaOH}$ in $70 \%$ methanol and an atmosphere of $\mathrm{N}_{2}$ for 18 hrs at room temperature. Thereafter ether extraction was done $(3 \times 2 \mathrm{ml})$, and the ether extract washed with $2 \mathrm{ml} 0.01 \mathrm{HaC}$ and $1 \mathrm{ml}$ distilled water. The organic phase was evaporated to dryness under $\mathbb{N}_{2}$, the residue dissolved in $0.2 \mathrm{ml}$ ethanol and subjected to TLC.

After elution of the silicagel, containing $E_{1}$ and $E_{2}$ the elutes were evaporated under $\mathbb{N}_{2}$, and the residue dissolved in ethylacetate ( $1 \mathrm{ml}$ ) and subjected to LSC and GLC. If after correction for procedurat losses the $E_{1}$ and $E_{2}$ content of the acetylated and deacetylated samples disagreed for more than $12 \%$, they were discarded and the values not used. The whole procedure is schematically depicted in fig. 3.4 .

The MCR was calculated according to the formula:

MCR $=\underset{b}{-}{ }_{b}^{r} \cdot \mathrm{min}^{-1}$

where, $r=$ the infusion rate $(\mathrm{dpm} / \mathrm{min})$ of the radioactive steroid and $b=$ the level of radio-activity of $E_{2}(\mathrm{dpm} / \mathrm{ml})$ in plasma after correction for procedural lasses.

\subsection{DATA ANALYSIS}

\subsubsection{Criteria for maximal tests}

For the evaluation of the influence of the phase of the menstrual cycle on maximal physical working capacity only maximal tests were used. To decide whether a test could be considered as maximal, the following criteria, of which 4 out of 6 had to be fulfilled were used (Kuipers, 1983):

1. a plasma lactate concentration of $8 \mathrm{mmol} .1^{-1}$ or more (Astrand and Rodah1, 1977; Hollmann and Hettinger, 1981). 


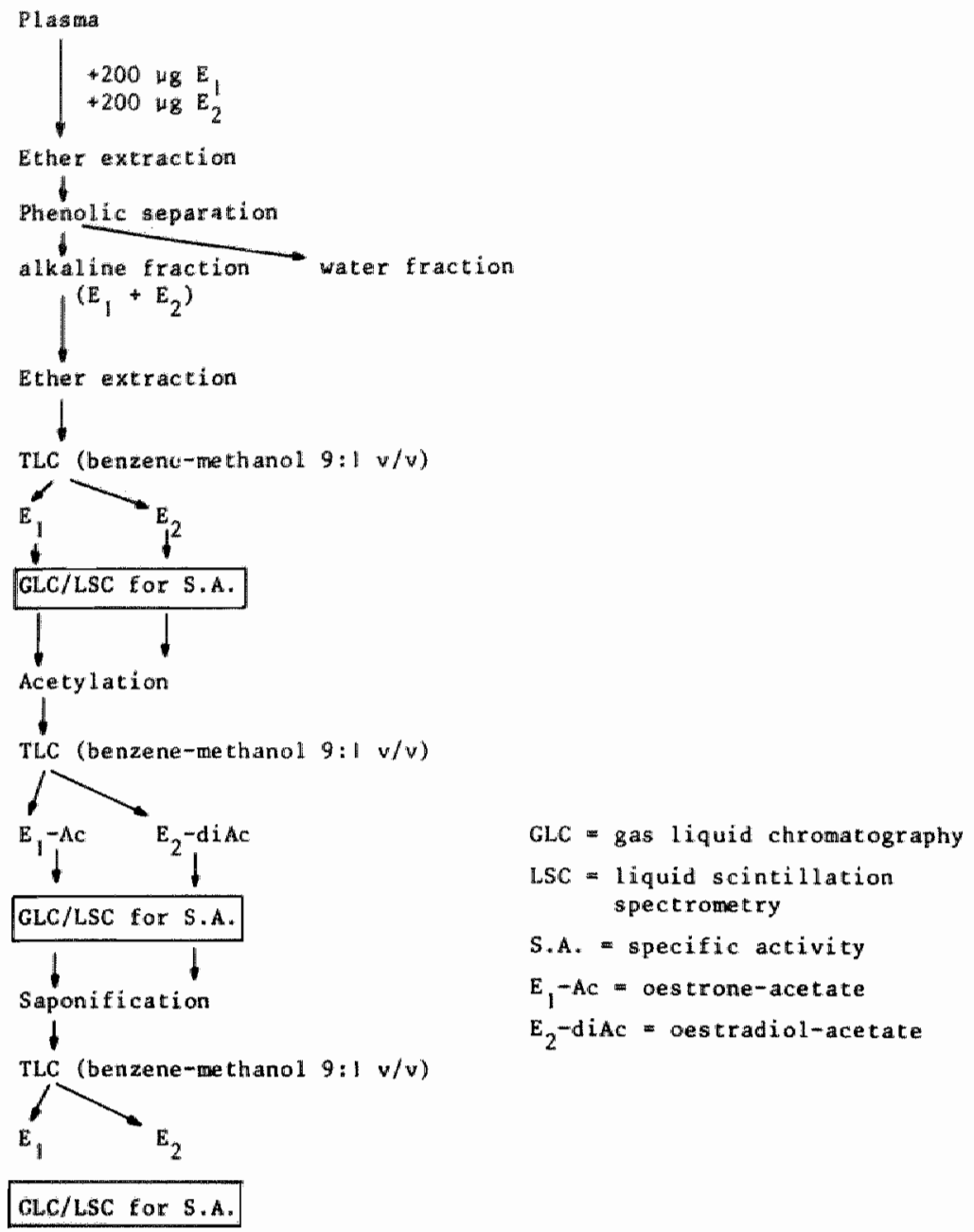

Fig. 3.4 Purification of plasma extracts for estimation of radiachemical homogeneity of estrone and estradial. 
2. a heart rate exceeding 180 beats.min ${ }^{-1}$.

3. a respiratory equivalent $\left(\dot{V}_{E} / \dot{V O}_{2}\right)$ above 30 (Hollmann and Hettinger, 1981).

4. an $\mathrm{R}$ value $\left(\mathrm{VCO}_{2} / \mathrm{VO}_{2}\right)$ over 1.00 (Binkhorst, 1963 ).

5. a respiratory rate of 45 or more

6. the investigator's judgenent of the subject's distress.

\subsubsection{Statistical analysis}

Statistical analysis was done by using the Biomedical Computer Program (BMDP package, Dixon and Brown, 1981). Glucose, lactate and all hormonal data, including the percentual changes, were analyzed with a two-way (exercise versus phase) ANOVA among groups with repeated measures (BMDP-2V). For the homonal data comparisom among groups were also conducted with the relative values. For this purpose, the mean of the two resting samples was aimed to be $100 \%$. The remainder of the values were expressed as the percentage of the mean resting value. Because not all subjects were able to reach the highest. $\left(90 \% \dot{1}_{0} \max \right)$ workload, only the first three workloads $(60,70$ and $\left.80 \% \bar{v}_{2_{2} \max }\right)$ were used to make intergroup comparisons. In addition, comparisons between the absolute walues at rest of the untrained (study I) and trained subjects (study II) were also conducted, using the same program. If the hormonal responses to exercise were significant a Wilcoxon signed-rank, test was conducted to evaluate which workload induced significant changes in pllasma hormone concentrations compared to the values at rest. For study III both the absolute and relative values during exercise were analyzed with BMDP-2V. For most of the changes in homone concentration variance stabilizing transformations were used. For the absolute values separate analyses of variance (2-way and 1-way ANONA) were al so conducted (BMDP-7D) for each group. Differences between maximal physical working capacity in the follicular and luteal phase, and between the percentages free $E_{2}$ and $T$ before and after exercise (study $I$ and III) were tested on statistical significance with a miltiple paired t-test (BMDP-3D).

The data of study IV were analyzed as follows:

For each individual the data were plotted as hormone concentrations versus time. To analyse the frequency and amplitude of secretory periods a homone pulse was defined as occurring when the hormone concentration of a sample exceeded the previous concentration by at least twice the intra-assay 
coefficlent of variation. Thus $L H, F S H$ and $E_{2}$ pulses were considered when the plasma concentration increased by more than $10.0,8.6$ and $8.2 \%$, respectively. The frequency was determined during the pre-and post-exercise period separately. The pulse amplitude was expressed in IU. $1^{-1}$ for LH and FSH and moll. $1^{-1}$ for $E_{2}$. In addition for each individual the pre- and post exercise periods were compared for each hormone by a multiple paired t-test (BMDP-30) using the last 8 pre- and the first post-exercise values only. BMDP-3D was also used to compare these periods for the group as a whole. Besides, the general trend of the changes in hormone concentrations before and after exercise were graphical depicted making use of techniques of exploratory data analysis as described by Tukey (1979).

The data of study $V$ were analysed with Mosteller"s test for a specified order (Sarris and wilkening, 1977). 
Table 3.6

Specifications, minimal detectable concentration and manufacturers of the RIA's used in the present investigation.

\begin{tabular}{|c|c|c|c|c|}
\hline Homone & Specification RIA & Tracer & $M D C$ & Manufacturer \\
\hline$E_{2}$ & $\begin{array}{l}\text { Direct, double } \\
\text { antibody, solid- } \\
\text { phase }\end{array}$ & $125 \mathrm{I}$ & $0.03 \mathrm{nmol} .1^{-1}$ & $\begin{array}{l}\text { Eir, wurlingen, } \\
\text { Swit serl and }\end{array}$ \\
\hline$P$ & $\begin{array}{l}\text { direct, double } \\
\text { antibody, liquid } \\
\text { phase }\end{array}$ & $125_{I}$ & $0.28 \mathrm{nmol} .1^{-1}$ & $\begin{array}{l}\text { Farmos Diagnostica, } \\
\text { Turku, Finland }\end{array}$ \\
\hline LH & $\begin{array}{l}\text { Direct, double } \\
\text { antibody, } 1 \text { iquid } \\
\text { phase }\end{array}$ & $125_{I}$ & $1.1 \mathrm{IU} . \mathrm{I}^{-1}$ & $\begin{array}{l}\text { Famos Diagnostica, } \\
\text { Turku, Finland }\end{array}$ \\
\hline FSH & $\begin{array}{l}\text { Direct, double } \\
\text { antibody, liquid } \\
\text { phase }\end{array}$ & ${ }^{12 b} \mathrm{I}$ & $0.8 \mathrm{IU}^{-1} \mathrm{1}^{-1}$ & $\begin{array}{l}\text { Famos Diagnostica, } \\
\text { Turku, Finiand }\end{array}$ \\
\hline$T$ & $\begin{array}{l}\text { Extraction, double } \\
\text { antibody, solid } \\
\text { phase }\end{array}$ & ${ }^{125} \mathrm{I}$ & $0.02 \mathrm{nmol} . \mathrm{I}^{-1}$ & $\begin{array}{l}\text { Difagnostic Products, } \\
\text { Los Angelos, USA }\end{array}$ \\
\hline A & $\begin{array}{l}\text { Direct, sollid } \\
\text { phase (without } \\
\text { chromatography) }\end{array}$ & ${ }^{3} \mathrm{H}$ & $0.042 \mathrm{nmol} .1^{-1}$ & $\begin{array}{l}\text { Bio Merieux, Charbon- } \\
\text { nieres-les-Baim, France }\end{array}$ \\
\hline & $\begin{array}{l}\text { separation of } \\
\text { antibody bound } A \\
\text { from free } A \text { by dex- } \\
\text { tran coated charcoal }\end{array}$ & & & \\
\hline DHEA-S & $\begin{array}{l}\text { Direct, sollid } \\
\text { phase. Separation } \\
\text { of ant ibody bound } \\
\text { DHEA-S from free } \\
\text { DHEA-S by dextran } \\
\text { coated charcoal }\end{array}$ & ${ }^{3} \mathrm{H}$ & $0.05 \mu \mathrm{mol} .1^{-1}$ & $\begin{array}{l}\text { Bio Merieux, Charbon- } \\
\text { nieres-lles-Baim, France }\end{array}$ \\
\hline ACTH & $\begin{array}{l}\text { Direct, solid } \\
\text { phase, double } \\
\text { antibody }\end{array}$ & ${ }^{125} \mathrm{I}$ & 4.4 pmol $.1^{-1}$ & $\begin{array}{l}\text { Immuno Nuclear Corp., } \\
\text { St } 111 \text { water, USA }\end{array}$ \\
\hline PRL & $\begin{array}{l}\text { antibody } \\
\text { Direct, sollid } \\
\text { phase, double } \\
\text { antibody }\end{array}$ & ${ }^{125} \mathrm{I}$ & $0.05 \mathrm{IU} .1^{-1}$ & $\begin{array}{l}\text { Abbot, North Chicago } \\
\text { USA }\end{array}$ \\
\hline
\end{tabular}


CHAPTER IV

\section{RESULTS}

4.1 MAXIMAL PHYSICAL WORKING CAPACITY (MPWC) IN RELATION TO THE PHASE OF THE MENSTRUAL CYCLE (STUDY I)

The mean MPWC of the untrained subjects participating in study I was calculated to be $164.8 \pm 4.2$ Watt and $165.5 \pm 4.5$ Watt in the follicular and luteal phase, respectively. This difference was not statistically significant. All subjects (except for subject 1307) participating in study II were able to complete the $75 \mathrm{~min}$ treadmill run in both phases of the menstrual cycle. Subject 1307 performed only for $60 \mathrm{~min}$ in the luteal phase of her menstrual cycle.

4.2 METABOLIC AND ENDOCRINE RESPONSES TO PROLONGED PHYSICAL EXERCISE IN UNTRAINED AND TRAINED WOMEN (STUDY I AND II)

The experiments in the follicular phase occurred 7-10 days after the first day of menstruation. Ovulation had not occurred in any of these subjects as indicated by the low $P$ concentrations at rest ( $<6$ nmal.1 ${ }^{-1}$ ). Conversely, from the untrained group, 15 out of 16 subjects were al so tested in the luteal phase of their menstrual cycle as judged by a rise of $0.3^{\circ} \mathrm{C}$ in BBT, later on confirmed by the increased concentrations of plasma $P$ ( $11 \mathrm{nmol} .1^{-1}$ ) at rest prior to exercise. It appeared that one subject (no. 1020) was tested on the day the LH surge accured instead of during the luteal phase, therefore her data were discarded from further statistical analysis. Two subjects (no. 1003 and 1004) could not fulfil the termis for a maximal physical perfonmance, so we excluded their data from further analysis too. The remainder of the untrained subjects $(n=13)$ and all trained subjects fulfilled all terms for both a maximal test and an apparent owulation prior to the "Iuteal phase" experiment.

Considerable care was taken to test each subject under the same experimental conditions. In study I and II, the exercise protocol started between 
8.30 and $10.30 \mathrm{a} . \mathrm{m}$. While each subject was retested at the same time $( \pm 15$ min), thus decreasing scattering of results due to differences in diurnal secretion pattern of some homones. The experimental design of these studies permitted analyses of the data according to group membership (group), the phase of the menstrual cycle (phase) and the responses during the exercise period (exercise). Consequently, comparisons of these main effects as well as their interaction were performed among the untrained and trained subjects and for both groups seperately. Because we were also interested in the relation between workload and exercise intensity, we tested each plasma homone value obtained during exercise against the mean of the two walues at rest. The plasma concentrations of glucose and lactate are presented as absolute values versus time or workload while the hormonal data are presented as absolute and relative values $(X \pm S E M)$ versus time or workload. For the latter purpose the mean of the two resting values obtained 15 and 30 min after the insertion of the catheter was taken as 100\%. Relative values were used since we were mainly interested in the pattern and magnitude of the hormonal responses to exercise. Besides, this response will be more clear when expressed as relative values, because of the large inter-individual variation in plasma hormone concentrations. The values of both groups had to be expressed in different ways (concentration versus workload or time) because not all subjects of the untrained group were able to sustain the $80 \%$ vo ${ }_{2} \max$ workload for $15 \mathrm{~min}$ (mean: $13 \mathrm{~min} 5 \mathrm{sec}$ and $13 \mathrm{~min} 23 \mathrm{sec}$ in the follicular and luteal phase, respectively). Therefore it was felt that expressing the hormone, glucose and lactate concentrations

against the workload was more appropriate. However, one has to bear in mind that despite these differences the first $45 \mathrm{~min}$ of the exercise period were well comparable between the two groups. Thus, the worklloads of 60,70 and $80 \% \mathrm{~V}_{2}$ max in the untrained group are comparable with the workload, 45, 60 and 75 min after insertion of the catheter in the trained group.

\subsubsection{Metabolic responses to exercise}

\section{Gll ucose}

In the untrained and trained subjects the glucose concentrations increased significantly $(p<0.001)$ during exercise. In the untrained subjects (fig. 4.1) the increments in plasma glucose concentration tended $(p=0.06)$ 
- be more pronounced in the luteal phase when compared to the follicular hase, whereas in the trained subjects (fig. 4.2) no differences could be ibserved between both phases. The responses to exercise in the trained subjects differed significantly from those in the untrained subjects $\{p<0.001)$. Whereas the plasma glucose concentration did not change significantly at lower workloads in the untrained subjects; it increased at the same workload in the trained subjects.

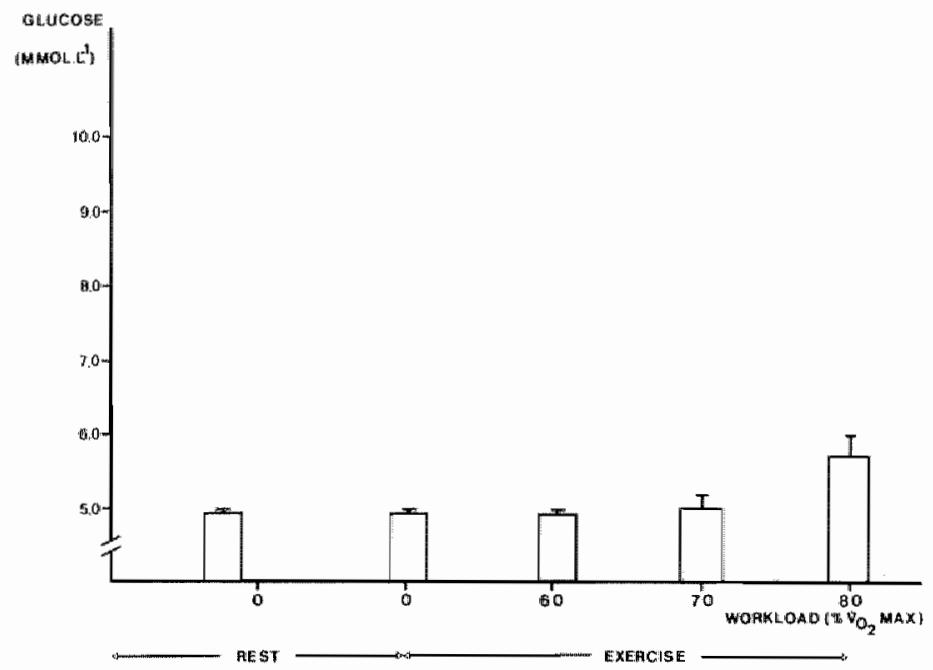

Eigura 4.1

Plasma glucose concentration during exerciee in untrained women $(N=13)$ in the folltoular phose of their menstruat oyote. 


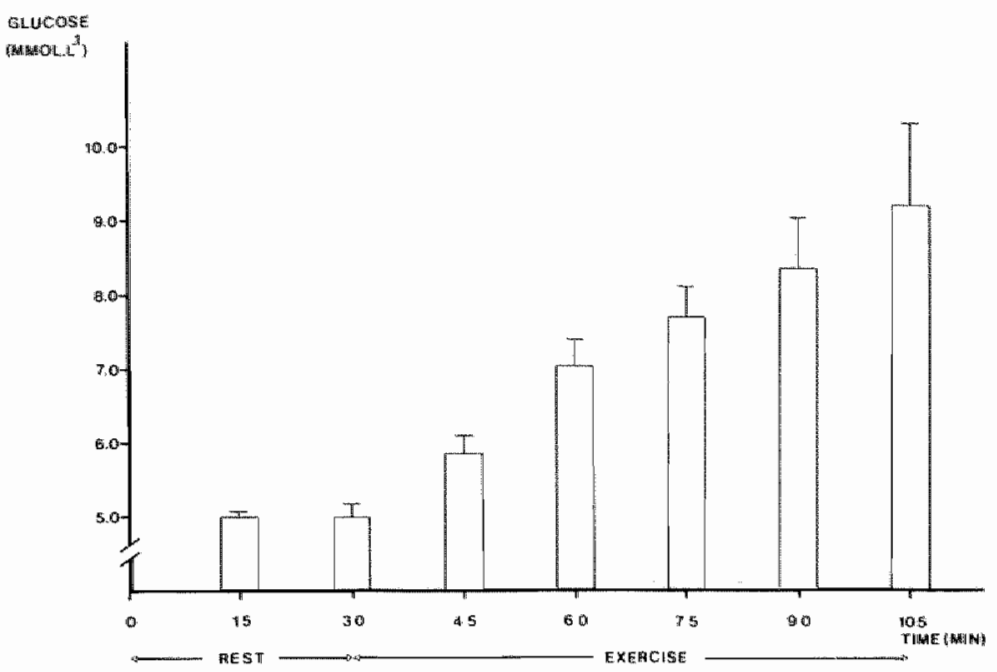

Figure 4.2

Plasma glucose concentmation duming exercise in trained women (n=6) in the follicular phase of their menstmul cycte.

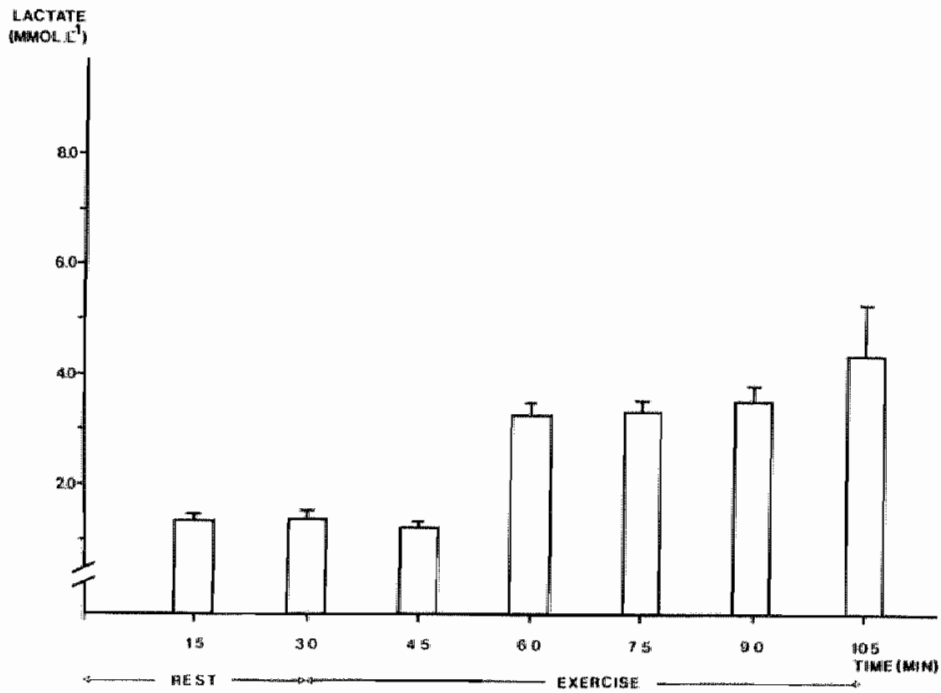

Figure 4.3

Plasma lactate concentration duming exeraise in tratined women ( $n=6$ ) in the follicular phase of their menstmual cycle. 


\section{Lactate}

In the untrained and trained subjects the plasma lactate concentrations increased significantiy during exercise ( $p<0.001)$. Wo statistically significant differences could be observed between the follicular and luteal phases of the menstrual cycle. As could be expected the plasma lactate concentration was significantly lower ( $p<0.001$ ) in the trained (fig. 4.3) than in the untrained subjects (fig. 4.4) at comparable workloads (i.e. 60, 70 and $80 \% \mathrm{VO}_{2}$ max and exercise times 15,30 and $45 \mathrm{~min}$. after the start of the exercise).

\subsubsection{Endocrine responses to exercise}

The basal hormone concentrations (the mean of the two values at rest) of the untrained and trained subjects are depicted in table 4.1.

\section{Estradiol $\left(\mathrm{E}_{2}\right)$}

During exercise the absolute $E_{2}$ values increased significantly (p<0.001) in bath groups. In the untrained subjects (fig. 4.5) the plasma $E_{2}$ concentrations were higher in the luteal phase ( $\left.p<0.001\right)$, while in the trained subjects (fig. 4.6) the plasma $E_{2}$ concentrations were more elewated in the follicular phase (table 4.1). In the untrained subjects all workloads were able to induce significant increments in plasma $E_{2}$ concentration (fig. 4.5). In the trained subjects similar results were obtained, with the exception of the first exercise value $(15 \mathrm{~min}$. after the start of the exercise), which was not statistically different from the values at rest (fig. 4.6). When expressed as relative values (data not shown) no significant effect of the phase of the menstrual cycle could be detected. In both phases the plasma $E_{2}$ concentration increased by about $15 \%$ at a workload of $60 \% \mathrm{W0}_{2}$ max and by about $40-50 \%$ at workload of $80 \% \mathrm{vo}_{2}$ max. These increases were comparable in both groups. In the untrained subjects the relative exercisse-induced increments in $\mathrm{E}_{2}$ concentration varied between 0 and $55 \%$, and between 5 and $64 \%$ in the follicular and luteal phase, respectively. In the trained subjects the increments ranged from 11 to $108 \%$ and 23 to $100 \%$ in the follicular and luteal phase, respectively. The differences in response between these groups appeared to be not significant. In the untrained subjects, the free fraction of $E_{2}$ at rest was calculated to be $1.55 \pm 0.04 \%$ and $1.62 \pm 0.08 \%$ in the follicular and 1uteal phase, respectivelly. The values 


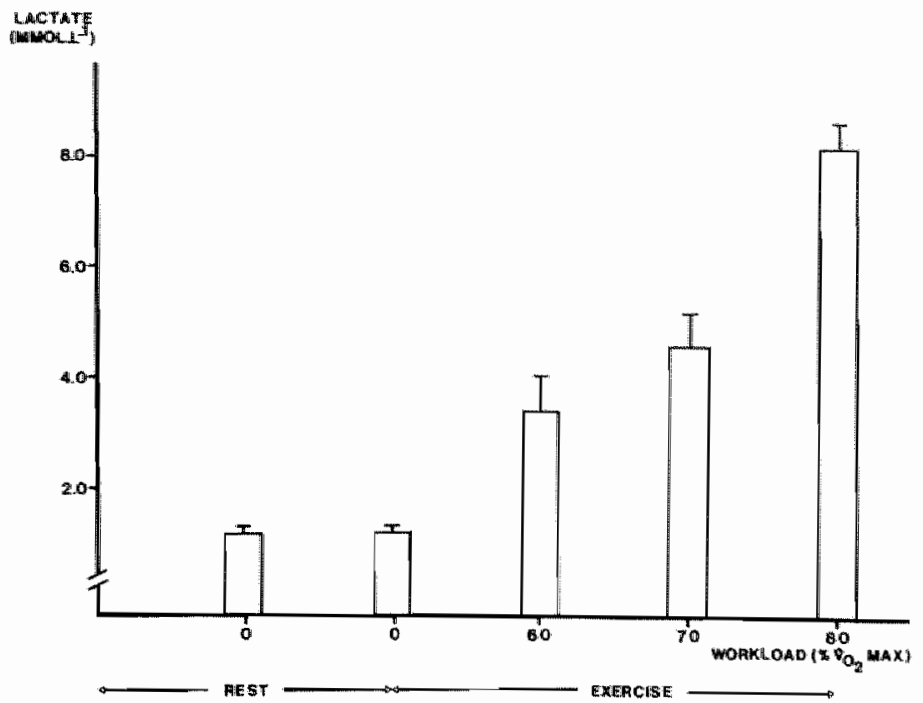

Figure 4.4

plasma lactate concentration during exencise in untrained women $(n=13)$ in the foltiaular phase of their menstruat cycte.

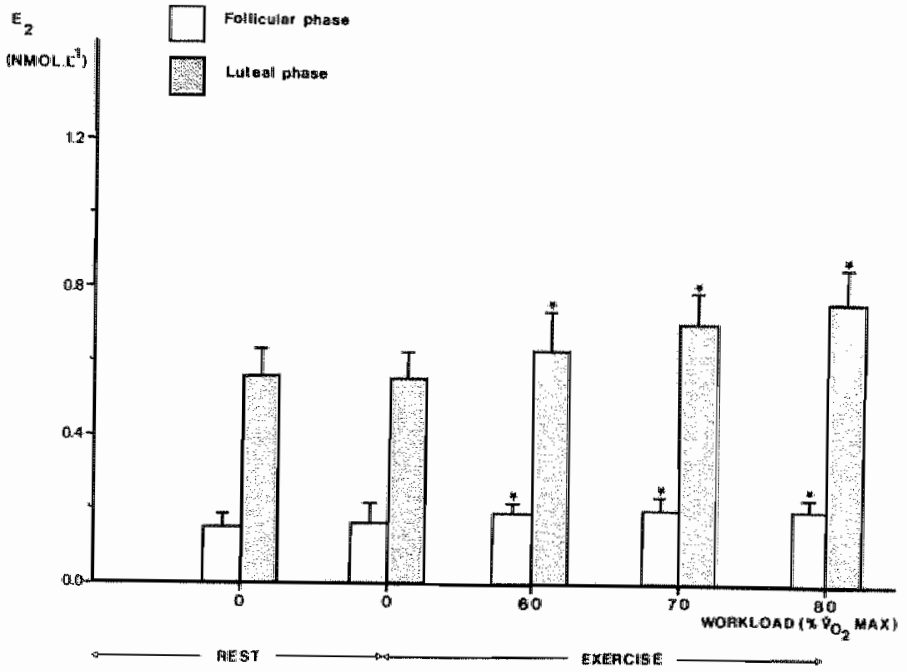

Pigure 4.5

Plabma $E_{2}$-oncentmations duming exercibe in untrained women ( $\left.n=13\right)$ in the follioular and luteal phases of their menstmual oycle. * = eignificantly different $(p<0.05)$ from the values at reat. 
Table 4, 1

Plasma concentration at rest (mean \pm SEM of the two values obtained 15 and $30 \mathrm{~min}$ after insertion of the catheter) of $E_{2}, P, L H, F S H, T, \triangle 4-A, D H E A-S$, PRL and ACTH in untrained and trained subjects in the follicular and luteal phases of their nenstrual cycle.

HORMONE

UNTRAINED SUBJECTS

TRAINED SUBJECTS

PHASE

FOLLICULAR LUTEAL

$0.15 \pm 0.03^{*}$

$0.56 \pm 0.07$

$5.2 \div 0.43$

$9.0 \pm 0.59$

$4.9 \pm 0.44$

(IU. $1^{-1}$ )

(nmol. $\left.1^{-1}\right)$

$\triangle 4-\mathrm{A}$

(mmo $.7^{-1}$ )

DHEA-S

(umo 1. $1^{-1}$ )

PRL

(IU. $\left.1^{-1}\right)$

ACTH

11. 1. \pm 1.06 *

$27.3 \pm 5.19$

$\stackrel{\mathrm{LH}}{\left(\mathrm{IU} . \mathrm{I}^{-1}\right)}$

$11.0 \pm 1.5^{*}$

$$
1.8 \pm 0.2^{*}
$$

$1.9 \pm 0.2^{*}$

$7.76 \pm 0.52^{\star}$

$8.77 \pm 0.78 *$

$7.04 \pm 0.92 *$

$7.32 \pm 0.80 \star$

$0.34 \pm 0.1$

$0.27 \pm 0.02$

$3.9 \pm 0.6$

$39.6 \pm 11.5$

PHASE

FOLLICULAR

LUTEAL

$0.56 \pm 0.12^{*}$

$0.44 \pm 0.03$

$9.4 \pm 0.18$

$5.8 \pm 1.1^{*}$

$1.3 \pm 0.44$ *

$1.1 \pm 0.3^{*}$

$5.7 \pm 0.68 *$

$5.5 \pm 0.6$

$2.3 \pm 0.32^{*}$

$2.36 \pm 0.4$ *

$0.22 \pm 0.05$

$0.21 \pm 0.06$

* denotes a significant difference $(p<0.05)$ between the values of the untrained and trained group.

after exercise were $1.52 \pm 0.05 \%$ and $1.51 \pm 0.05 \%$ in both phases respectively. The post-exercise values were significantly $(p<0.05)$ decreased as compared to the pre-exercise values. In the trained group, the free $E_{2}$ fraction at rest was calculated to be $1.22 \pm 0.04 \%$ and $1.25 \pm 0.02 \%$ in the follicular and 


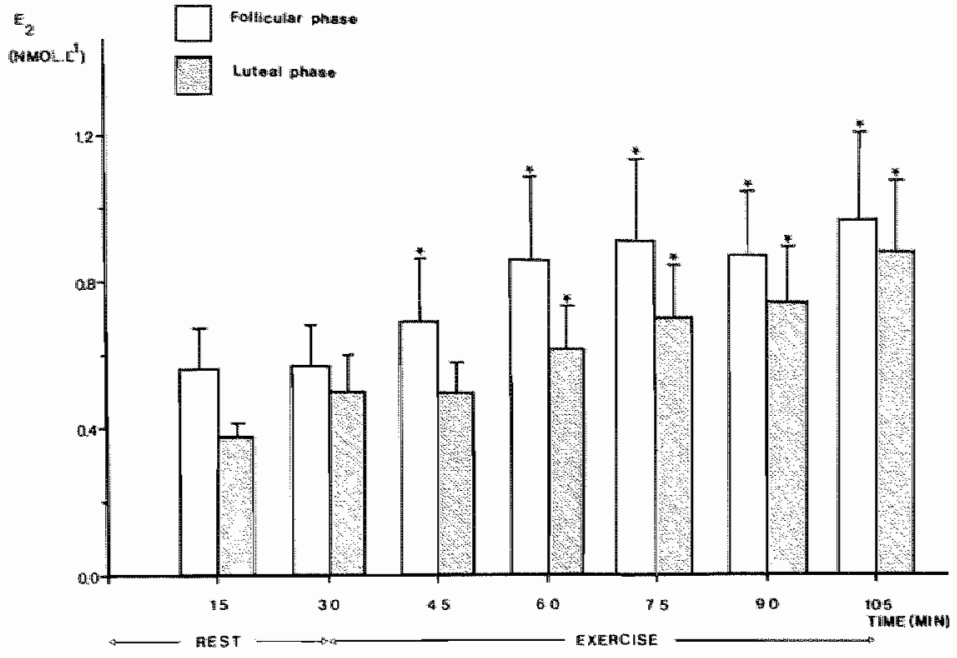

Figure 4.6

PLama $E$ concentratione during exercise in trained women ( $n=6$ ) in the follicular and luteal phases of their menstrual cycle.

* = significantly different $(p<0.05)$ from the values at rest.

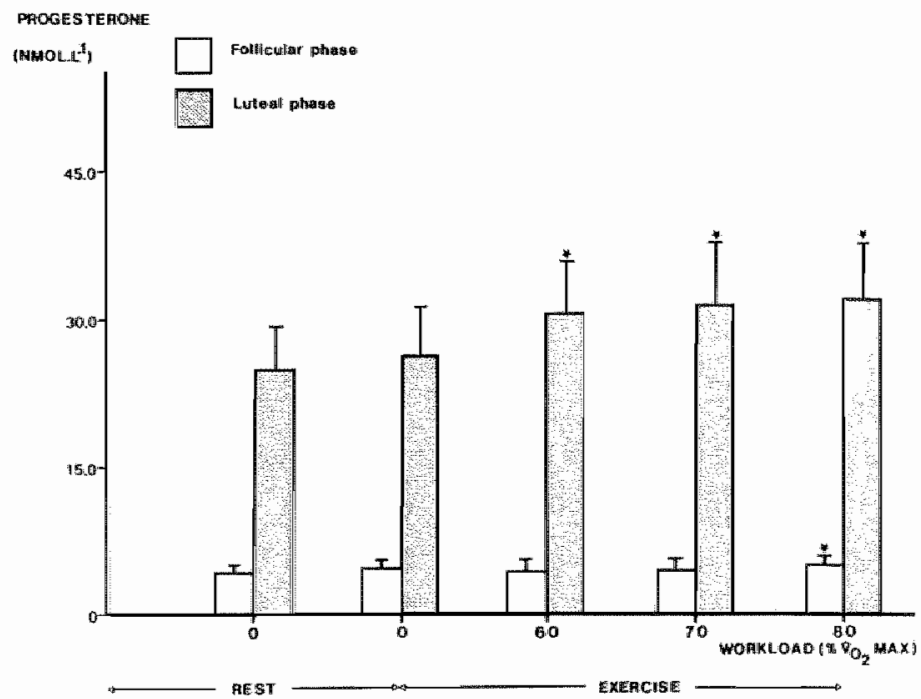

Figure 4.7

Plabma $P$ concentrations duming exercise in untrained women $(n=13)$ in the follicular and luteal phases of their menstrual cycle.

* = eignificantly different $(p<0.05)$ from the values at rest. 
luteal phase, respectively. No significant differences could be observed after the exercise. In the latter situation the values were measured to be $1.32 \pm 0.05$ and $1.24 \pm 0.04 \%$ in the follicular and luteal phase, respectively. The mean free $E_{2}$ fraction at rest in the untrained subjects was significantly (p<0.01) higher than the mean $E_{2}$ fraction in the trained subjects.

\section{Progesterone (P)}

In the untrained and trained subjects the absolute plasma $P$ concentrations increased significantly $(p<0.001)$ during exercise in the follicular and luteal phase (Fig. 4.7 and 4.8). In the untrained subjects only the highest workload $\left(80 \% \mathrm{~V}_{2} \max \right)$ was able to induce a significant increment in plasma $P$ levels in the follicular phase (fig. 4.7). In the trained subjects, all plasma $P$ values during exercise lexcept for the first exercise value) were significantly elevated as compared to the walues at rest (fig. 4.8).

Exercise in the luteal phase provoked significant increments at all exercise intensities $\left(60,70\right.$ and $80 \% \mathrm{VO}_{2}$ max) in the untrained subjets, whereas this was also true for the trained subjects with the exception of the lowest workload (i.e. $15 \mathrm{~min}$. after the start of the exercise). No statistically significant differences in relative values between both phases could be observed in the trained group in the follicular phase as compared to the luteal phase (fig. 4.9). In the untrained subjects the relative increase was greater $(p<0.005)$ in the luteal phase (fig. 4.10). No differences in percentual changes in $P$ concentration could be observed between the trained and untrained group at comparable exercise times $(15,30$ and 45 min. after the start of the exercise) and workloads (60,70 and $80 \%$ $\mathrm{NO}_{2}$ max).

Luteinizing Hormone (LH).

In the untrained and trained subjects the plasma LH concentration decreased significantly $(p<0.05)$ during exercise. In the untrained group only the highest workload $\left(80 \% v_{2}\right.$ max $)$ was able to induce a significant decrease in plasma LH concentration in the follicular phase, whereas in the luteal phase, the mean plasma concentrations of this hormone were decreased at all workloads (fing. 4.11). In the trained subjects exercise induced significant decrements in the mean plasma LH concentration (with the excep- 


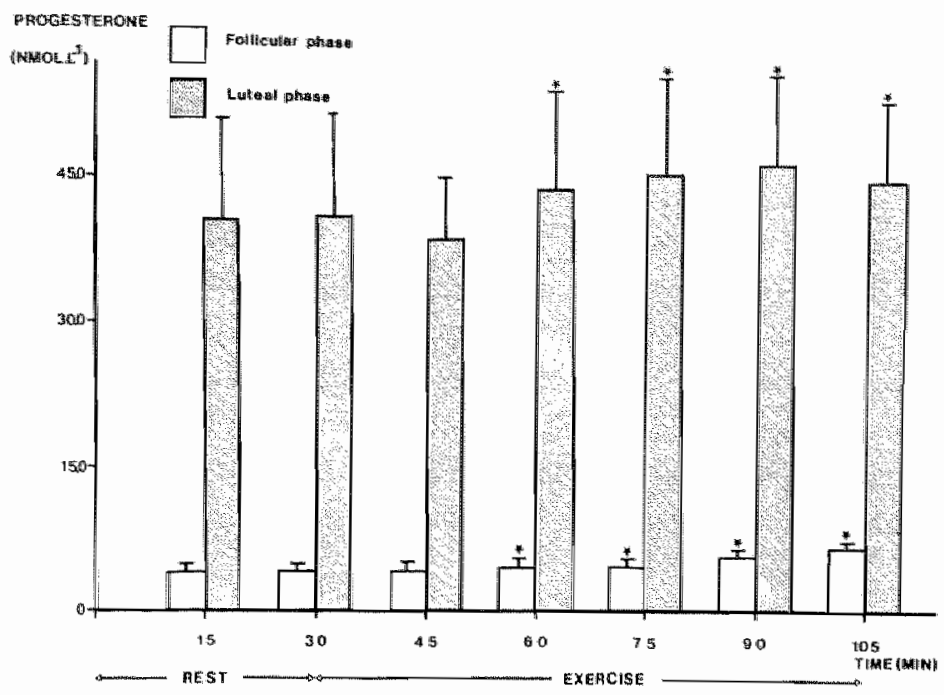

Figure 4.8

Plasma P concentrations duming exemise in trained women ( $n=6)$ in the follicular and luteal phases of their menetrual cycle.

$*$ significantly different $(p<0.05)$ from the values at meat.

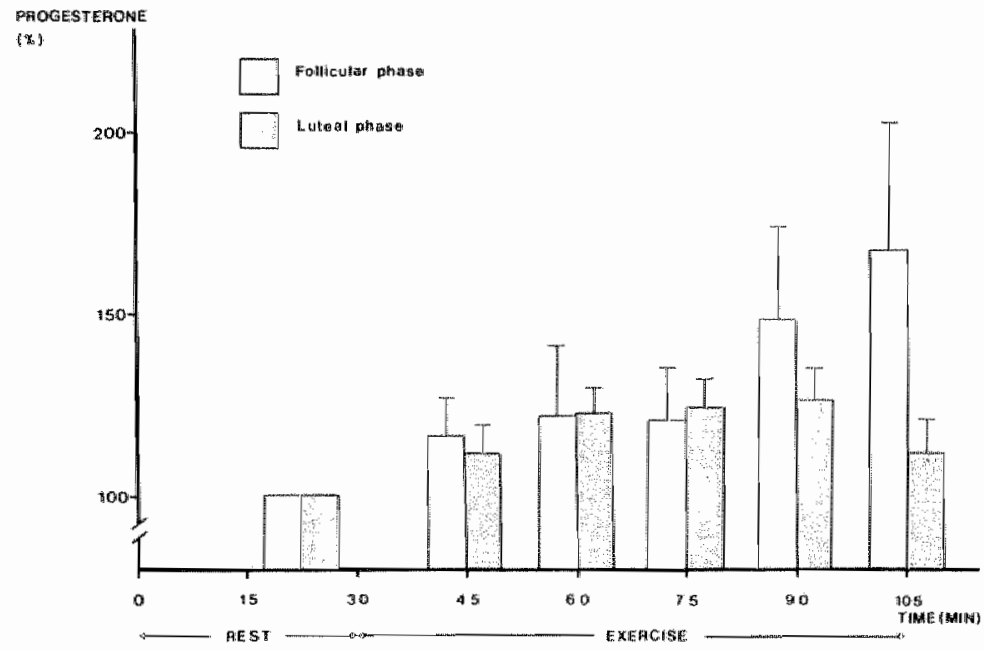

Figure 4.9

Retative ohanges (percentage of the mean basal val we) of the plasma $P$ concentration in trained women $(n=6)$ in the follioular and luteal phases of their menstrwal cycte. 
tion of the last experimental value of the follicular phase, which tended to increase as compared to the previous samples (fig. 4.12). In the untratned subjects, the absolute mean LH concentration in the blood was significantly higher in the luteal phase $(p<0.005$ ) (fig 4.11 ), whereas in the trained subjects the LH walues were higher in the follicular phase ( $p \times 0.05$ ) (figure 4.12). The relative changes revealed a significant linear decrease $(p<0.001)$ in plasma LH concentration during exercise in both phases in the untrained group; the decrease being more pronounced $(p<0.005)$ in the luteal phase of the menstrual cycle (fig. 4.13). Although the relative decrease in plasma LH concentration was al so significant $(p<0.001)$ in the trained group the linear trend was not existent and there was no phase effect (fig. 4. 14).

Follicle Stimulating Homone (FSH).

In the untrained and trained subjects the absolute plasma FSH concentration was not significantly affected by exercise. In both groups the absolute FSH concentrations were significantly $(p<0.01)$ higher in the follicular phase of the menstrual cycle (table 4.1). In the untrained group there was a significant $(p<0.005)$ linear decrease of the relative values during exercise and a significant $(p<0.05)$ phase effect. The relative decrease in the luteal phase was less pronounced than in the follicular phase $(p<0.05)$ (fig. 4.15). In the trained group no significant differences could be observed in relative FSH walues as a function of the exercise period or phase of the menstrual cycle (data not shown). In the untrained subjects the relative changes varied between -33 and $0 \%$ and between -44 and $7 \%$ in the follicular and luteal phase, respectively. In the trained subjects these values varied between -21 and $74 \%$ and -50 and $119 \%$ in the follicullar and luteal phase, respectively.

Testosterone (T).

In the untrained subjects the mean plasma $T$ concentration at rest was significantly $(p<0.05)$ higher than in the trained subjects (table 4.1$)$. In the untrained group the absolute plasma $T$ concentrations were significantly $(p<0.05)$ increased above the resting value at workloads exceeding $60 \%$ $\mathrm{v}_{2}{ }_{2}$ max. No significant differences could be detected between the phases of 


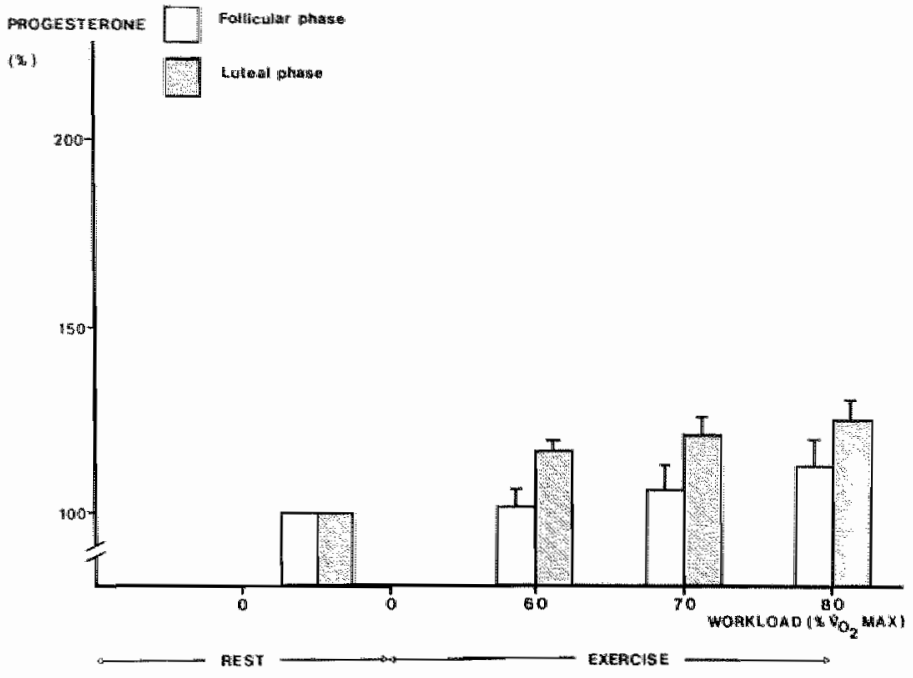

Figure 4.10

Relative changes (percentage of the mean basal value) of the plaema P concentration in untrained women $(n=13)$ in the follicutar and luteal phases of their menstrual cycte.

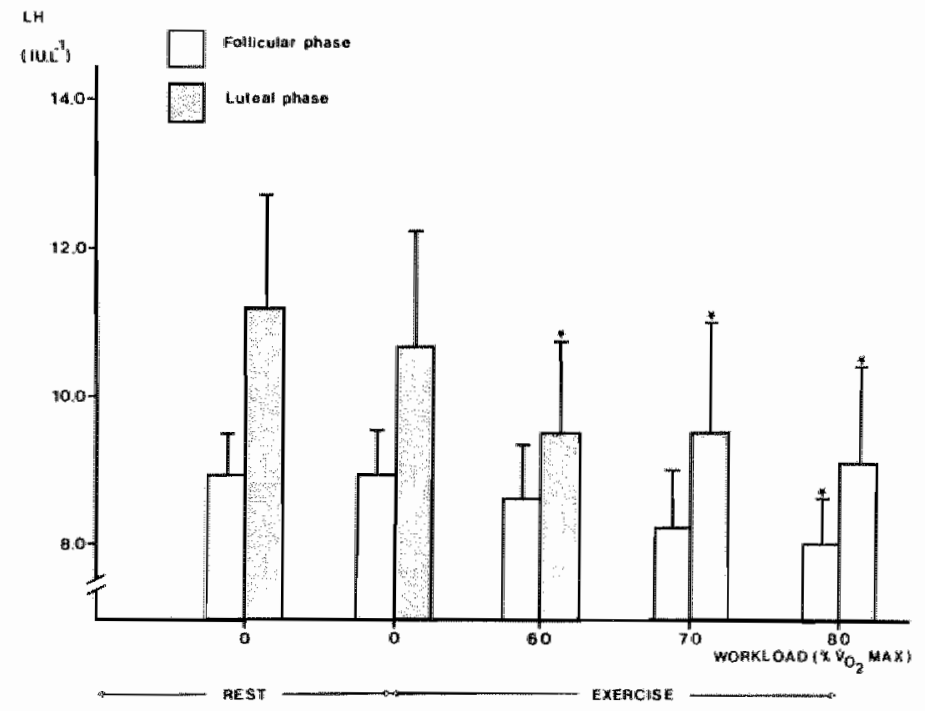

Figure 4.11

PLama $L H$ concentration dumg exemaibe in untrained women (n=13) in the follicular and luteal phases of their menstrual cyole.

* aignificantly diffement $(p<0.05)$ from the values at rest. 


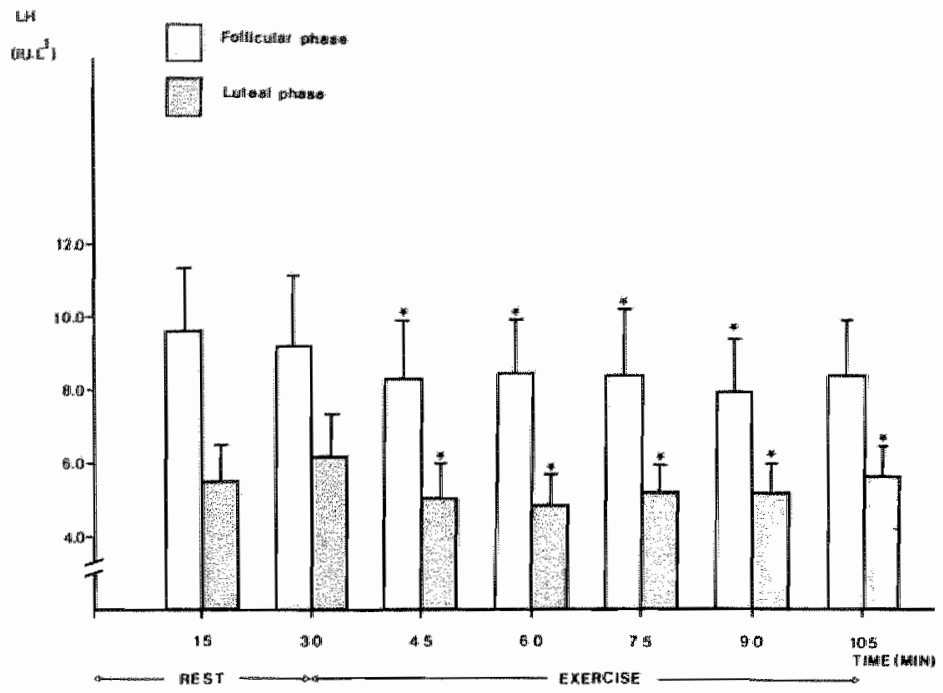

Figure 4.12

Plasma LH concentration duming exercise in trained women ( $n=6)$ in the follicular and 2 uteal phases of their menstrual aycte.

* = ignificantly different $(p<0.05)$ from the valuss at rest.

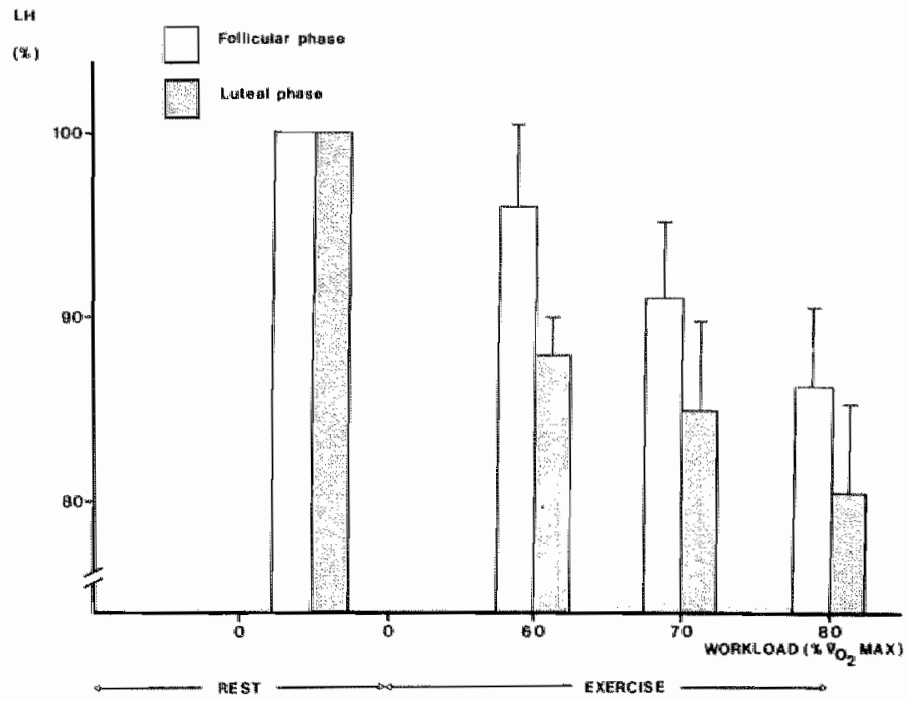

Fighe 4.13

Relative changes (pereentage of the nean basal vatue) in plasma LH concentration duming exerctes in untrained women (n=13) in the follicular and luteal phases of their menstruat cycte. 
the menstrual cycle in this group (fig. 4.16). In the trained subjects the absolute plasma $T$ concentration increased significantly $(0<0.01)$ during the exercise period (fig. 4.17). This increase was significant at exercise times greater than 15 min. (follicular phase) or 30 nin. (luteal phase) after the start. The relative values showed a significant linear increase ( $p<0.001)$ during exercise in both groups. At comparable work1oads $(60,70$ and $80 \% \mathrm{~V}_{2}$ max) and exercise times $(15,30$ and $45 \mathrm{~min}$ after the start of the exercise) the relative $T$ vallues increased more pronounced $(p<0.05)$ in the trained than in the untrained subjects as shown for the follicular phase in fig. 4.18 and 4.19. No significantly different responses between the phases of the menstrual cycle could be detected.

In the untrained group the percentage of free $T$ increased significantly $(p<0.05)$ from $2.32 \pm 0.11 \%$ and $2.33 \% \pm 0.11 \%$ at rest to $2.52 \pm 0.09 \%$ and $2.57 \pm 0.11 \%$ at the end of the exercise period in the follicular and luteal phase, respectively. In the trained group the walues at rest were calculated to be $2.08 \pm 0.07 \%$ and $2.02 \pm 0.08 \%$ in the follicular and luteal phase, respectively. These values increased significantly $(p<0.01)$ to $2.26 \% \pm 0.06$ in the follicular and $2.25 \pm 0.09 \%$ in the luteal phase. In both groups no difference could be observed between the phases.

Androstenedione $(\Delta 4-A)$.

In the untrained subjects the mean plasma $\Delta 4-\mathrm{A}$ concentrations at rest were significantly $(p<0.01)$ higher than those in the trained subjects (table 4.1 ). In the untrained subjects the mean plasma $\Delta 4-A$ concentration did not change significantly (fig. 4.20) during exercise. In the trained subjects, however, exercise induced a significant increase ( $p<0.001$ ) (fig. 4.21) in the plasma concentration of this hormone in both phases of the menstrual cycie. These increments accurred at each workload (fig. 4.21). At comparable workloads $\left(60,70\right.$ and $\left.80 \% \mathrm{vo}_{2} \mathrm{max}\right)$ and exercise times $(15,30$ and $45 \mathrm{~min}$ after the start of the exercise) the relative walues showed a significant ( $p<0.01)$ different response between both groups, the relative increments, being more pronounced in the trained group (fig. 4.22 and 4.23). In the latter group the relative values showed a levelling-off after 60 min of exercise, especially in the follicular phase of the menstrual cycle (fig. 4.23). 
L.H

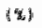

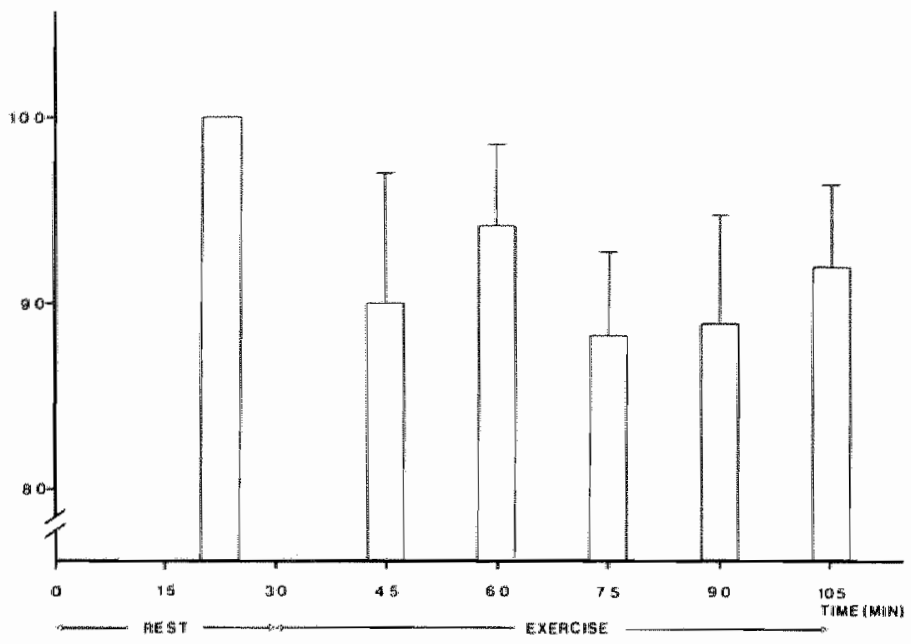

Figure 4.14

Retative changes (percentages of the mean basal values) in plasma LH comeentration duming exercise in trained wamen ( $n=6)$ in the fot tiaular phase of their menstruat cyete.

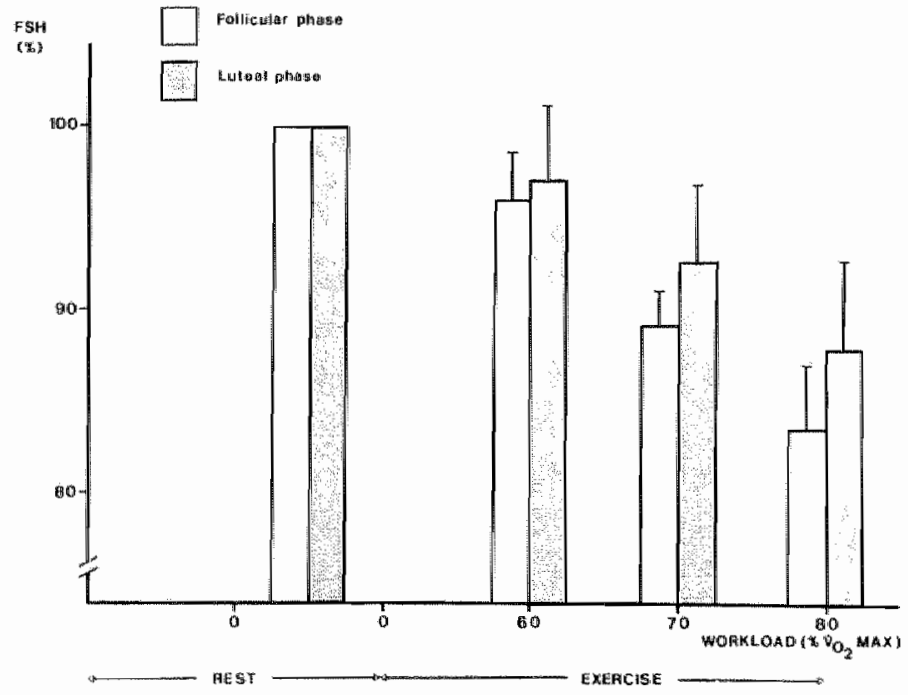

Figure 4.15

Ralative ahonged (percentage of the mean basal value) in plabma FSH concentration during exemats in untrained women ( $m=13$ ) in the follioular and luteal phases of their menatmual cycle. 


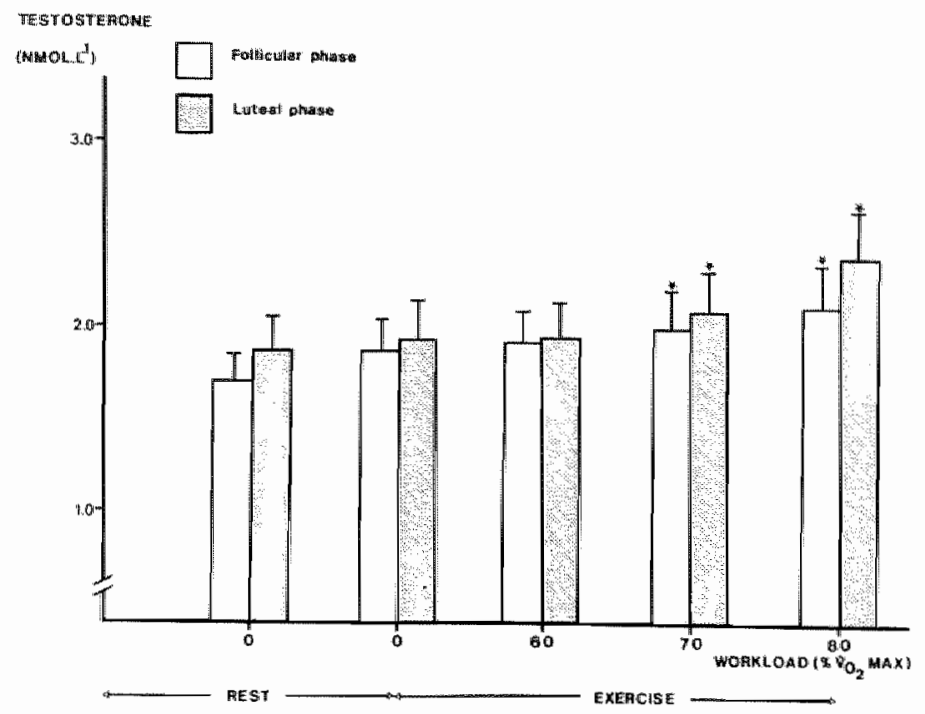

Figure 4.16

PLasma $T$ concentmations (romot. $t^{-1}$ ) during exereise in untrained women $(n=13)$ in the follicular and luteal phases of their menstruat cycte.

* = signifiaantly different (p<0.05) from the values at mest.

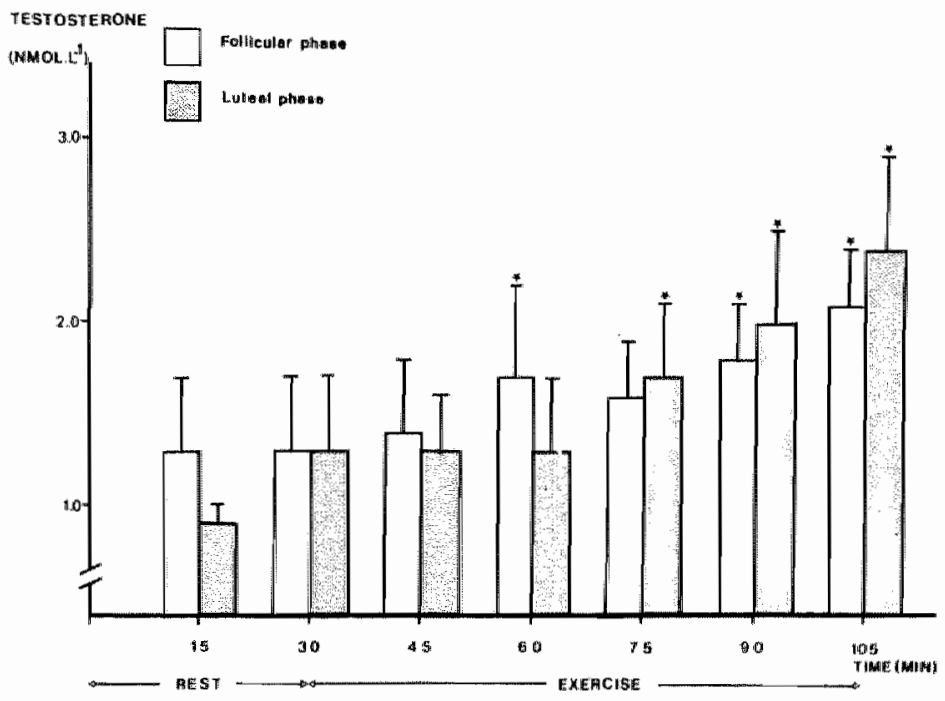

Pigune 4.17

Plabma $T$ concentration during exeroitie in trained women $(m=6)$ in the follioular cand luteal phases of thei" menotruat ayole.

* = ignifiacatidy different $(p<0.05)$ from the values at rest. 


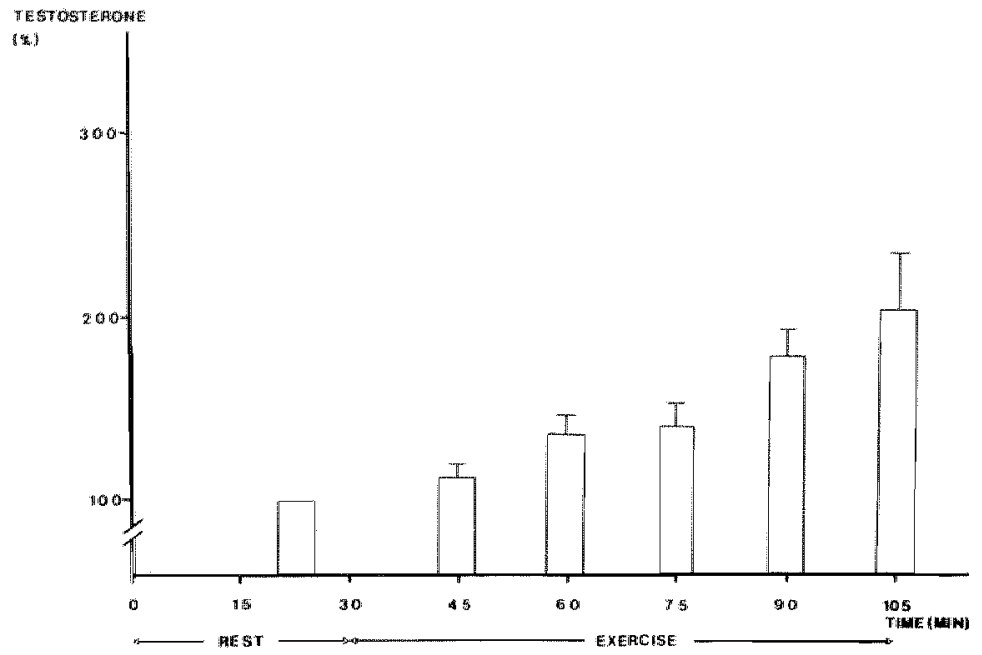

Figure 4.18

Relative ahanges (percentage of the mean basal value) in plasma $T$ concentration during exercise in trained women $(n=6)$ in the follicular phase of their menotmal cycle.

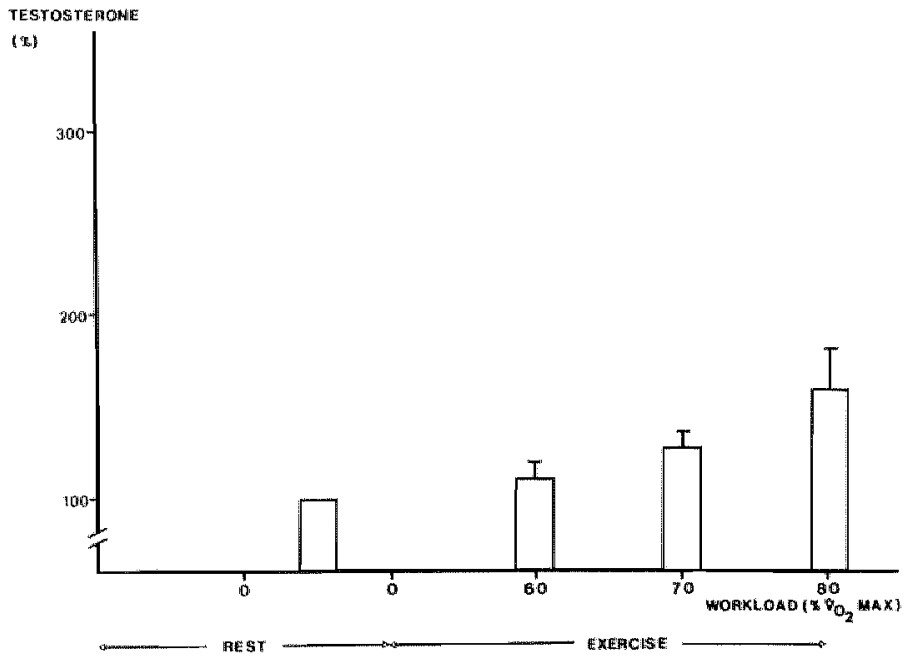

Figure 4.19

Relative changes (percentage of the mean basal value) in plasma $T$ concentration duming axameise in untrained women ( $n=13$ ) in the follicular phase of their menstruat oycte. 


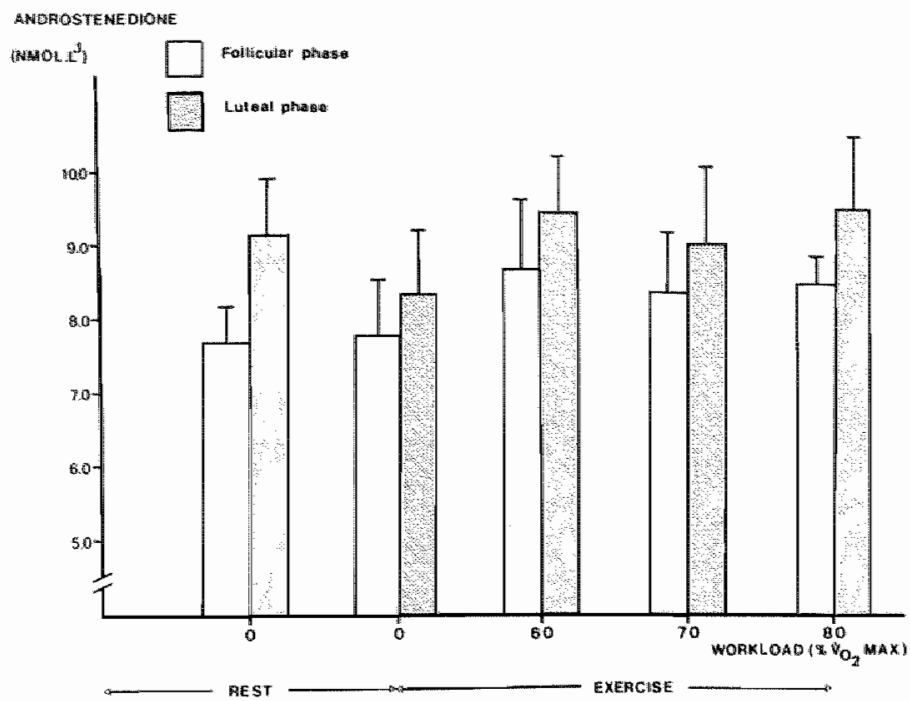

Eigure 4.20

PLasma $\Delta 4-A$ concentration during exeroise in untrained women (n=13) in the follioular and tuteal phases of their menstrual cycle.

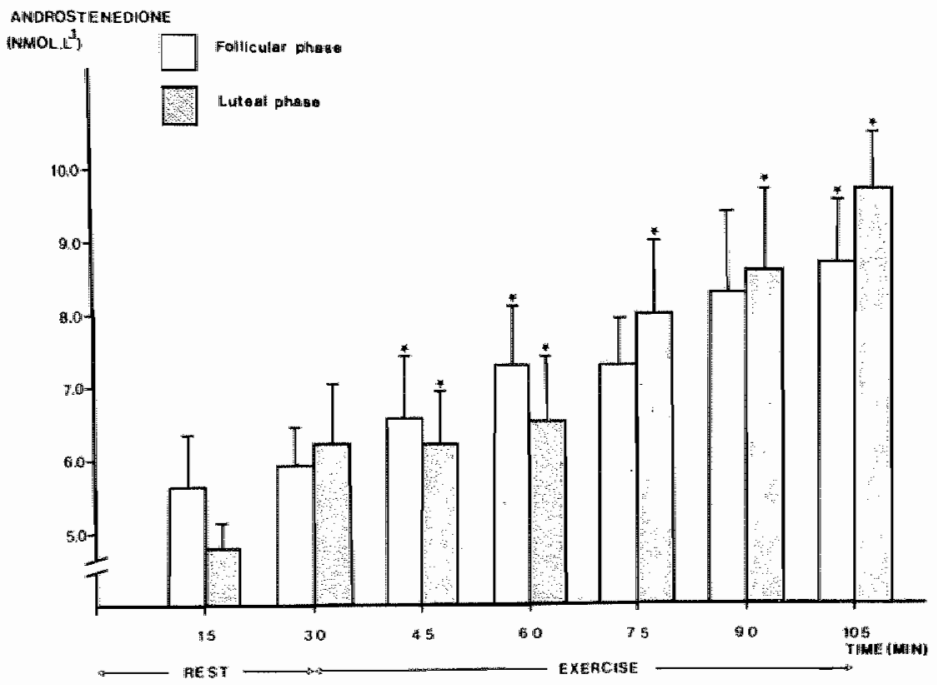

Figure 4.21

Plasma $\triangle 4-A$ concentmation during exemcise in trained women ( $n=6)$ in the foltioular and luteal phases of their menetrual cycle. $*=$ ignificantly different $(p<0.05)$ from the values at reat. 


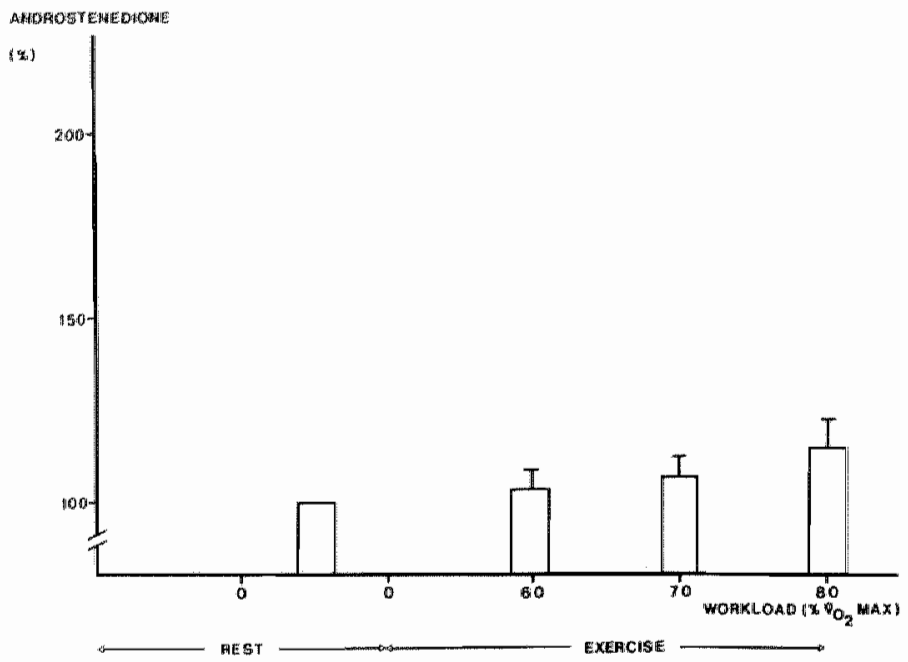

Figure 4.22

Retative changes (pencentage of the mean basal value) in plasma 4 4-A concentration during exeise in untrained women ( $n=13$ ) in the follicular phase of their menetmual cyole.

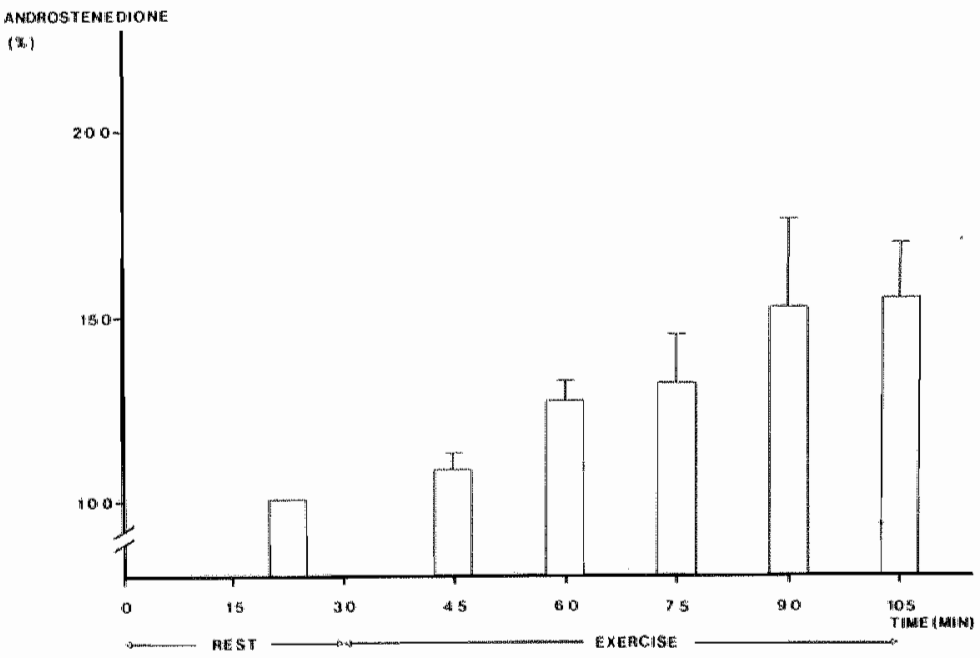

\section{Figure 4.23}

Relative changes (peroentages of the mean basal value) in plasma 44-A concentration duming exeraise in trained women ( $n=6$ ) in the folliaular phase of their menstrual cycle. 
Dehydroepiandrosterone sulfate (DHEA-S).

In the untrained subjects the mean plasma CHEA-S concentrations at rest were significantly $(p<0.05)$ higher than those in the trained subjects (table 4.1). In the untrained subjects the absolute DHEA-S concentration was not significantly affected by exercise nor by the phase of the menstrual cycle. In the trained subjects both the absolute and the relative values increased significantly with exercise ( $p<0.05$ and <0.001) (fig. 4.24 and 4.25). Physical exercise was able to provoke a statistically significant increase in plasma DHEA-S levels at the lowest workloads (fig. 4.24). In the trained group, the plasma DHEA-S concentration changed relatively more in the follicular phase $(p<0.01)$ as compared to the luteal phase, ranging from 46 to $64 \%$ and from -6 to $54 \%$ in the follicular and luteal phase, respectively (fig. 4.25). In both phases the relative values showed a leveliing-off after 30-45 min of exercise.

\section{Prolactin (PRL).}

In both groups and in both phases of the menstrual cycle the absolute plasma PRL concentrations increased significantly ( $p<0.005)$ during exercise (fig. 4.26 and 4.27). However, in the untrained subjects a sigmificant increase $(p<0.05)$ could only be observed at the highest work loads ( $80 \%$ $\overrightarrow{\mathrm{v}} \mathrm{O}_{2} \max$ ) in the follicular phase, whereas the plasma PRL levels decreased significantly $(p<0.05)$ at $60 \% \mathrm{~V}_{2} 2^{\text {max }}$ in this phase. In the Iuteal phase physical exercise was able to induce significant increases $(p<0.05)$ in plasma PRL concentrations at workloads exceeding $60 \% \mathrm{~V}_{2} \max$ in this group (fig. 4.26). In the trained subjects physical exercise was able to induce significant increments in plasma PRL concentrations at all workloads (fig. 4.27). The individual responses could be strikingly different in both groups. In the untrained group the relative values showed an initiall decrease at a workload of $60 \% \mathrm{~V}_{2}$ max, followed by a gradual increase at higher workloads (fig. 4.28). At comparable workloads $(60,70$ and $80 \%$ $\left.\mathrm{V}_{2^{\max }}\right)$ and exercise times $(15,30$ and $45 \mathrm{~min}$ after the start of the exercise) the relative changes in plasma PRL were more pronounced $(p<0.01)$ in the trained than in the untrained group (fig. 4.28 and 4.29 ). 


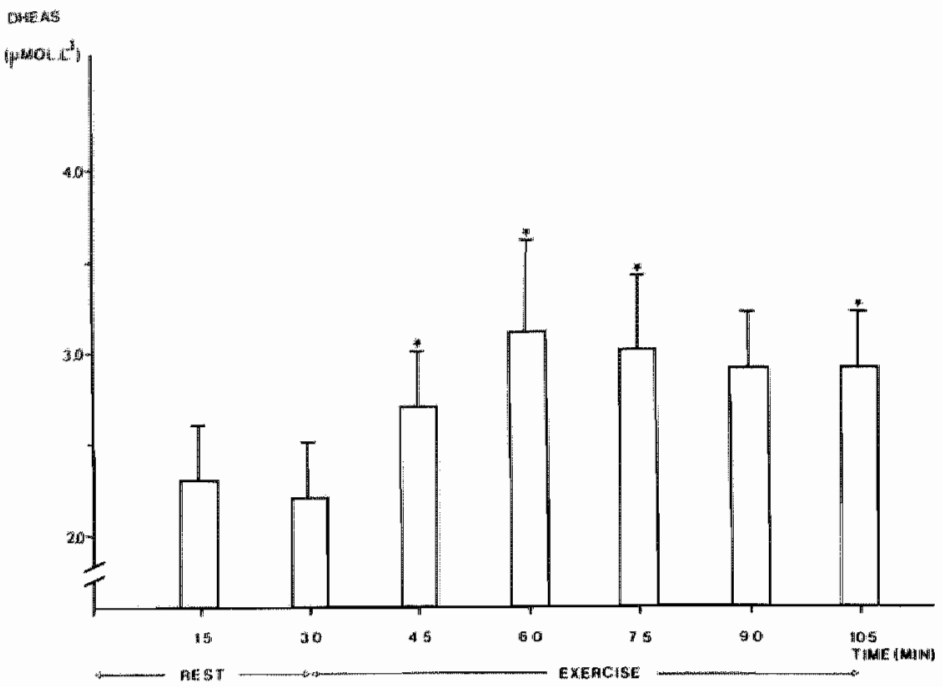

Figure 4.24

Plarma DHEA-S cancentration during exercise in trained women (n=6) in the folliaular phase of their menstrual cycle.

$*=$ significantly different $(p<0.05)$ from the values at rest.

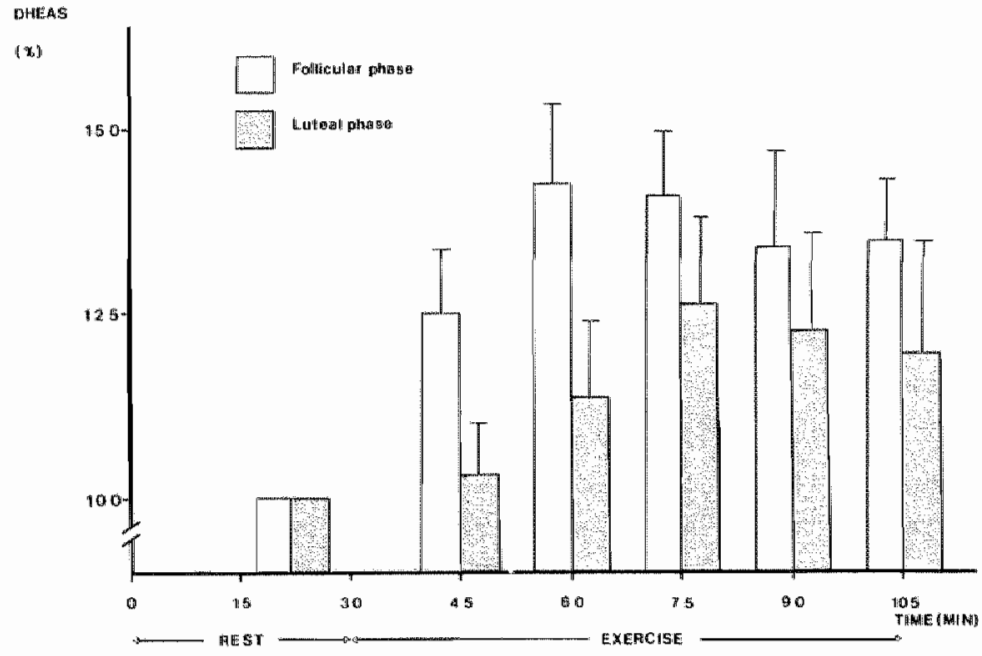

Figure 4.25

Relative changes (percentage of the mean basal value) in plasma DHEA-S concentration during exercise in trained women ( $n=6)$ in the follioutar and tuteal phases of their menstruat cycte. 


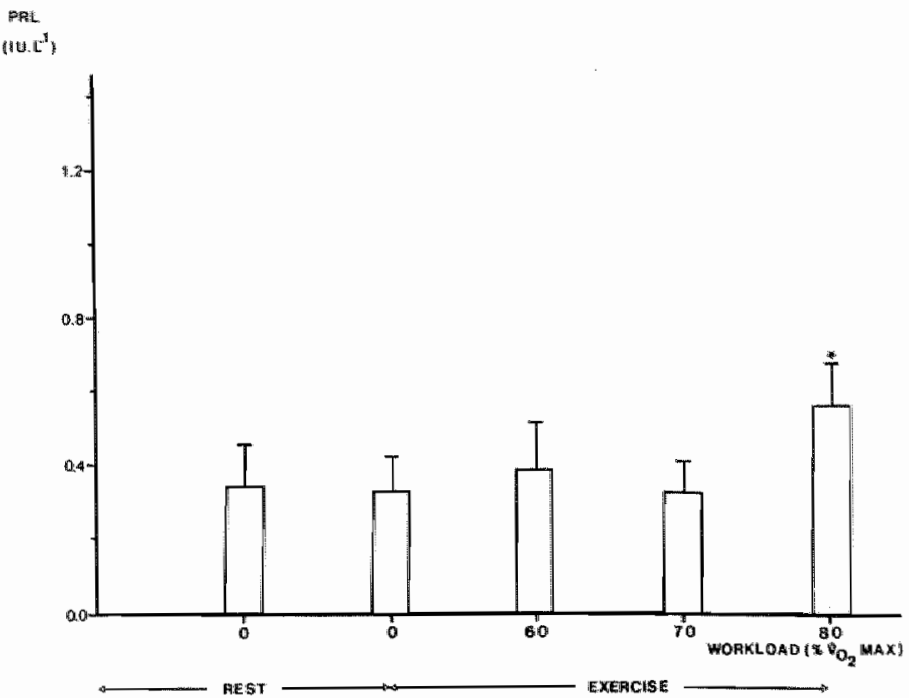

Figure 4.26

PLasma PRL concentration during exercise in untrained women $(n=13)$ in the folliculam phase of their menstmal cyote.

* = significantly different $(p<0.05)$ from the values at meat.

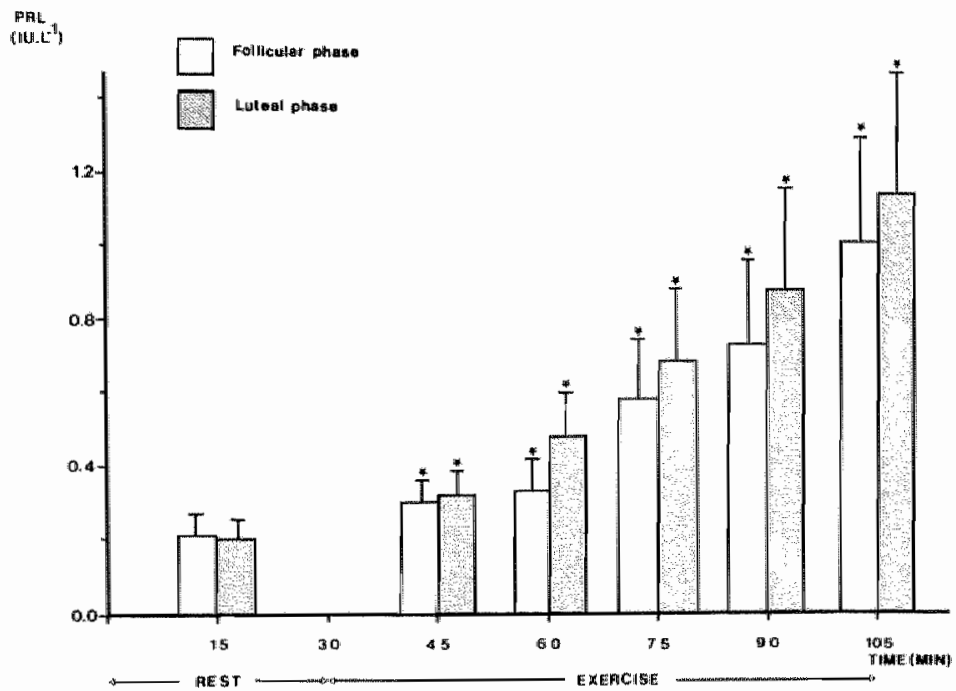

Pigure 4.2 ?

PLama PRL ancentration duming exerciae in tmained women ( $m$ ) in the follioular and Luteal phases of theim menstrual cycte.

* = eignificantity different $(p<0.05)$ from the values at rest. 


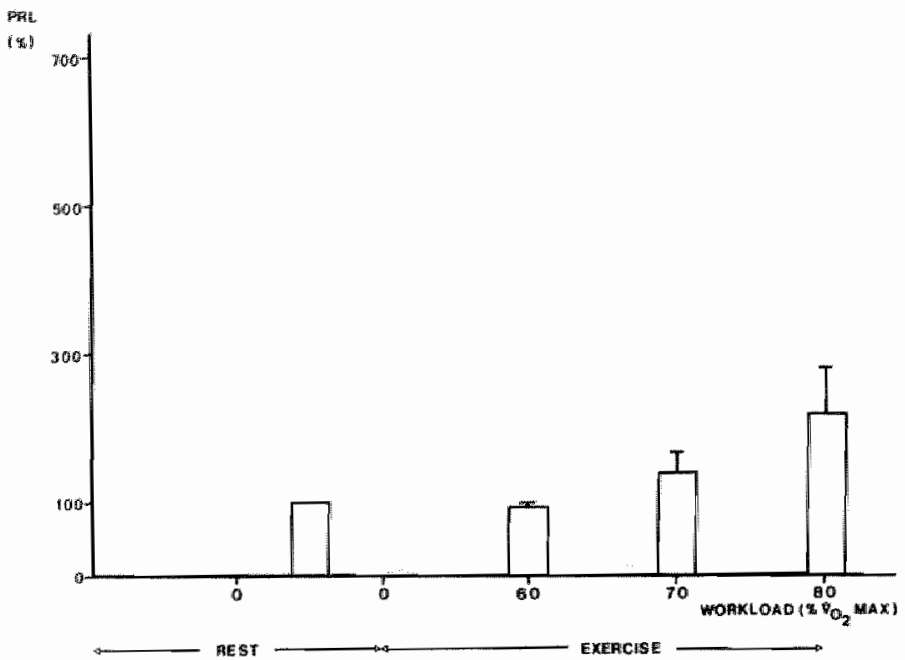

Eigure 4.28

Relative changes (percentage of the mean basal valuel in plama PRL concentration duming exeraise in untrained women $(n=13)$ in the follicular phase of the thr menetmul cycte.

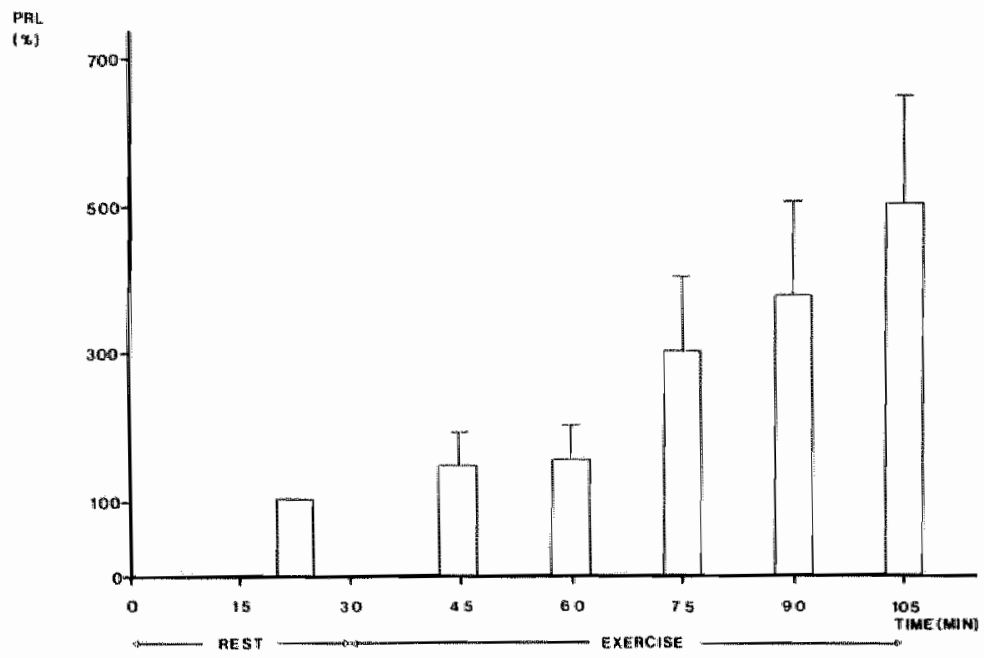

pigure 4.29

Relative ahanges (percentage of the mean basat valuel in plasma PRL concentration duming exerates in trained women (n=6) in the follitoutar phase of their menstrual eyote. 
Adrenocorticotropic homone (ACTH).

In the untrained subjects the mean plasma $A C T H$ concentrations at rest were significantly higher $(p<0.05)$ than those in the trained subjects (table 4.1). During exercise the absolute plasma ACTH concentrations showed a significant increase $(p<0.05$ ) in both groups (fig. 4.30 and 4.31 ). No statistically significant effect of the phase of the menstrual cycle could be detected. In the untrained group the plasma ACTH concentration increased only significantly at the highest workload $\left(80 \%\left(0_{2} \max \right)(f i g .4 .30)\right.$. In the trained group the plasma $A C T H$ concentration was significantly elevated after $15 \mathrm{~min}$ of exercise $\left(85 \% \quad \mathrm{~V}_{2}\right.$ max)(fig. 4.31$)$. The rellative values differed significantly between the groups $(p<0.05$ ) (fig. 4.32 and 4.33 ). In the untrained group (fig. 4.32) the plasma ACTH concentrations showed a significant increase only at the highest workloads, whereas in the trained group (fig. 4.33) the concentration was already silgnificantly increased at 60\% $\mathrm{V}_{2} 2_{\mathrm{max}}(15 \mathrm{~min}$ after the start of the exercise).

\subsubsection{The influence of a three month training period on hormonal and meta}

\section{bol ic responses to exercise (study III)}

\subsubsection{Maximal physical warking capacity (MPWC).}

In the 8 volunteers, participating in this part of the study, the MPWC increased significantly $(P<0.05)$ from $168.1 \pm 4.6$ to $178.9 \pm 5.4$ Watts and from $168.8 \pm 6.0$ to $182.1 \pm 5.9$ Watts in the follicular and 1 uteal phase, respectively, after a three months endurance training program.

Neither in the pre- nor in the post-training tests the MPWC was significantly different between both phases of the menstrual cycle.

\subsubsection{Metabol ic responses to exercise.}

Exercilse-induced glucose and lactate responses.

No differences in glucose responses to exercise could be found between the post- and pre-training period. After the training period, blood lactate increased significantly $(p<0.001)$ more pronounced as compared to the pretraining period. After training the blood lactate responses appeared to be lower $(p<0.01$ ) in the luteal than in the follicular phase (fig. 4.34), whereas no such a difference could be observed before the training period. 


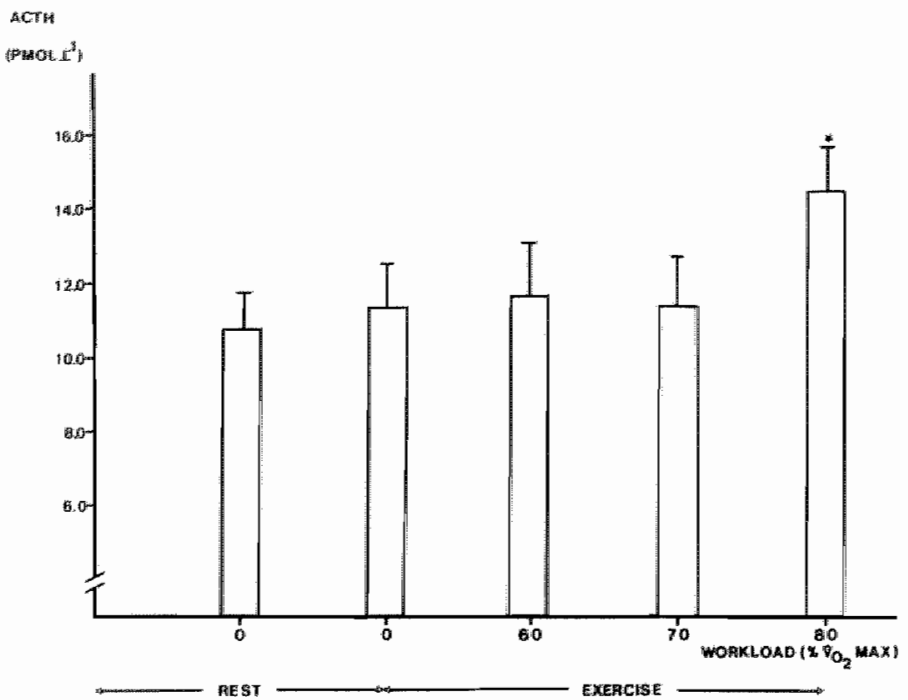

Figure 4.30

Plabma ACrH concentration (pmol..$^{-1}$ ) during exercibe in untrained women ( $n=13$ ) in the follicular phase of their menstmul aycle. * = significantily different $(p<0.05)$ from the values at reat.

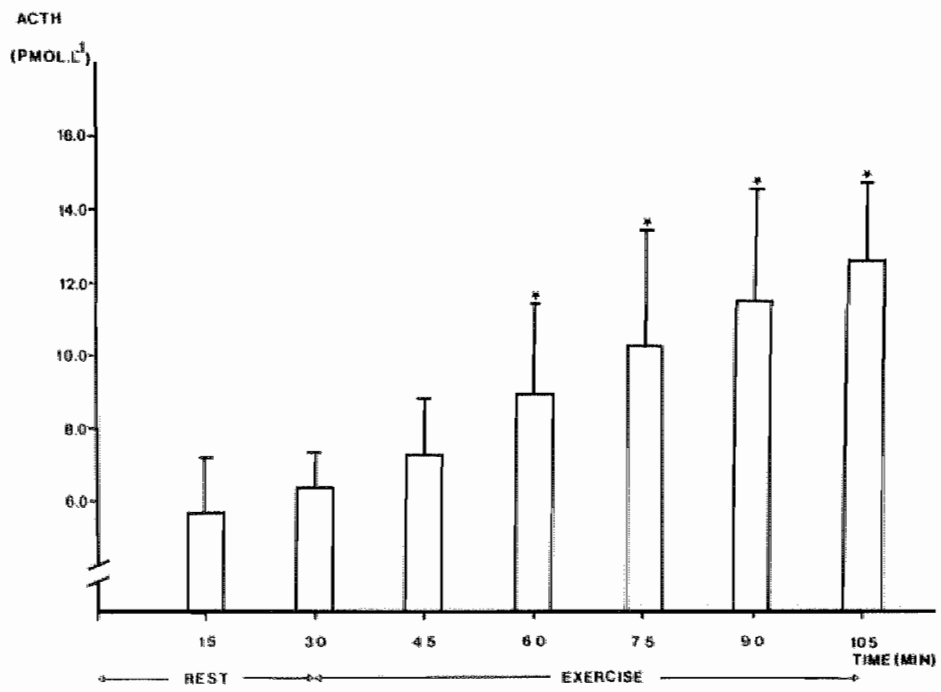

Figume 4.31

Changes in plasma ACrH concentration (pmot. $2^{-1}$ ) during exercise in trained women ( $n=6$ ) in the follicular phase of their menatruat oycle. * = ignificantly different $(p \times 0.05)$ from the vatues at 


\subsubsection{Endocrine responses to exercise.}

All relative wallues are depicted in tables 4.2 and 4.3 .

Table 4.2

Relative changes (mean \pm SEM; the mean basal walue was aimed to $100 \%$ ) in plasma $E, P, T, \triangle 4-A, P R L$ and $A C T H$ during exercise before and after a three month training period in 8 subjects in the follicular phase of their menstrual cycle.

$$
\text { WORKLOAD }\left(\% \mathrm{NO}_{2} \text { max }\right)
$$

Hormone

60

70

80

$\begin{array}{lccc}\begin{array}{l}\text { Eqfore } \\ \text { Befter }\end{array} & 120,9 \pm 7,6 & 133,2 \pm 8,8 & 136,4 \pm 4,9 \\ \text { After } & 112,9 \pm 5,4 & 119,0 \pm 4,0 & 131,7 \pm 4,8 \\ \text { P } & & 104,1 \pm 6,9 & \\ \text { Before } & 101,6 \pm 5,6 & 110,9 \pm 9,1 & 118,3 \pm 9,3 \\ \text { After } & 102,9 \pm 5,0 & & 121,7 \pm 9,2 \\ \text { T } & & 110,3 \pm 5,9 & \\ \text { Before } & 105,9 \pm 8,4 & 136,2 \pm 19,1 & 126,4 \pm 4,7 \\ \text { After } & 124,9 \pm 17,4 & & 146,3 \pm 20,7 \\ & & 108,5 \pm 5,2 & 121,8 \pm 6,5 \\ \begin{array}{l}\Delta 4-A \\ \text { Before }\end{array} & 106,2 \pm 6,1 & 107,2 \pm 7,5 & 114,3 \pm 7,5 \\ \text { After } & 99,2 \pm 3,7 & & 334,8 \pm 159,6 \\ \text { PRL } & & 113,2 \pm 25,7 & 233,6 \pm 61,8 \\ \text { Before } & 94,0 \pm 9,2 & 132,3 \pm 22,2 & \\ \text { After } & 97,3 \pm 7,2 & & 145,4 \pm 10,7 \\ \text { ACTH } & & 105,0 \pm 7,1 & 111,6 \pm 39,5 \\ \text { Before } & 111,5 \pm 7,3 & 113,9 \pm 10,8 & \\ \text { After } & 108,9 \pm 7,6 & & \end{array}$


Table 4.3

Relative changes (mean \& SEM; the mean basal value was aimed to $100 \%$ ) in plasma $E, P, T, \triangle 4-A$, PRL and ACTH during exercise before and after a three mofth training period in 8 subjects in the luted phase of their menstrual cycle.

$$
\text { WORKLOAD }\left(\% \mathrm{VO}_{2} \text { max }\right)
$$

Hormone

60

$113,0 \pm 4,2$

$109,8 \pm 3,0$

$110,3 \pm 4,8$

$110,0 \pm 3,8$

$102,5 \pm 19,5$

$96,0 \pm 3,3$

$101,8 \pm 5,4$

$100,4 \pm 1,6$

$95,1 \pm 2,5$

$92,2 \pm 4,3$

$98,4 \pm 6,4$

$91,4 \pm 5,4$

PRL

Before

After

ACTH

Before

After
70

80

$128,0 \pm 4,8$

$142,7 \pm 4,8$

$121,2 \pm 3,6$

$136,0 \pm 3,4$

$110,4 \pm 5,3$

$116,6 \pm 5,1$

$119,6 \pm 9,1$

$121,7 \pm 6,5$

$111,3 \pm 7,1$

$109,6 \pm 3,6$

$128,1 \pm 8,4$

$129,2 \pm 6,3$

$103,4 \pm 4,7$

$111,4 \pm 4,5$

$109,7 \pm 5,3$

$118,4 \pm 6,5$
$106,7 \pm 8,2$

$152,1 \pm 21,8$

$219,8 \pm 40,8$

$291,2 \pm 58,9$

$101,3 \pm 5,7$

$96,4 \pm 6,8$
$157,1 \pm 25,3$

$136,8 \pm 15,5$ 


\section{Estradiol $\left(E_{2}\right)$}

After training, the mean $E_{2}$ levells in the luteal phase were lower ( $p<0.05)$ as compared to the pre-training tests (fig. 4.35). The mean of the two vallues at rest were measured to be $0.15 \pm 0.03$ and $0.58 \pm 0.1 \mathrm{nmol} .1^{-1}$ in the pre-training test in the follicular and luteal phase, respectively. After training these values were $0.26 \pm 0.1$ and $0.33 \pm 0.07$ nnol. $1^{-1}$ for the follicular and luteal phase, respectively. The post-training absolute plasma $E_{2}$ levels increased $(p<0.01)$ significantly during exercise both in the follicular and luteal phase. The luteal phase values were higher than the follicular phase values $(p<0.001)$.

\section{Testosterone (T)}

The mean of the two values at mest was measured to be $1.8 \pm 0.18$ and $2.2 \pm 0.2$ nmol. $1^{-1}$ in the pre-training test in the follicular phase and luteal phase, respectively. After training these values were measured to be $1.6 \pm 0.2$ and $1.7 \pm 0.1$ nmol. $1^{-1}$ in the follicular and luteal phase, respectiveliy. In the pre-training test physical exercise did not affect $(p=0.08)$ the absolute $T$ values. After training, however, the $T$ concentrations increased significantly $(p<0.005)$ during exercise (fig. 4.36). No effect of the phase of the menstrual cycle could be detected in this situation, but in the pre-training test the $T$ concentrations in the lluteal phase were significantly ( $\beta<0.005)$ increased as compared to the follicular phase (fig. 4.36). In the luteal phase the post-training values before and during exercise were significantly lower as compared to the pre-training values (fig. 4.36). No significant differences could be observed between the relative values of the post-and pre-training tests in both phases of the menstrual cycle, although there was a slight $(p=0.07)$ indication that the increments in the follicular phase were more pronounced after training (table 4.2 and 4.3 ).

Androstenedione $(\Delta 4-A)$

In the follicular phase the mean plasma $\Delta 4-A$ concentrations at rest were measured to be $8.22 \pm 0.74$ nmol. $1^{-1}$ and $8.79 \pm 0.7$ nmol. $1^{-1}$ in the preand post-exercise periads, respectively, whereas in the luteal phase these wallues were $10.0 \pm 0.75 \mathrm{nmol} .1^{-1}$ and $8.98 \pm 0.77 \mathrm{nmol} .1^{-1}$. The absolute $\Delta 4-\mathrm{A}$ levels were not affected by exercise, neither in the pre- nor in the post- 


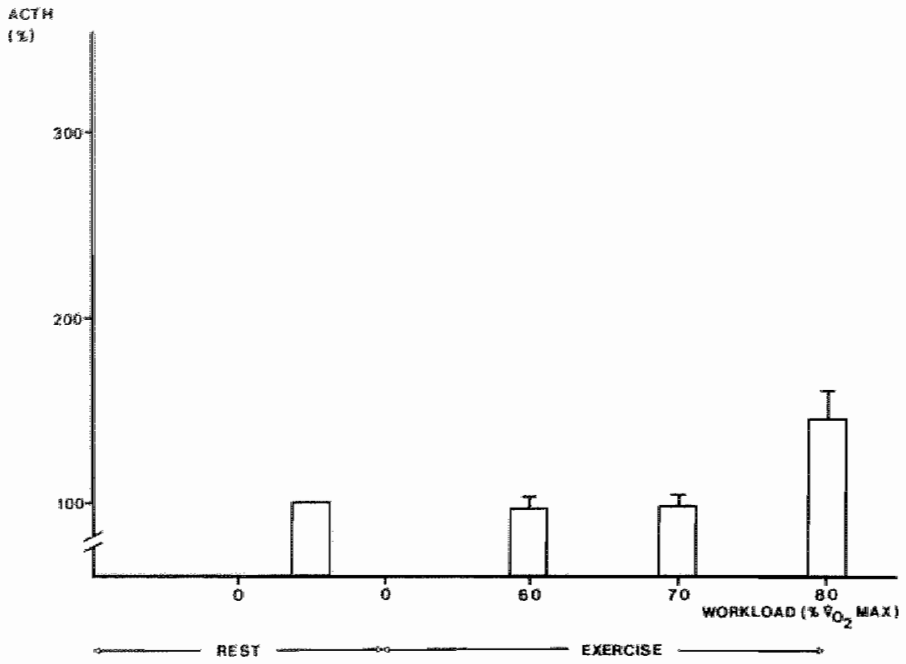

Eigure 4.32

Retative changes (percentage of the mean basat vatwe) in plasma ACTH concentration duming exercise in untrained women $(n=13)$ in the follicular phase of theim menstmal ayale.

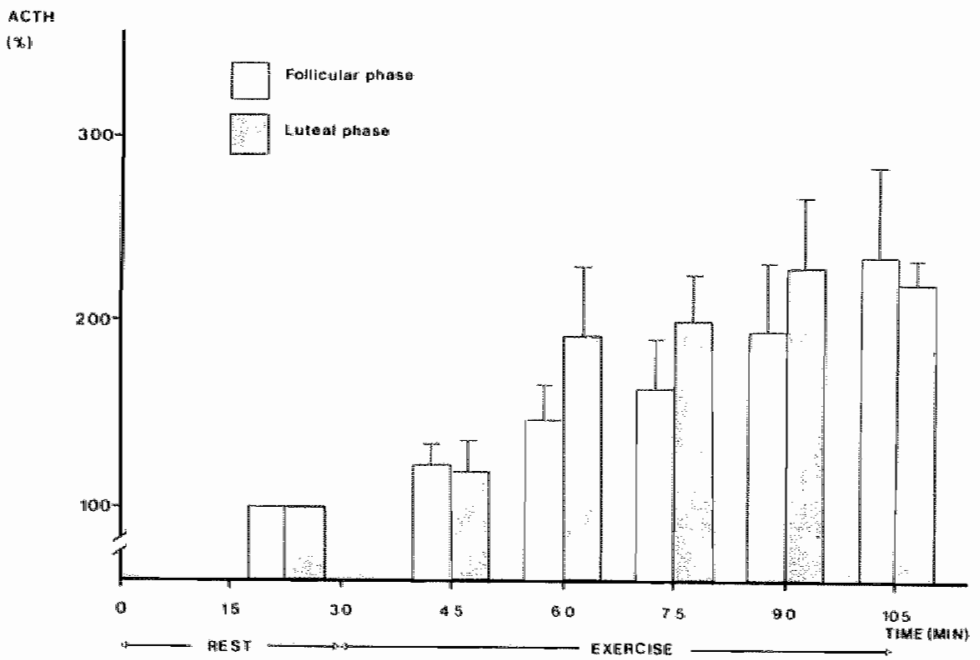

Pigure 4.33

Retative changes (pereentage of the mean basal value) in plaama Acm concentration duming exeroise in trained women ( $n=6)$ in the follioular and luteal phases of their menstruat aycle. 
training test. The relative values increased significantly (p<0.001) both in the pre- and post-training period. No statistically significant differences between the two periods could be observed (table 4.2 and 4.3).

Dehydroepiandrosterone sulfate (DHEA-S)

In the follicular phase, the mean plasma DHEA-S concentrations at rest were measured to be $8.44 \pm 0.96$ nmol. $1^{-1}$ and $6.02 \pm 0.75$ nmol. $1^{-1}$ in the preand post-exercise periods, respectively, whereas in the luteal phase these val wes were $8.68 \pm 0.68 \mu \mathrm{mol} . \mathrm{I}^{-1}$ and $6.71 \pm 0.89 \mu \mathrm{mol} .1^{-1}$.

Neither the absolute nor the relative DHEA-S values were significantly affected by exercise both in the pre- and post-training period ldata not shown).

Progesterone (P)

In the pre-training test the mean of the two values at rest was measured to be $4.8 \pm 0.4$ and $22.3 \pm 4.9 \mathrm{nmol} .1^{-1}$ in the follicular and luteal phase, respectively. After training these values were $4.0 \pm 0.51$ and $20.8 \pm 0.4$ nmol. $\|^{-1}$ in the follicular and luteal phase, respectively. In both phases the absolute $P$ values increased significantly (p<0.001) during exercise both in the pre- and post-training tests (fig. 4.37). In both cases the absolute values were as expected sigmificantly ( $<<0.001)$ higher in the Tuteal phase as compared to the follicular phase (fig. 4.37). The relative increases in plasma $P$ concentrations were not significantly different between both phases and both periods (table 4.2 and 4.3 ).

Adrenocorticotropic hormone (ACTH)

In the pre-training test, the mean of the two values at rest was measured to be $12.8 \pm 1.1$ and $10.6 \pm 1.5 \mathrm{pmol}^{-1}$ in the follicular and luteal phase, respectively. After training these vaiues were $6.1 \pm 0.89$ and $6.8 \pm 1.0$ pmol. $1^{-1}$ in the follicular and luteal phase, respectively. The absolute ACTH walues increased significantly (p<0.05) both in the pre- and posttraining tests. The post-training values were significantly (p<0.001) lower than the pre-training values (fig. 4.38). No significant differences between the follicular and Tuteal phase could be observed neither in the pre- nor in the post-training tests. 


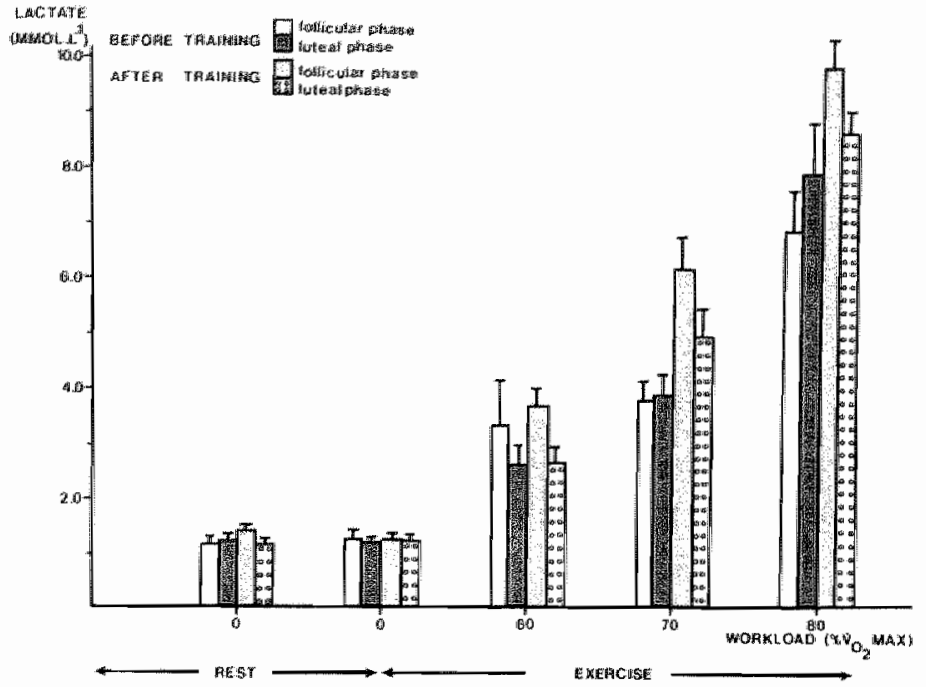

Pigure 4.34

PLama Lactate concentration duming exerciee in women (n=8), before and after a three month endurance training program, in the folliaular and luteal phase of their menotrual aycles.

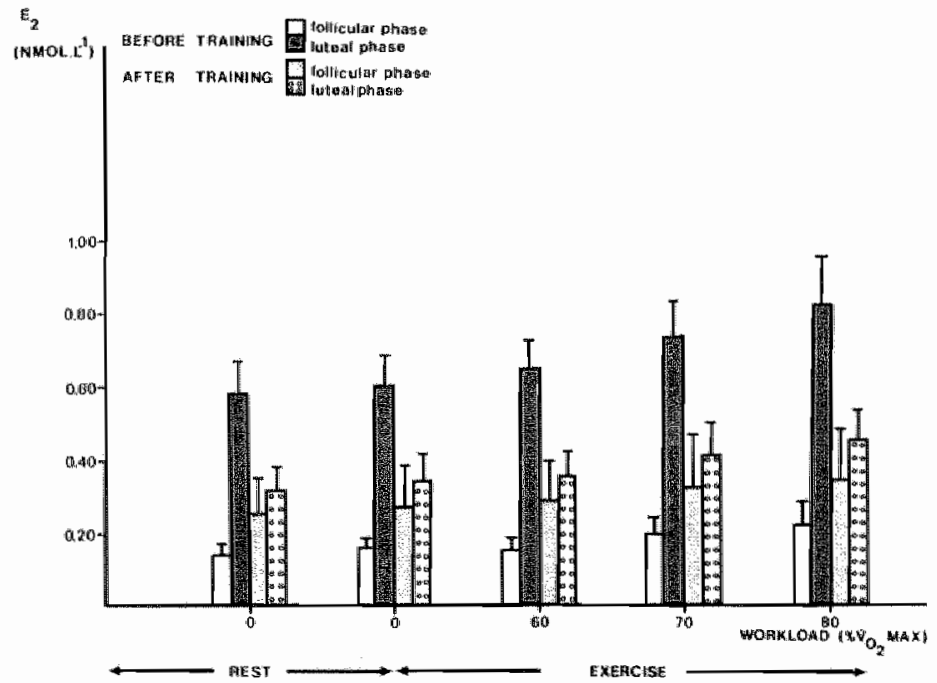

Figure 4.35

Plama $E_{1}$ concentration duming exercise in women ( $\left.n=8\right)$, before and after a Inree month endurance training pragnam, in the follicutar and luteal phase of thein memstrual cycle. 


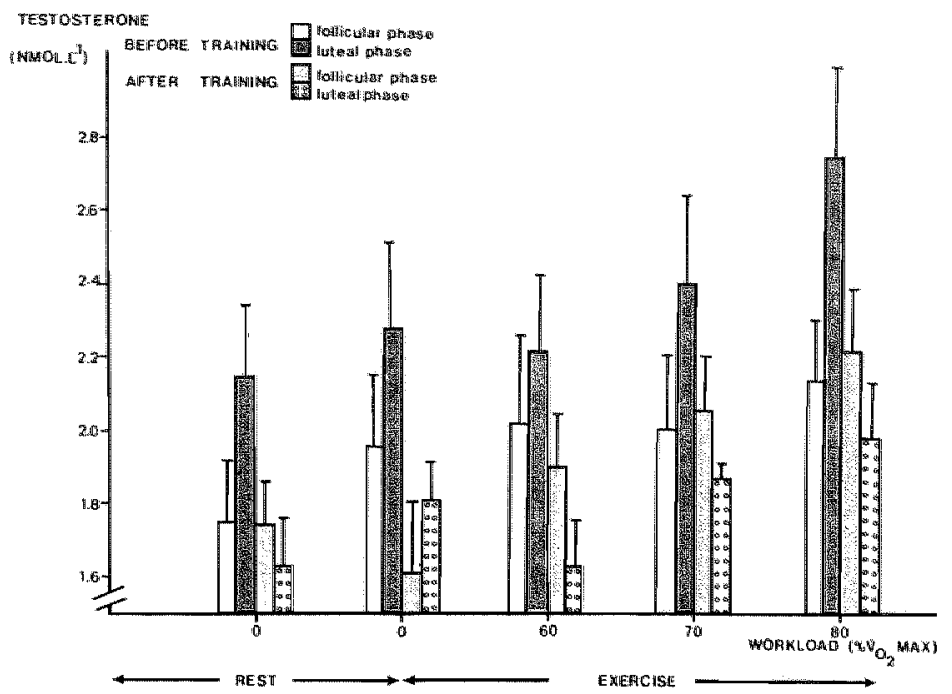

Figure 4.36

Plawa $T$ concentration during exercibe in women $(n=8)$, before and after a three month endurance training program, in the follicular and tuteal phases of their menstrual cycle.

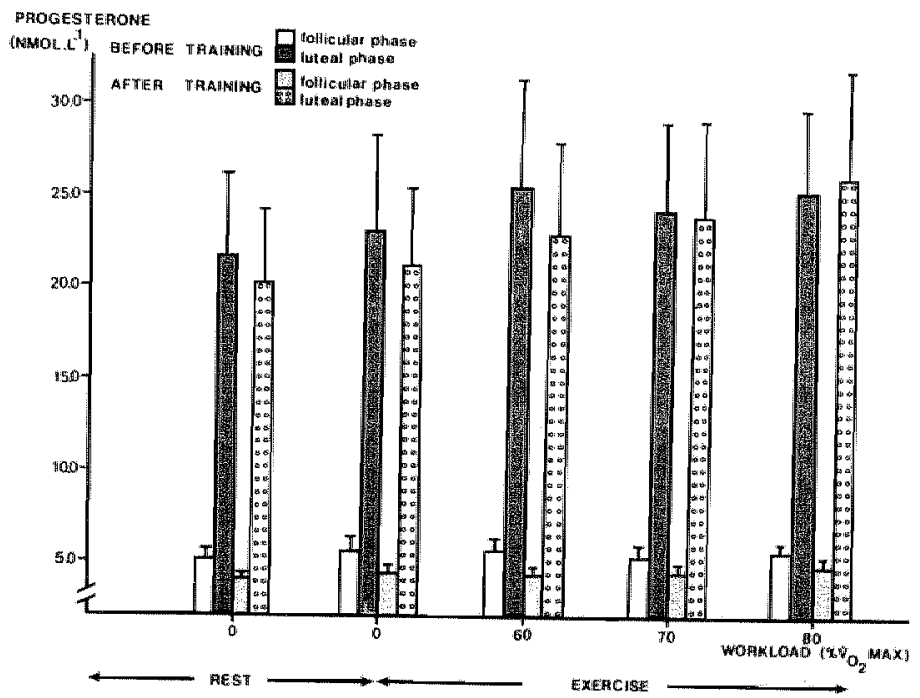

Pigure 4.37

Plasma $P$ concentmation duming exercise in women ( $n=8)$ before and after a three month endurance training program in the follitoular and luteal phases of their menstrual cycle. 


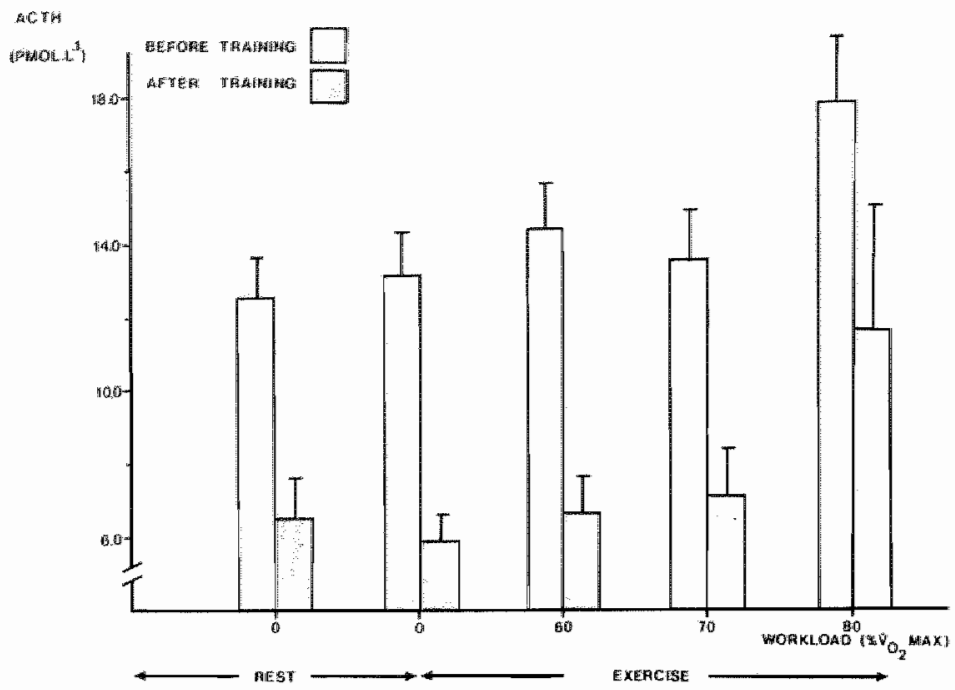

Eigure 4.38

PLama ACTH concentration during exercise in women, before and after a three month enduranee training program in the folticular phase of their menetruat cyote.

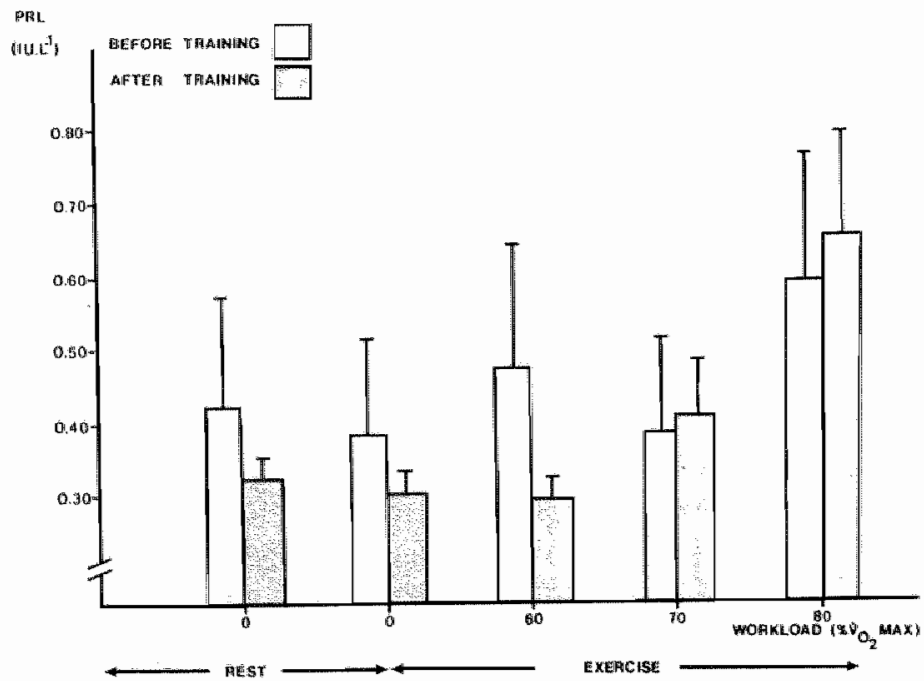

pigure 4.39

PLama PRL coneentration during exereibe in women ( $n=8$ ) before cond after a thrae month endurance training program in the follicular phase of their menatruat cycle. 
The relative $A C T H$ responses to exercise in the post-training period were not statistically different from those in the pre-training period (table 4.2 and 4.3 ).

\section{Prolactin (PRL)}

In the follicular phase the mean of the two samples obtained at rest was $0.4 \pm 0.02$ and $0.32 \pm 0.031 U . \mathrm{L}^{-1}$, in the pre- and post training test, respectively. In the luteal phase these values were $0.29 \pm 0.03$ and $0.25 \pm 0.03$ $10.1^{-1}$. Before and after training the absolute PRL values increased significantiy $(p<0.05)$ (fig. 4.39). No effect of the phase of the menstrual cycle could be detected, neither in the post-nor in the pre-exercise tests. The relative changes during exercise were not statically different between the pre- and post-training periods (table 4.2 and 4.3).

\subsection{GONADOTROPIN AND ESTRADIOL SECRETION PATTERNS BEFORE AND AFTER}

\section{PROLONGED PHYSICAL EXERCISE (STUDY IV)}

The subjects who volunteered in this part of the study were in the follicular phase of their menstrual cycle. The experiments were necessarily performed on different days in the follicular phase, which probably introduced marked differences in plasma $E_{2}$ levels. Subjects 1006,1012 and 1023 were investigated on the 8th day of their menstrual cycle, whereas subjects $1002,1010,1022$ and 1024 were investigated on the 10th or 11th (1022) day of their cycles. Except for subject 1023, all investigations started between 7.30 and $8.30 \mathrm{a} . \mathrm{m}$. Subject 1023 was necessarily studied between 12.00 a.m. and 17.00 p.m.

The results of this study show an extreme, inter-individual variation in pre- and post-exercise gonadotropin and $E_{2}$ levels. Therefore, statistical analyses for the whole group, could easily masque the typical individual responses to exercise, reason why all individual pre- and post-exercise values are given in table A-1 to A-3. Data concerning pulse frequency, pulse amplitude and pulse increment before and after exercise are depicted in tables 4.4 to 4.6 . For the purpose of this study a hormone pulse was defined as occurring when the hormone concentration of a sample exceeded the previous concentration by at least twice the intra-assay coefficient of 
variation. The pulse amplitude was calculated from nadir to the peak of the pulse, whereas the pulse increment was calcullated as the relative (percentual) dffference in concentration between peak and nadir of a pulse.

From table 4.4 it can be observed that the mean post-exercise values for the pulse frequency, pulse amplitude and pulse increment of LH were increased as compared to the pre-exercise values. The post-exercise pulse frequency, pulse amplitude and pulse increment of FSH were not different from the pre-exercise values (table 4.5). The post-exercise pulse frequency, pulse amplitude and pulse increment of $E_{2}$ seems to be different from the pre-exercise walues (table 4.6$)$. In some cases $(1010,1012,1022$ ) no distinct pulses could be observed after exercise.

The mean pre- and post-exercise LH, FSH and E2 levels are depicted in table 4.7. From this table it can be observed, that in two cases (subjects 1002 and 1010$)$ the mean post-exercise $L H$ values were significantiy $(p<0.05)$ increased as compared to the pre-exercise values. In two subjects (1012 and 1022) the mean post-exercise FSH values exceeded the pre-exercise values significantiy ( $p<0.001)$, while in one subject (1024) this value was decreased $(p<0.01)$. In 6 out of 7 subjects, the mean post-exercise $E_{2}$ levels were significantly $(p<0.05)$ elevated as compared to the pre-exercise levels. As an example of the changes in gonadotropin and $E_{2}$ levels the data of two subjects (no. 1006 and 1012) are depicted in figures 4.40 to 4.43)

Pooling all individual data of the pre- and the post-exercise period showed a significantly $(p<0.05)$ increased mean $L H$ level in the post-exercise period as compared to the pre-exercise period. Trend analysis also showed a pre-start increase in plasma LH levels (figure 4.44). 
Table 4.4

Pulse frequency (pulses/2 hours), pulse amplitude (10.1 ${ }^{-1}$ ) and pulse increment $(y)$ of plasma LH before and after physical exercise.

Before exercise

sub- pulse ject frequency code (in 2 hrs) pullse amplitude increment (II. $1^{-1}$ )

\section{After exercise}

\begin{tabular}{lllllll}
\hline 1002 & 1 & 1.7 & 34.0 & 2 & 1.85 & 26.9 \\
1006 & 2 & 0.9 & 20.6 & 2.5 & 1.7 & 38.2 \\
1010 & 1 & 1.7 & 34.0 & 1 & 1.3 & 20.6 \\
1012 & 2 & 1.6 & 30.0 & 2 & 4.2 & 96.4 \\
1022 & 2 & 1.7 & 23.0 & 2 & 2.1 & 34.1 \\
1023 & 1 & 3.6 & 87.8 & 2 & 3.3 & 86.4 \\
1024 & 3 & 3.3 & 41.7 & 2 & 2.6 & 50.4 \\
$\bar{x}$ & 1.71 & 2.08 & 38.8 & 1.93 & 2.43 & 50.4 \\
SEM & 0.265 & 0.34 & 7.98 & 0.158 & 0.357 & 10.39 \\
\hline
\end{tabular}

Table 4.5

Pulse frequency (pulses/2 hours), pulse amplitude (IU. $)^{-1}$ ) and pulse increment $(\%)$ of plasma FSH before and after physical exercise.

\section{Before exercise}

sub- pulse pulse ject frequency amplitude increment code (in 2 hrs) $\left(10.1^{-1}\right)$

\section{After exercise}

\begin{tabular}{lllllll}
\hline 1002 & 2 & 0.9 & 25.0 & 3 & 1.6 & 41.4 \\
1006 & 3 & 1.4 & 28.7 & 1 & 1.2 & 21.0 \\
1010 & 1 & 1.6 & 37.2 & 1 & 1.7 & 34.0 \\
1012 & 2 & 2.6 & 39.4 & 2 & 0.9 & 34.6 \\
1022 & 2 & 1.2 & 30.0 & 2 & 2.5 & 28.8 \\
1023 & 1 & 1.4 & 25.0 & 1 & 2.0 & 14.3 \\
1024 & 1 & 2.3 & 54.8 & 2 & 1.4 & 36.6 \\
SEM & 1.71 & 1.64 & 34.3 & 1.71 & 1.62 & 30.1 \\
& 0.265 & 0.213 & 3.73 & 0.265 & 0.181 & 3.32 \\
\hline
\end{tabular}


Table 4.6

Pulse frequency (pulses/2 hours), pulse anplitude (nnol. $1^{-1}$ ) and pulse increment $(\%)$ of plasma $\mathrm{E}_{2}$ before and after physical exercise.

Before exercise

sub- pullse

ject frequency

code (in 2 hrs) pulse amplitude

(nmo1.1 $)^{-1}$ )

\section{After exercise}

pul se

increment

(\%)

\section{pulse} frequency (in 2 hrs)

\section{pul se} ampl itude (nmol. $7^{-1}$ ) pill se increment

(\%)

\begin{tabular}{|c|c|c|c|c|c|c|}
\hline 1002 & 1 & 0.04 & 50.0 & 1 & 0.05 & 50 \\
\hline 1006 & 1 & 0.09 & 69.2 & $1 \cdot 5$ & 0.04 & 16.4 \\
\hline 1010 & 1 & 0.25 & 108.7 & 0 & - & - \\
\hline 1012 & 2 & 0.07 & 11.9 & 0 & - & $\rightarrow$ \\
\hline 1022 & 0 & - & - & 0 & - & - \\
\hline 1023 & 1 & 0.05 & 100.0 & 1 & 0.014 & 14.0 \\
\hline $\bar{x}$ & 1 & 0.09 & 58.4 & & & \\
\hline SEM & 0.2 & 0.031 & 14.6 & & & \\
\hline
\end{tabular}

\section{Table 4.7}

Plasma $L H, F S H$ and $E_{2}$ concentration ( $\bar{x} \pm S E M$ ) before and after exercise. The values represent the mean of the last 8 values before and the mean of the first 8 vallues after exercise. Significancy is denoted by * if $0.05>p>0.01$; ** if $0.01>p>0.001 ; * * *$ if $p<0.001$.

\begin{tabular}{|c|c|c|c|c|c|c|}
\hline \multirow[t]{2}{*}{$\begin{array}{l}\text { Subje } \\
\text { code }\end{array}$} & \multicolumn{2}{|c|}{$\left(\begin{array}{c}\mathrm{LH} \\
\left(\mathrm{IU} . \mathrm{I}^{-1}\right)\end{array}\right.$} & \multicolumn{2}{|c|}{$\begin{array}{c}\text { FSH } \\
\left(\mathrm{IU} .1^{-1}\right)\end{array}$} & \multicolumn{2}{|c|}{$\left(\mathrm{E}_{2}{ }^{\mathrm{E}_{2}} .1^{-1}\right)$} \\
\hline & Before & After & Before & After & Before & After \\
\hline $\begin{array}{l}1002 \\
1006 \\
1010 \\
1012 \\
1022 \\
1023 \\
1024\end{array}$ & $\begin{array}{l}5.5 \pm 0.26 \\
4.8 \pm 0.21 \\
6.0 \pm 0.19 \\
6.2 \pm 0.25 \\
8.1 \pm 0.28 \\
5.9 \pm 0.4 \\
6.6 \pm 0.47\end{array}$ & $\begin{array}{l}6.3 \pm 0.25^{\star} \\
5.3 \pm 0.44 \\
6.6 \pm 0.17^{\star} \\
7.4 \pm 1.05 \\
8.1 \pm 0.54 \\
6.7 \pm 0.6 \\
6.9 \pm 0.48\end{array}$ & $\begin{array}{l}4.3 \pm 0.14 \\
5.6 \pm 0.68 \\
5.6 \pm 0.22 \\
2.3 \pm 0.11 \\
4.7 \pm 0.22 \\
6.7 \pm 0.19 \\
5.7 \pm 0.4\end{array}$ & $\begin{array}{l}4.9 \pm 0.45 \\
5.8 \pm 0.18 \\
5.8 \pm 0.2 \\
3.4 \pm 0.22^{\star \star \star} \\
7.6 \pm 0.18^{\star \star \star} \\
6.8 \pm 0.29 \\
4.3 \pm 0.16^{\star \star}\end{array}$ & $\begin{array}{l}0.07 \pm 0.002 \\
0.18 \pm 0.009 \\
0.33 \pm 0.04 \\
0.63 \pm 0.012 \\
0.13 \pm 0.008 \\
0.09 \pm 0.29 \\
0.31 \pm 0.008\end{array}$ & $\begin{array}{l}0.09 \pm 0.006^{\star} \\
0.21 \pm 0.008^{\star} \\
0.25 \pm 0.01^{\star} \\
0.66 \pm 0.04 \\
0.15 \pm 0.005^{\star *} \\
0.12 \pm 0.007^{*} \\
0.37 \pm 0.02^{\star}\end{array}$ \\
\hline
\end{tabular}




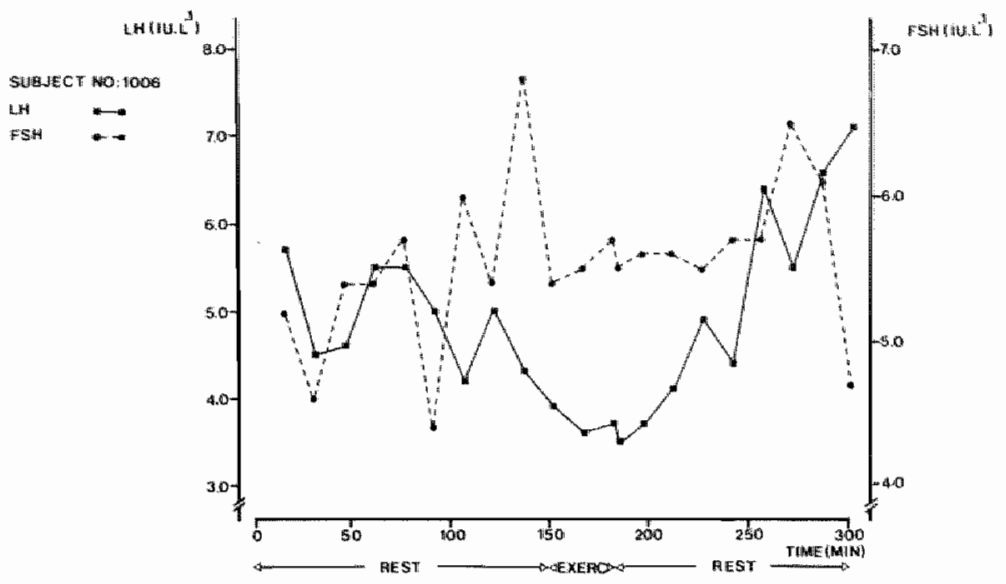

Figure 4.40

Changes in ptasma LH and FSH concentration before, duming and after physical exeraise in subject 1006.

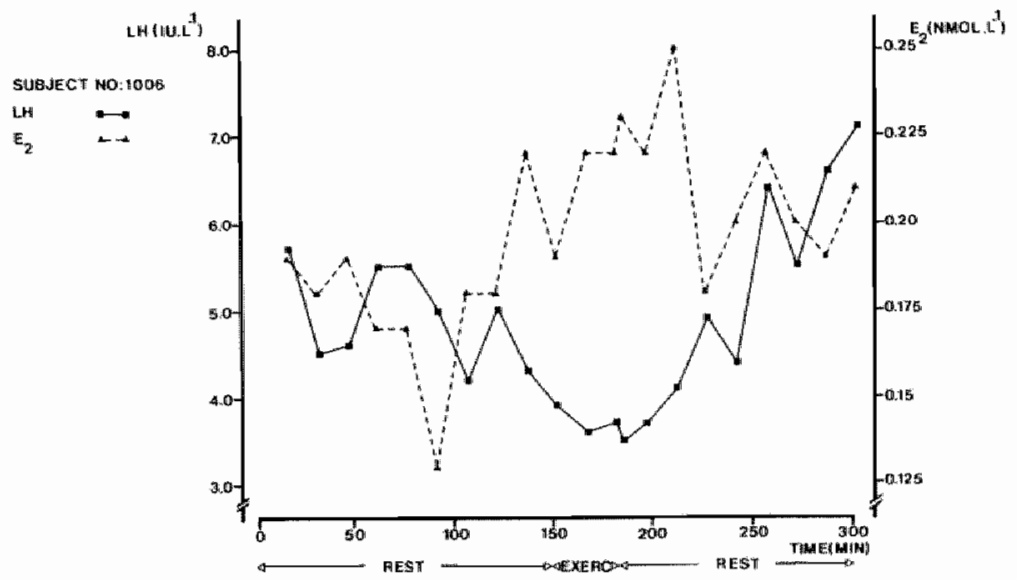

Figure 4.41

Chonges in plasma LH and $E_{2}$ concentmation before, duming and after physical exeraise in aubjeat 1006. 


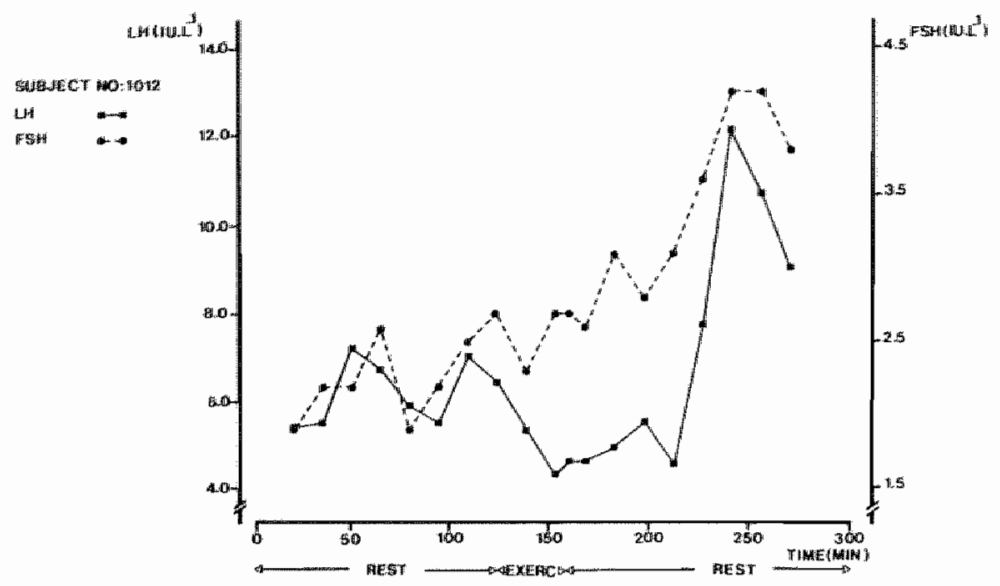

Eigure 4.42

Changes in plasma LH and FSH concentration before, during and after physical exerotie in aubject 1012.

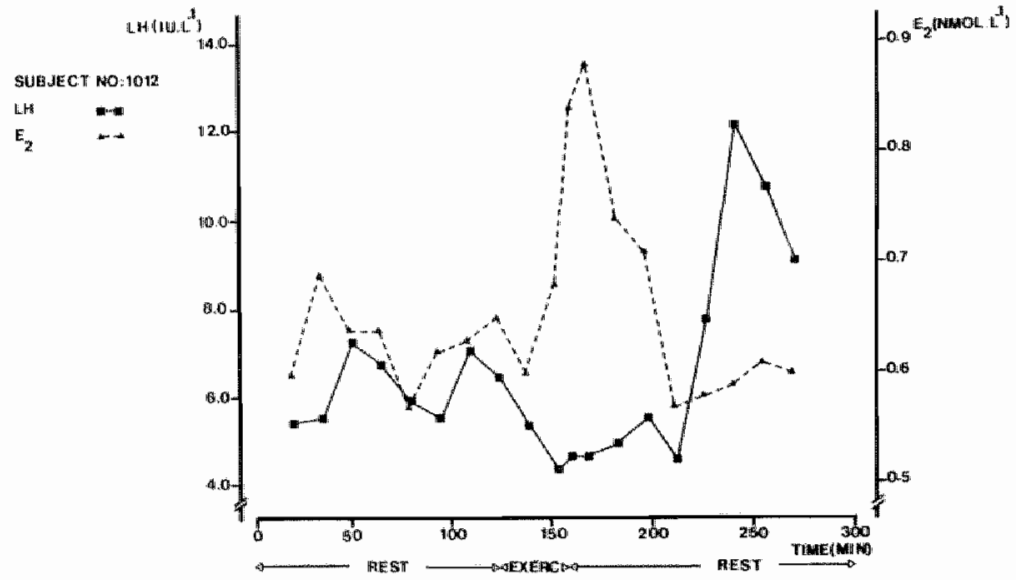

Peighere 4.4

Changes in $p$ tasna $L H$ and $E_{2}$ concentration before, duming and after physical exenetse in subjeat 1012 . 


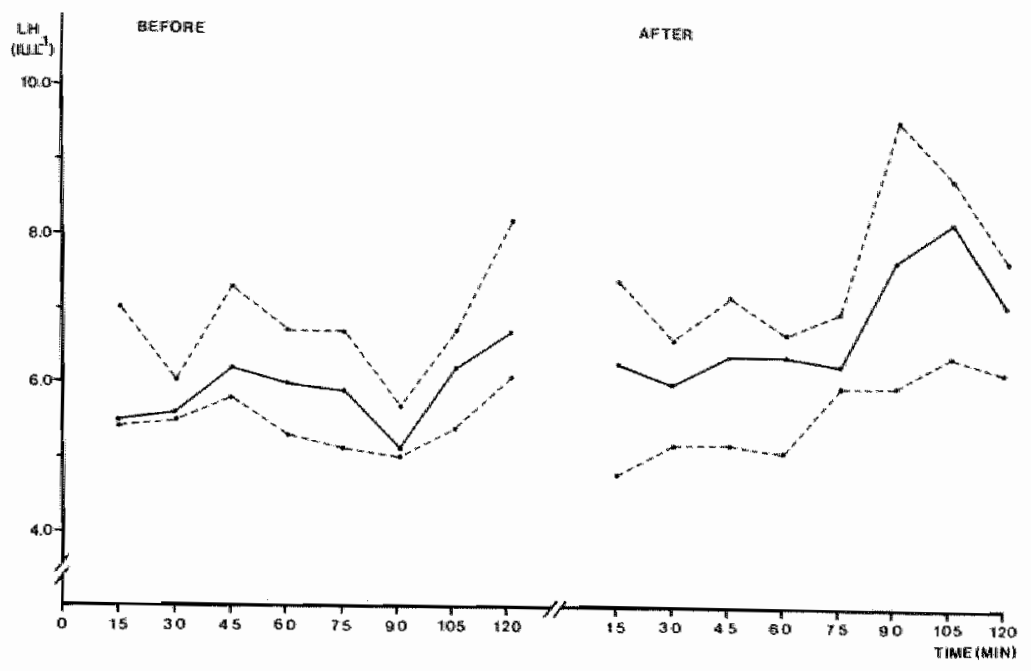

Eigure 4.44

Fre-and post-exereice plasma LH concentmations in 7 women in the follidutar phase of the menatrual cyche. The solid line represente the median of al $I$ LH concentrations, the dotted lines represent the aecond and thim quartizes, reapeotively. 
4.4 THE INFLUERICE OF SHORT-TIME PHYSICAL EXERCISE ON THE METABOLIC CLEARANCE RATE OF ESTRADIOL (STUDY Va AND Vb)

The first two blood samples were drawn 120 and $135 \mathrm{~min}$ after the priming dose. These two bloodsamples usere to establish the steady state condition between the infusion rate and the disappearance rate of the tracer. It appeared that in all cases a steady state was reached $120 \mathrm{~min}$ after the priming dose. The MCR as calculated from these two samples differed less than $10 \%$ with no systematic upward or downward trend. The mean of these two values was used as the resting or basal value of the MCR. The mean basal value for all subjects participating in both studies was calculated to be $1254 \mathrm{l} /$ day (range $669-1765 \mathrm{l} /$ day) or $870.8 \mathrm{ml}^{\mathrm{min}} \mathrm{m}^{-1}$. In table 4.8 and 4.9 the MCR values (corrected for hemoconcentration) are depicted in relation to the duration and intensity of the exercise. In fig. 4.45 and 4.46 the changes in the MCR of $E_{2}$ are presented as a percentage of the basal MCR, which was assumed to be $100 \%$. The data in these figures show that there is a sharp and consistent decrease $(p<0.001)$ in the MCR of $E_{2}$ for all subjects at 70 and $100 \% V_{2} \max$. The mean decrease at the end of the workload of $70 \% \mathrm{~V}_{2}$ max was 41.3 and $36 \%$ for study $\mathrm{Va}$ and $\mathrm{Vb}$, respectively. The mean decrease at the end of the $100 \% \mathrm{~V}_{2} 2_{2} \max$ load (study $\mathrm{Vb}$ ) was calculated to be $80.0 \%$. During the recovery period at $25 \% \mathrm{~V}_{2} \max (f i g .4 .46$ ) the MCR of $E_{2}$ remained well below the basal vallue. 
Table 4.8

The metabolic clearance rate of $E_{g}\left(m i\right.$. min $\left.{ }^{-1}\right)$ during short-term maximal exercise in young women in the folficular phase of their menstrual cycle (study $V_{a}$ ).

Work Time

Subject

Mean

load after

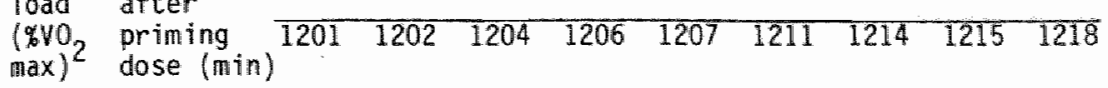

ISEM

Rest $135^{\mathrm{a}}$

$986 \quad 807$

$\begin{array}{lll}732 & 1043 & 871\end{array}$

850

$1226 \quad 1050$

953946.6

$70 \%$

102774

$509 \quad 316 \quad 148$

$804 \quad 411$

$\pm 47.2$

$100 \% \quad 149.4^{b}$

$167 \quad 121$

732

148

$306 \quad 555.6$

$\begin{array}{lllllllll}82 & 339 & 127 & 106 & 207 & 336 & 219 & 189.5 \\ & & & & 29.9\end{array}$

a: The basal MCR is calculated as mean from 2 samples, 1.e. 120 and 135 min after the priming dose.

b. This value represents the mean time at which the subjects had to give up (range 147-150 min after the priming dose).

Table 4.9

The metabolic clearance rate of $E_{2}\left(m_{1} \mathrm{~min}^{-1}\right)$ during submaximal exercise, and in the recovery period in young women (study $V b$ ).

\begin{tabular}{|c|c|c|c|c|c|c|c|c|}
\hline \multirow{2}{*}{$\begin{array}{l}\text { Work } \\
\text { laad } \\
\left(\mathrm{gVO}_{2}\right. \\
\max )^{2}\end{array}$} & \multirow{2}{*}{$\begin{array}{l}\text { Time } \\
\text { after } \\
\text { priming } \\
\text { dose (min) }\end{array}$} & \multicolumn{6}{|c|}{ Subject } & \multirow{2}{*}{$\begin{array}{l}\text { Mean } \\
\pm \text { SEM }\end{array}$} \\
\hline & & 1221 & 1222 & 1223 & 1224 & 1225 & 1226 & \\
\hline Rest & $135^{*}$ & 509 & 465 & 796 & 1083 & 858 & 1056 & $\begin{array}{l}794.4 \\
\pm 98.1\end{array}$ \\
\hline $70 \%$ & 140 & 432 & 529 & 976 & 689 & 669 & 433 & $\begin{array}{l}621.4 \\
\pm 76.9\end{array}$ \\
\hline$n$ & 145 & 343 & 383 & 597 & 804 & 450 & 346 & $\begin{array}{r}487.3 \\
\pm 67.8\end{array}$ \\
\hline $25 \%$ & 150 & 501 & 440 & 626 & 763 & 405 & 493 & $\begin{array}{l}540.0 \\
\pm 49.8\end{array}$ \\
\hline H & 160 & 322 & 349 & 465 & 902 & 505 & 494 & $\begin{array}{l}506.3 \\
\pm 77.7\end{array}$ \\
\hline : & 175 & - & 242 & 519 & 657 & 396 & 524 & $\begin{array}{r}467.6 \\
\pm 57.1\end{array}$ \\
\hline
\end{tabular}

* The basal MCR is calculated as the mean from 2 samples i.e. 120 and 135 min after the priming dose. 


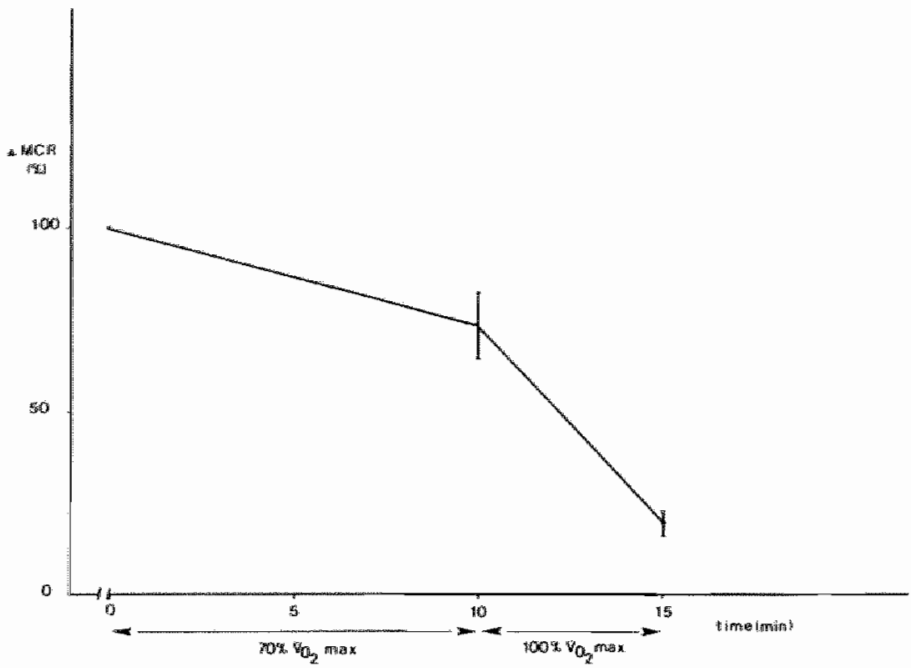

Figure 4.45

Mean relative changes (percentage of the mean barat value) of the MCh $E_{g}$ duming physical exercise in women $(n=9)$ in the folliaular phase of the menstruat cycle.

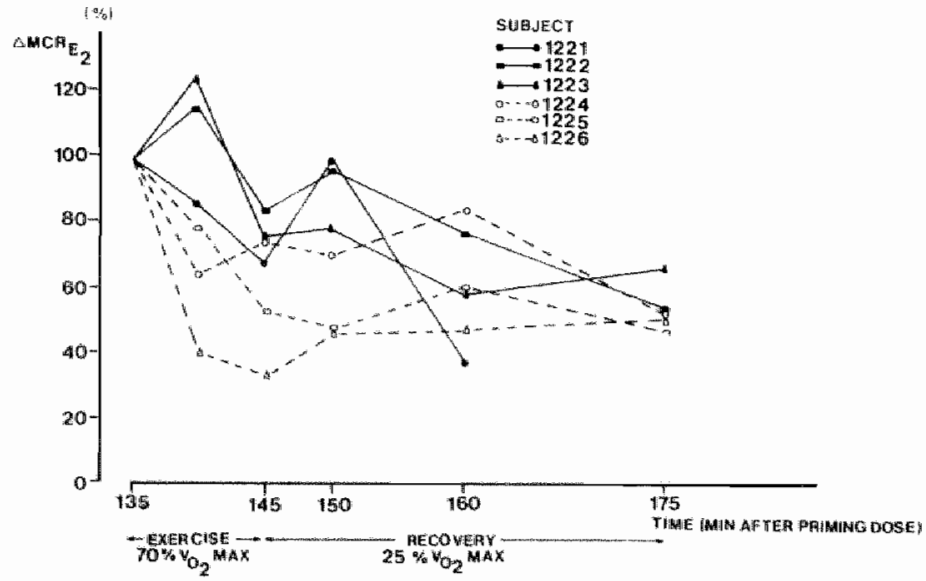

Pigume 4.46

Mean retative changes (peroemtage of the mean basat value) of the MCR $E_{2}$ during physiad exiotise in worten $(n=6)$.

Solid Itnes, changes in untrained aubjeats; dashed lines, changes in trained ones. 
CHAPTER V

\section{DISCUSSION}

5.1 PHYSICAL WORKING CAPACITY AND METABOLIC RESPONSES IN RELATION TO THE PHASE OF THE MENSTRUAL CYCLE (STUDIES I AND II)

Maximal physical working capacity.

In the present investigation we were not able to demonstrate a significant effect of the phase of the menstrual cycle on maximal physical performance neither in trained, nor in untrained women. In the trained group, one subject was not able to complete the $75 \mathrm{~min}$ treadmill run in the luteal phase. In the other subjects, no differences in physical performance between both phases of the menstrual cycle could be observed.

The lack of influence of the phase of the menstrual cycle on physical performance is in agreement with data of several other investigations (Doolittle and Engebretsen, 1972; Drinkwater, 1973; Verstappen et al, 1981; Kuipers, 1983). However, other investigators showed an enhanced physical performance in either the follicular phase (Millahn and Drecoll, 1960; Klaus and Noack, 1961; Pahike and Smitka, 1977; Schoene et a1, 1981), or the luteal phase of the menstrual cycle (Muiler-Limmoth and Lohaus, 1963; Jurkowski et al, 1978). These conflicting results may be explained partly by differences in the experimental protocols and partly by the lack of a correct detemination of the phase of the menstrual cycle (by measurement of plasma steroids and/or gonadotropins). Especially the latter is important and therefore the data of the investigations lacking hormonal data have to be interpreted with care (Doolittle and Engebretsen, 1972; Drinkwater, 1973; Millahn and Drecol1, 1960; Klaus and Noack, 1961; Pahlke and Smitka, 1977; Verstappen et al, 1981; Kuipers, 1983). The results of the only two investigations where the phase of the menstrual cycle was correctly determined (Jurkowski et al, 1981; Schoene et a1, 1981) render conflicting data. In both studies the exercise experiments were performed on a bicycle ergometer and hence they are comparable in this respect. Jurkowski and co-investigators (1978) found an enhanced maximal physical perfomance in the luteal phase in 10 untrained women, whereas Schoene and co-investi- 
gators (1981) found an increase in the follicular phase in both trained and untrallined women.

Gilucose and lactute plasma levels during exercise.

During exercise, no differences in lactate response could be detected between both phases of the menstrual cycle in study $I$ and $\mathbb{I}$ of the present investigation. This is in agreement with findings of Bonen and co-investigators (in press) and Dalsky (1982), in untrained and trained women during bicycle ergometer and treadmill work. Jurkowsi and co-investigators (1978 and 1981), however, have reported a lower lactate level in the luteal phase during progressive bicycle ergometer work 120 min consecutive loads at 33 , 66 and $90 \%(10, \max )$.

In the present study, the blood glucose responses to exercise were different in the untrained and trained groups. The blood glucose response to exercise in the untrained group is comparable with the results of previaus reports for male subjects in similar experiments (Ahiborg et al, 1977 ; Bonen et al, 1979; Bonen et al, 1981; Costi1l et al, 1977; Galbo et a1, 1977). The high blood glucose levels, however, found in the trained group is an unexpected finding which has not been observed in males. Although comparlisons between trained and untrained women are lacking in the literature, our findings confirm the data of Berg and Keul (1981) who al so reporthed significantly higher plasma glucose values after endurance work (lang distance running, cross country skiing) in a group of 38 female athletes as compared to their male counterparts. The underlying mechanism is unknown, but one should bear in mind that steroid hormones are able to influence carbohydrate and fat metabolism (Reinke et a1, 1972; Gorski et a1, 1976; Chainy et al, 1976; Morrow et al, 1981) both in man and rats. For example Gorski and co-investigators (1976) showed in ovariectomized rats a glycogen sparing effect of $E_{2}$ during prolonged exercise. This suggests an enhanced fatty acid oxidation under these circumstances. The higher plasma glucose levels in the traimed women as compared to their male counterparts may originate from higher nor-epinephrine levels in the former as reported by Berg and keul (1981).

However, controlled animal experiments with and without sex hormones administration together with measurements of giucose turn-over rates are needed to get more insight into the mechamisms of these hormones on sub- 
strate turn-over.

5.2 ACUTE EFFECTS OF PHYSICAL EXERCISE ON PLASMA LEVELS OF SEX HORMONES AS A FUNCTION OF THE LEVEL OF PHYSICAL FITNESS

In the present investigation serial homonal concentrations were measured during physical exercise in two groups of wonen with different daily physical activities to ascertain the typical hormonal responses in the follicular and luteal phases of their menstrual cycles. The homone concentrations were expressed as absolute and relative (percentual change) values, both as a function of time (trained women) and workload (untrained wanen). We used relative values because we were primarily interested in the changes relative compared to the resting situation. Besides, they also reduce the large inter-individual variation in homone concentrations and responses to exercise. Therefore, intergroup comparisons were also made making use of the relative values.

\section{Estradiol $\left(\mathrm{E}_{2}\right)$}

During exercise, the absolute $E_{2}$ concentration increased significantly in the two groups, both in the follicular and luteal phase of the menstrual cycle. The relative values showed similar increments in the untrained and trained group, with no significant differences between both phases of the menstrual cycle. Our results agree well with those of other investiglators as far as the luteal phase is concerned (Jurkowsky et al. 1978; Bonen et al. 1979; Cumning et al. 1981). These investigators did not obserwe an increase in the folliticular phase of the menstrual cycle. The discrepancy between their and our findings is difficult to recover, but it may be caused by a lower sensitivity of their assay. Support for this idea can be found by expressing their data as relative changes, resulting in comparable relative increments in both phases of the cycle as found in the present investigation.

\section{Free estradiol fraction}

In the present investigation we have studied the effect of physical exercise and the related increase in body temperature on the free percentage of plasma $E_{2}$ and $T$. In the method we employed, undiluted plasma and 
physialogical temperatures $\left(37^{\circ} \mathrm{C}\right.$ and $\left.39.5^{\circ} \mathrm{C}\right)$ were used. For practical reasons, we used a fixed post-exercise temperature, although it is well recognized that there could be inter-individual differences in this respect.

In the untrained group the mean free $E_{2}$ fraction at rest was measured to be about $1.5 \%$ and decreased significantly with exercise. In the trained group the mean free $E_{2}$ fraction at rest was measured to be about $1.23 \%$. In this group physical exercise did not affect this value. In both groups no differences in free $E_{2}$ values between the phases of the menstrual cycle were found.

Dur data show a free percentage of $E_{2}$ which is lower as those reported by ather investigators (Wu et al. 1976; Harmond et al, 1980; Dumn et al, 1981; Mol1 and Rosenfield, 1980). Dunn and colleagues (1981) reported mean free $E_{2}$ fraction of $1.81 \%$ in both phases of the menstrual cycle in 40 women, whereas wu and co-investigators (1976) found even higher values $(2.0-2.6 \%)$. The differences between our values and those of these authors may be explained by the different techniques used and the endocrine characteristics of the subjects participating in the present investigation.

The slight, but significant decrease in free plasma $E_{2}$ fraction after physical exercise is an unexpected finding. This decrease, however, has to be handled with much reservation. Since the intra-assay coefficient of variation of our method was calculated to be $7.3 \%$, it is obvious that the decrease in free percentage $E_{2}$ is well within these limits. Therefore, we consider this finding as a coincidence. The finding that a concomitant rise in total plasma $E_{2}$ and body temperature does not necessarily affect the free $E_{2}$ fraction may be explained by the observations of Vigersky and co-investigators (1979), who were not able to show any significant $E_{2}$ binding to $S H B G$ at $37^{\circ} \mathrm{C}$. This means, that albumin accounts for almost all $E_{2}$ transport in the blood under physiological conditions. Since the binding capacity of albumin for $E_{2}$ is almost unlimited it is unlikely that an exercise induced rise in total plasma concentration can overwhelm it. Hence, the free percentage is left unaffected. At the other hand, the results of other investigations (wu et a1, 1976; Moll and Rosenfield, 1980; Dunn et a1, 1981) are not in agreenent with the findings of Vigersky and colleagues. They found that SHBG accounted for 35-40\% of the $E_{2}$ transport in plasma. Nevertheless, we assume that the biological activity of $E_{2}$ may 
be increased due to the increased dissociation rate of $E_{2}$ from albunin (Vermeulen, 1973; Lata et a]. 1980) at body temperatures corresponding with prolonged heavy exercise.

\section{Progesterone (P)}

The data reported in the present investigation might indicate that most participants did ovulate as judged by the rise of the plasma $P$ concentration above $10 \mathrm{nmol}^{-1} \mathrm{1}^{-1}$. The low plasma $P$ concentration may indicate that some of the experiments in the luteal phase, which were considered to be done mid-luteal, were possibly conducted in the early luteal phase. However, it is well recognized that the inter-individual variation in plasma $P$ concentration is rather extensive. The unreliability of the BBT for detection of the moment of ovulation (Wetzels et al, 1982) made that in the present investigation, the mid-luteal phase could not be accurately determined.

In the untrained and trained subjects the absolute $P$ concentrations increased sigmificantly with exercise. The relative values showed a significant linear increase with exercise (mean $25.1 \%$, range 10.8 to $74.2 \%$ ) in the untrained group, while in the trained group, the changes in relative values (mean increase $67 \%$, range $0-192.8 \%$ ) showed a levelling-off, especially in the luteal phase. No phase effect could be detected in the trained group, while in the untrained group the relative increase in $P$ concentration was more pronounced in the luteal phase. The differences in response between the groups were not significant.

Our results agree well with the findings of other investigators (Jurkowski et al, 1978; Bonen et al, 1979; Bonen et al, in press). They found increments of about 38\% (Bonen, 1979) and $40 \%$ (Jurkowski, 1978) at comparable workloads $\left(70 \% \mathrm{VO}_{2}\right.$ max) and exercise times $(30-40 \mathrm{~min})$, while at $80 \%$ $\mathrm{V}_{2}$ max Bonen and co-investigators (in press) found increments of about $71 \%$ in the luteal phase and of more than $100 \%$ in the follicular phase. A claser examination of the data of Jurkowski and co-investigators (1978) showed that the increase in $P$ concentration levels off at high workloads, which corroborates our findings. The explanation for this finding might be a levelling-off of the MCR, which is considered to reach its minimum values at high workloads (see paragraph 5.3). The almost $200 \%$ rise in $P$ concentration, as recorded in some of our subjects, suggests in the first place a 
decreased MCP. In the second place also other mechansisms such as an enhanced adrenal secretion, may be involved. However, this hypothesis has to be handled with care. Since the greatest relative increments have been shown in the follicular phase it is obvious that the high variability of the radio-immunio-assay occurring with low plasma $P$ concentrations can easily averestimate the true values. Expressing the absolute values in relative ones may even increase this error considerably.

\section{Gonadotropins}

The absence of any change in absolute FSH levels during exercise is in keeping with the findings as reported by others (Bonen et a1, 1979; Jurkowski et al, 1978). In both groups significant differences between the phases could be observed at rest. In the trained subjects, the LH and FSH concentrations were lower in the luteal than in the follicular phase, but in untrained subjects this was only true for FSH. The relative plasma LH concentrations showed a linear decrease with exercise in the untrained group, which was calculated to be about $13 \%$ and $20 \%$ in the follicular and luteal phase, respectively, at a workload of $80 \% \mathrm{VO}_{2}$ max, whereas in the trained group a linear trend was not apparent. At comparable exercise time ( 45 min) and worklaads $\left(85 \% 0_{2}\right.$ max) the mean decrease was calculated to be 8.2\% (range $-22.5 \%$ to $3.4 \%$ ). The relative FSH concentration decreased onty in the untrained group. The differences in FSH responses between the untrained and trained subjects were not significant $(p=0.06)$. In the untrained subjects the relative FSH values were slightly less affected by exercise than those of the relative LH values whereas this was not the case in the trained group. This means, that in both groups the LH/FSH ratio's decreased by about 10-20\%. Our results do not confirm the findings in recent investigations (Jurkowski et al, 1978; Bonen et al, 1979; Bonen et al, 198:2). Jurkowski and co-investigators (1978) have reported unchanged absolute LH and FSH levels during a progressive exercise protacol (20 min consecutive loads at 33,66 and $90 \% \dot{\mathrm{V}} \mathrm{2}_{2}$ max) in young women, a1 though the $\mathrm{LH}$ concentration tended to be llowered in the luteal phase during the first 35 min of exercise, whereafter it seemed to increase. Their graphs further suggest a divergent response of this hormone between the phases i.e. the plasma concentration tended to increase during the follicular phase. Bonen and co-investigators (1979) did not find any significant effect of a 30 min 
bicycle ergometer ride $\left(74 \% \dot{V}_{2} \max \right)$ on the gonadotropin response in young women, although they reported a mean (non-significant) exercise-induced decrease of $7.1 \%$ and $2.6 \%$ in untrained $(n=10)$ and moderately trained $(n=5)$ young women, respectively. Recently Bonen and co-investigators (in press) found an increase in plasma L.H concentration at the end of a progressive treadmill protocol ( 30 min consecutive loads at 40 and $80 \% \mathrm{VO}_{2}$ max) in 19 women. This increase, however, was not significant for the lower workloads. In additon, their results suggest a slightly different response in fasted, glucose loaded and control subjects. In the fasted subjects the LH concentrations at rest were lower than in the control and glucose loaded group. Their results show that the plasma $L H$ concentration did not change during exercise in the fasted subjects, whereas it seened to increase in the glucose-loaded group. It might be that the differences between our results and the results of the afore mentioned investigators can be explained by differences in methads. In our study, also the untrained subjects exercised after a overnight fast, and especially in this group gonadotropin levels, were significantly decreased. A pre-exercise increase in plasma LH levels, as observed in study IV (paragraph 4.3) of the present investigation, cannot be excluded. This might cause an overestimation of the resting value. Nevertheless, al so in this part of the study it has been shown that most subjects responded to exercise with a decrease of the plasma LH levels during exercise.

\section{Prolactin}

Exercise induced a significant linear increase in plasma PKL concentrations in the untrained and trained subjects. This finding partiy disagrees with the results of Brisson and co-investigators (1980). They found a significantly increased PRL concentration after a $30 \mathrm{~min}$ bicycle ergoneter ride $\left(70 \% \mathrm{~V}_{2}\right.$ max $)$, but only in women with a "sport history". This disagreement is probably caused by the specific endocrine characteristics of the subjects participating in this study. This idea is not supported by the findings in study III of the present investigation. In this part of the study eight previously untrained wonen volunteered in a training program. Both in the untrained and trained state the PRL values were affected by exercise. On the other hand in study $\mathbb{I}$ and $\mathbb{I} I$ we have shown a more pronounced relative increase in plasma PRL concentration in the trained runners 
than in the untrained subjects, which confims the abserwations of Brisson and colleagues (1980). It is most likely that the enhanced plasma levels of PRL are caused by a greater sensitivity of the anterior pituitary to stimulating agents. This is supported by the obserwations of Boyden and co-investigators (1982), who showed a significantly increased PRL secretion during physical exercise and thyroid releasing homone (TRH) stimulation after a training period in a group of previously untrained women. This might be caused by the chronic enhanced plasma $E_{2}$ levels during exercise, which sensitize the pitulitary to prolactin releasing factors. Hence, it is likely that in trained women the greatly enhanced PRL concentration after physical exercise as reported in the present and other studies (Shangold et a1, 1981; Baker et a1, 1982) can be attributed to physical conditioning. However, the present study clearly indicates that the inter-individual variance is extremely large. In some untrained subjects post-exercise values exceeding $1.510 .1^{-1}$ or an increase of more than $1250 \%$ were found, while in others no changes at all or even a decrease could be observed. Therefore, it is concluded from the present investigation that a "sport history" is not a condition per se to increase PRL secretion during exercise.

An exaggerated response to exercise in untrained women may be a sign of greater sensitivity of the hypothalanic-pituitary system to stress, which might make them more sensitive to menstrual cycle disturbances, especially because PRL is able to inhibit GRRH secretion.

\section{Androgens}

- Testosterone (T)

One of the most striking findings in the present investigation is the difference in plasma androgen levels between the untrained and highly trained subjects. Whereas in the untrained group the plasma $T$ concentration was about $1.8 \mathrm{nmol} .1^{-1}$, which was at the upper limit of the nomal range, the trained group showed a plasma $T$ concentration of about 1.2 nmol. $\|^{-1}$, which is the same as reported for untrained women (see table 2.2).

Our results are not in agreement with those of Dale and co-investigators (1979), who reported high levels of $\mathrm{T}$ in female long distance runners as compared to an age matched control group. On the contrary, carli and co-investigators (1983) found a marked reduction in plasma $T$ levels at 
rest, in a group of girl swimers after a period of competitive swiming training. The discrepancy between our results and those of Dale and colleagues may be due to a different training program or to higher pre-existing andragen levels. There is little doubt, that competitive runing training may considered to be stressful. In men it has been showm that physical exertion is associated with a decrease in plasma $T$ levels (Kuoppasalmi et a1, 1981; Opstad and Aakwaag, 1982). The reason for this phenomenon is not: clear, but may be due to a decreased secretion rate and probably an increase in MCR mediated by the increased free fraction (Vemeulen and Ando, 1979) and elevated ACTH levels which in turn enhance the MCR of T (Pratt and Longcope, 1978). In addition the body temperature after long-lasting physical exercise remains elevated for more than 24 hours (L. Hermanssen, personal communication) which may enthance the MCR at rest.

During exercise the absolute $T$ concentration increased significantly in the trained and in the untrained group when the exercise intensity exceeded $70 \% \mathrm{VO}_{2} \max$. The relative changes were more pronounced in the trained than in the untrained group. In some cases in the trained group the plasma $T$ concentration exceeded the base line walue with mome than $200 \%$, whereas in the untrained women the highest walue reached was $65 \%$ above the resting levell. This finding has to be handled with some reservations. Especially in the trained runners, we have measured rather low $T$ levels (mean 1.3 , range 0.6-3.5 nmol $.1^{-1}$ ), which implicates a considerable intra-assay coefficient of variation (with a concentration of $2.5 \mathrm{nmol} .1^{-1}$, the variation was measured to be $8.8 \%$ ). Expressing the results in relative values could double the error. Nevertheless, this cannot fully explain the differences between the trained and untrained subjects.

Onily a few investigations deal with androgen responses in women. Keil and co-investigators (1979) reported a 17-230\% increase in plasma $T$ concentration after a $75 \mathrm{~km}$ run in 13 women of variable age (16-5il years). Schmitt and co-investigators (1981) reported a mean increase in plasma $T$ concentration of $84 \%$ in women (mean age $48 \mathrm{yr}$ ) after a marathon run. No Information was prowided in both cases about the reliation between the time of the experiment and the phase of the mensitrual cycle. Shangold and coinvestigators (1981) reported a mean increase in plasma $T$ levels of $21 \%$ in the follicular phase and of $54 \%$ in the luteal phase in two groups of 3 women after a $30 \mathrm{~min}$ run (no indication of the workload). Baker et al 
(1982) compared the plasma $T$ levells of 6 women after a marathon race with samples collected 12-24 hrs after a practice run. They found significantly elevated $T$ levels (about 120\%) after a marathon run as compared to the control value. An increase in plasma $T$ levels may be caused by a decreased MCR as has been shown by sutton and co-investigators (1973) in males, but also an enhanced glandular secretion rate and/or conversion rate might be involved. Although the enomous potential of the ovary for synthesizing sterold hormones is not easily overestimated, it is unlikely that it plays an important role especially since the LH levels decrease during exercise (chapter 4.2). It seems more likely that the adrenal cortex is involved. particularly in the trained subjects. This assumption is supported by the finding that both the plasma ACTH and DHEA-S levels are markedly increased in these subjects.

An enhanced peripheral conversion from $\Delta 4-A$ is also likely to play an important role in the increased plasma $T$ levels, although this has to be proven in future research. The results of the present investigation did not show any effect of the phase of the menstrual cycle upon the plasma $T$ response. This finding is in disagreement with the results of Shangold and co-investigators (1981), who found an enhanced plasma $T$ response in the 1 uteal phase. However, due to the methodological weaknesses of their experiment (different volunteers, $n=3$, were used in different phases of the menstrual cycle) their findings have to be interpreted with some reservations.

- Free testosterone fraction

The free $T$ fraction at rest was 2.33 and $2.05 \%$ (mean of the values in the follicular and 1 uteal phase) in the untrained and trained group, respectively, with no differences between the phases of the menstrual cycle. These values are well above those reported in the 1 itterature (Verneulen, 1973; Hanmond et al, 1980; Moll and Rosenfield, 1979) and are close to values reported for hirsute females (Venneulen, 1973; Moll and Rosenfield, 1979). Vermeulen (1973) and Hammond and co-investigators (1980) reported nomal values of about $1 \%$. However, it has to be mentioned that the method of Vermeulen (dialysis, diluted plasma) is clearly different from our method. Although Hammond and co-investigators (1980) al so used undiluted plasma with a centrifugal ultrafiltration dialysis method, the number of 
subjects $(n=5)$ studied in their investigation is too small to draw conclusions about a normal distribution. Besides, any information about the subjects is lacking in their paper. Moll and Rosenfield (1979) found a mean free $T$ percentage of $1.38 \%$ (range $0.86-2.40$ ) in 32 normal women (age 19-36 yrs) using the flow-dialysis technique. Our values al so clearly exceed the values of these investigators. We cannot provide an explanation for these differences, but the differences in techniques used or intergroup differences may be considered. Besides, repeated measurements (the free percentage $T$ and $E_{2}$ was measured in each subject 4-6 times) revealed a high reproducibility of the individual values, thus excluding methodological errors so far.

Physical exercise produced a significant increase in the mean percentage of free $T$ in the untrained group $(8.6$ and $10.2 \%)$ and in the trained group $(8.7 \%$ and $11.4 \%$ ) in the follicular and luteal phase, respectively. These results corroborate the data of Vigersky and co-investigators (1979) and Dunn and co-investigators (1981) who showed that an increase in total T concentration caused a less pronounced increase in free $T$ concentration due to the binding capacity of the plasma for this steriod. In women, no data are available concerning exercise-induced changes in free $T$. However, Kuoppasalmi (1980) found a rise in 10 male athletes after strenous running in the T/SHGB ratio and concluded that the free $T$ fraction might have increased, which is confirmed by the present investigation in women. As mentioned earlier the enhanced free fraction of $T$ will increase the MCR and interconversion of this hormone (Vermeulen and Ando, 1979). The high percentage of free $T$ may be attributed to a low plasma SHBG concentration. For the trained women the daily physical exercise with its conconitantly enhanced plasma T levels, may be attributed to a decline in SHBG concentration.

\section{- Androstenedione (A)}

The findings of the present investigation indicate that in the untrained women the plasma $\triangle 4-A$ concentration was clearly different from that in trained women. In the untrained group we measured a mean $\triangle 4-A$ concentration of 7.8 and 8.8. nmol. $1^{-1}$ in the follicular and luteal phase, respectively, whereas these values in the highly trained women were about $5.5 \mathrm{nmol}^{-1}$ in both phases. The values of the untrained subjects are slightly above the upper limit of the nomal range (see table 2.2) (Judd and Yen, 1973), 
whereas the values of the tralned group are within the nomal range. The high values in the untrained group are certainly not attributable to methodological errors since the plasma of the trained subjects was assayed in the same runs.

The findings in the present study indicate that prolonged physical exercise induced a significant increase in plisma 4 -A concentrations. The response to exercise was much less variable in the trained than in the untrained group, as judged from the significant increases in both absolute and relative values. In the trained subjects a significant increase in absolute $\Delta 4-A$ concentrations was observed at all exercilise intensities.

Data on 4-A responses to physical exercise in women are hardly available. Only Baker and co-investigators (1982) recently reported a significantly increased plasma $\Delta 4-A$ concentration after a marathon race in six women. From their graphs (no detalled information was given in their paper) we calcullated a mean increase of about $60 \%$ after the marathon as compared to the control situation. These values are comparable with our findings in the trained women. In men several authors (Brisson et al, 1981; Kuoppasalmi et a1, 1981; Pesquies et a1, 1981) have reported an increased plasma $\Delta 4-A$ concentration after physcial exercise of different duration and intensity. Brisson and this colleagues (1981) observed a slight increment in plasma 44-A concentration in 8 male basketball players after two bicycle ergometer rides of $30 \mathrm{~min}\left(70 \%\right.$ and $\left.85 \% \quad 10{ }_{2} \mathrm{max}\right)$. Kuoppasalmi and co-investigators (1981) found an almast similar increase of the plasma $\Delta 4-A$ concentration after anaerobic $(0.25-2 \mathrm{~min})$ and intense aerobic running $(15-230 \mathrm{~min})$ in well trained athletes. Our results agree we11 with these findings; the increments in plasma $\Delta 4-\mathrm{A}$ showed levelling-off at the end of the treadmill run in the trained subjects in the follicular phase.

\section{- Dehydroepiandrosterone sul fate (DHEA-S)}

In the untrained subjects, which were considerably younger than the trained ones, the DHEA-S concentration at rest (about 7.0 umo $1.1^{-1}$ ) was at the upper limit of the normal range which is reported to be 2-9 $\mu$ mol. $]^{-1}$ (Buster and Abraham, 1972; Metcalf, 1976). On the contrary, in the marathon runners the plasma DHEA-S concentration (about $2.3 \mu \mathrm{mol} .1^{-1}$ ) was measured to be at the lower limits. Although at first glance, methodological error may be considered, this has to be rejected because the plasma samples of 
the trained and untrained subjects were done in the same assay. The discrepancy nay likely be explained by the difference in age, since Drucker and David (1980) reported a clear difference between two groups of women within the third and fourth decade of their lives. The data they reported for these two groups agree rather well with our findings. They found a mean plasma DHEA-5 level of 6.6 and 4.7 umol. $1^{-1}$ for women of $21-30$ and $31-40$ years of age, respectively, whille we found about 7.5 and 2.5 umol..$^{-1}$ for the same age categories. In the highly trained rumers, but not in the untrained subjects, prolonged exercise induced a $40 \%$ increase in plasma DHEA-S concentration. During the first $45 \mathrm{~min}$, the plasma DHEA-S concentration increased linearly with exercise, whereafter a levelling-off was observed. Until now, no detailed information is available about plasma DHEA-S responses to physical exercise in women. To our knowledge, only one investigation (Baker et al, 1982) has been dealing with this subject matter in trained women. These investigators compared the DHEA-S concentration in blood as sampled within 20 min after a marathon race with that in blood samples taken in the control situation (12-24 hrs after a practice run) in 6 women. From their graphs we calculated a mean increase of about $24 \%$ which is in the same order of magnitude as the increase observed in the present investigation. After the treadmill run we found mean increments of 35 and $20 \%$ in the follicular and luteal phase, respectively. In our study no significant change in plasma DHEA-S concentration could be observed in the untrained women.

\section{- Adrenocorticotropic hormone (ACTH)}

In the present investigation we observed an exercise induced increase in plasma ACTH concentration, both in trained and untrained women. At comparable workloads and exercise times, the absolute plasma ACTH concentration was higher in the untrained than in the trained subjects; the relatiwe changes being more pronounced in the trained group. Several investigators (Frailoli et a1, 1981; Carr et a1, 1981) showed exercise-induced increnents in plasma ACTH concentrations using trained or untmained volunteers. These findings are in agreement with the results of the present investigation. However, in the afore mentioned investigations no comparisons have been made between trained and untraimed subjects regarding the response of plasma ACTH to physical exercise. This makes it difficult to 
test our finding, that exercise of the same relative intensity and duration provokes a mone pronounced increase in plasma ACTH concentration in trained women. This finding suggests an increased sensitivity of the pituitary gland or the hypothalamus to physical stress in trained subjects, but further inwestigations are required to test this hypothesis.

The relatively more pronounced exercise-induced increase in plasma ACTH concentration in trained as compared to untrained women may explain the differences in plasma concentration of adrenal sex hormones between these two groups. In addition, experiments in rats (Frenkl et al, 1975) have shown that administration of ACTH causes a more pronounced increase in plasma sex steroids in the trained as compared to the untrained animals.

5.2.1. Effect of a three month endurance training program on metabolic and homonal responses to exercise (study III)

\subsubsection{Maximal physical working capacity and metabolic responses to exercise.}

In the present investigation eight subjects from the untrained group wolunteered in an endurance training program for three months. The training was initiated directly after the first set of experiments, and continued until the subjects finished the last experiments. The endurance training program consisted of 2-3 times per meek running (interval and continuous ruming) during 25-60 min. In addition the subjects performed one training per week on the bicycle ergometer. The intensity and vol ume of the training was gradually increased till all subjects were ablle to run for 45 to 55 min continuously. It has to be mentioned that the intensity and volume of the tralning had to be very low during the first 1 to 2 months because most of the subjects experienced (minor) injuries of the lower extremities since they were unacqualinted to this type of exercise.

Maximal physical working capacity (MPWC)

The MPWC increased by about 6-8\% after the training periad. Several investigators (Astrand and Rodah1, 1977; Hollmann and Hettinger, 1981) reported greater increments (about 15\%) in MPWC after a three month training period, using different exercise protocolls. If we calculate the MPWC from the $\mathrm{V}_{2}$ max test which preceded the prollonged experiment, a $12 \%$ increa- 
se in MPWC was obtained. However, this test lasted for only 10-15 $\mathrm{min}$, whereas the prolonged experiments had a duration between 40 and $60 \mathrm{~min}$. Nevertheless, we conclude that the increase in physical performance after the three month training period is moderate.

Metabolic responses after training.

Glucose and Lactate

The blood lactate response to exercise was significantly increased after the training period despite the same relative workload. This again indicates the moderate adaptation of the subjects to the endurance training program. Whereas in the pre-training tests no difference in exercise-induced changes in blood lactate concentration could be observed between the luteal and follicular phases, a significant difference between both phases was found in the post-training tests, the luteal phase values being lower as compared to the follicular phase values. This finding is in agreement with the findings in some other studies (Jurkowski et al, 1978; Hall-Jurkowski et a1, 1981), but disagrees with the results as obtained in the present investigation (studie I and II) and other investigations (Dalsky et al, 1982; Bonen et al, in press). To our opinion the lower plasma lactate concentration in the luteal phase has to be considered as a coincidence. This idea is supported by recent findings of Kuipers (1983) who showed a variability of blood lactate concentrations of $5 \%$ during a series of 20 or more bicycle ergometer rides performed weekly in a group of male and female volunteers. The changes in blaod lactate concentration, as found in this part of our study, might be well within these limits. The blood glucose response after training was similar to the one in the pre-training situation. No clear differences between the phases could be detected.

\subsubsection{Endocrine responses to exercise after a period of endurance training}

The results of the present prospective study showed at rest decreased post-training levels of ACTH in both phases of the menstrual cycle, whereas the $E_{2}$ and $T$ concentration were lowered in the luteal phase. After the three month training period a significant increase in plasma $T$ levels was observed during exercise, whereas in this period the plasma levels of this hormone rose relatively more during exercise as compared to the pre-trai- 
ning period. The relative post-training changes of $E_{2}, P$, and PRL were not statistically different from the pre-training values.

Prospective contralled studies dealing wilth hormonal changes in women are limited. Bonen and co-investigators (1979) found in 10 young women a decrease in baseline FSH values after a training period ( 3 times/week, 30 min cycling). They could not find an exercise-induced increase in plasma $\mathbb{E}_{2}$ levels after physical conditioning. Prior and co-investigators (1981) found decreased baseline gonadotropin levels and a decreased sensitivity of the pituitary to GnRH in a pilot-study conducted in 4 young women. However, despite these lower gonadotropin levels no significant differences could be observed in $E_{2}$ and $P$ values during exercise and 90,120 and 180 minutes after the GnRH injections.

Our results probably confirm the data of Bonen and co-investigators. Although we could not find an altered $E_{2}$ and $P$ response to exercise, the $E_{2}$ levels in the post-training test conducted in the luteal phase were lower as compared to the pre-training tests. However, this finding has to be handled with care, because it is well recognized that the cyclic changes in plasma $E_{2}$ levels make comparison between two days in different menstrual cycles hazardous. We could also not confirm the results of some investigators (Brisson et al, 1981; Boyden et al, 1982) concerning the increased plasma PRL response after physical conditioning. Some possible explanations for this discrepancy will be given. Firstily, in our study the volume and intensity of the training program were rather low. Secondly our subjects responded already with an enhanced plasma PRL concentration to exercise before they were submitted to the training program. To our opinion the results of Brisson and co-investigators are at least questionable. Too much information about their subjects is lacking, i.e. no other hormonal data were presented while they also did not describe what a "sport history" means. In the present investigation we have shown that untrained women, and especially those who did not have any experience in athletic or physical activies, are able to respond to physical exercise with a pronounced increase in plasma PRL levels. Nevertheless, the elegant study of Boyden and co-investigators (1982) showed a greater PRL response to physical stress after a training period. Another striking finding in the present investigation is the significant increase of plasma $T$ concentration after the training perlod. The increase in plasma $T$ is very well explaimable by a decrea- 
sed MCR. One should know, however, that hepatic blood flow is significantiy less decreased, ewen with the same relative warkloads, after physical conditioning (Rowell et al, 1964). Therefore, it is most likely that beside a decreased MCR, an increased adrenal secretion rate is involved, which idea is supported by the relatively greater increase in plasma ACTH as compared to the pre-training period. In conclusion, the results of the present study suggests that the pituitary-adrenal axis respond to physical exercise with greater sensitivity. However, future research is required to estimate this hypothesis at its true value.

\subsection{CHANGES IN GONADOTROPIN AND ESTRADIOL SECRETION PATTERNS} (study III)

The findings in study III, which have to be considered as preliminary ones, indicate that physical exercise is able to induce marked changes in gonadotropin and $E_{2}$ secretion patterns during and after exercise. However, due to the extreme variation in secretion patterns and the relatively small number of subjects, adequate statistical analysis could not be performed. Therefore, simple analyses (multiple paired t-test) were used to evaluate possible general trends.

In general, the pulse amplitude and pulse increment of LH was enhanced after physical exercise. No changes in pulse frequency, pulse amplitude and pulse increment of FSH could be observed after exercise as compared to the pre-exercise period, whereas the pulsatile secretion pattern of $E_{2}$ almost disappeared after exercise.

The individual results showed marked differences in response pattern after physical exercise. Both an enhanced mean post-exercise LH and FSH level was observed, causing an increased or decreased LH/FSH ratio. Despite the fact that 3 is well recognized that a sampling period of 2 hours is too short to gather appropriate results about gonadotropin secretion patterns, our data agree well with those of other investigators (Backstrom et al, 1982; Dmowski et al, 1983). They found an LH and FSH pulse frequency of about 4-5 per 6 hours. We found a mean pre-exercise LH and FSH pulse frequency of 5.2 in 6 hours. The pre-exercise $E_{2}$ pulse frequency as found in the present investigation was in keeping with the results of Lenton and co-investigators (1978). During the post-exercise period the 
pulsatile $\mathbb{E}_{2}$ secretion pattern disappeared almost completely. This might be explained by the disappearance of the nomal $\mathrm{LH}$ secretion pattern during exercise, which occured in almost all subjects, although the degree of this disappearance was different from subject to subject. The depression of the LH secretion during and directly after exercise may be explained by the greatly enhanced $E_{2}$ concentration, which is thought to inhibit gonadotropin secretion at the hypothalamic pituitary level (Knobil, 1980). The different response of the plasma $L H$ and FSH levels to inhibitory factors may be explained by the much lower MCR of FSH (Trager, 1977). The inter-individual variety in gonadotropin and $E_{2}$ responses before, during and after exercise as found in the present study may be explained by differences in hypothalamic-pituitary sensitivity to changes in $E_{2}$ levels.

since $\mathbb{E}_{2}$ exerts both a negative inhibitory effect and a positive stimulatory effect on LH secretion, which is depending on the "estrogenic state" of the subject, an increase as well as a decrease of LH secretion can be expected after a rise in $E_{2}$ levels. The two hours after physical exercise we observed in three out of seven subjects an increased LH/FSH ratio, whereas in all subjects a post-exercise rebound in $L H$ levels was observed. Recently, Judd and co-investigators showed a similar effect after withdrawal of a dopamin infusion in fertile women. The LH rebound clearly exceeded the FSH rebound and was most pronounced near mid-cycle. These observations might suggest that after physical exercise the LH/FSH ratio increases. The magnitude of this increase will probably depend on the intensity and duration of the exercise (i.e the inhibitory factors) and the relation between the phase of the menstrual cycle and the moment of the exercise.

In conclusion, the present study revealed a dramatic influence of physical exercise on gonadotropin and $E_{2}$ secretion patterns. Al though due to the marked inter-individual differences no general conclusions can be drawn, it is tempting to speculate that the observed changes may be attributable to menstrual cycle disturbances if they occur too often (i.e. the training frequency is high). One of the possible mechanisms may be the enhanced LH/FSH ratio after exercise, which may stimulate ovarian steroidogenesis. If, however, the stage of follicular development is not appropriate f.e. the granulosa cell, is not able to aromatize the enhanced supply of androgens, the follicle will become more androgenic and atretic. 


\subsection{POSSIBLE MECHANISMS OF THE EXERCISE-INDUCED INCREMENTS OF PLASMA SEX HORMONES}

5.4.1 The adrenal cortex as a possible source of enhanced plasma androgen levels

In the present investigation serial blood samples were taken during exercise to measure the plasma concentrations of androgens of mixed ovarian and adrenal origin ( $T$ and $\triangle 4-A$ ), DHEA-S, which originates exclusively from the adrenal cortex and ACTH. The changes in plasma concentration, if any, of the two latter homones could provide us more insight into the involvement of the adrenal cortex in the production of androgens during exercise.

The exercise-induced increase in ACTH concentration in trained and untrained subjects indicates that the hypothalamo-pituitary system is activated in this situation. Since the DHEA-S concentration rose in accordance with the extent and intensity of the exercise in trained, but not in untrained women, the synthesis of sex steroids by the adrenal cortex might be enhanced during exercise. Observation of the pattern of the DHEA-S changes in the trained group (fig. 4.25 and 4.26 ) revealed a levelling-off after an initial linear increase. Two explanations can be given for this phenomenon:

- an increase of the MCR during the later stages of the experiment.

- a decrease in adrenal secretion rate.

Although under resting conditions, the MCR of DHEA-S is reported to be very low (Longcope et al, 1972; Poortman et al, 1973)) this does not necessarily have to be the case during exercise, because the rise in body temperature will probably enhance the dissociation rate from albumin considerably. Consequentily the MCR of DHEA-S might be increased. Since $\triangle 4-A$, but also $T$ partly arises by peripheral conversion from DHEA and DHEA-S investigation of the relative increases in plasma concentration of these hormones may provide some insight into the relations existing between these homones. Examination of the relative increments of DHEA-S, $\triangle 4-A, T$ and $P$ reveals that the pattern is dissimilar. Whereas the relative plasma $T$ values showed an almost linear increase with exercise, the percentage changes in $\triangle 4-A$ and DHEA-S concentrations showed a non-linear trend, especially the last half our of exercise. However, the $\triangle 4-A$ curve is shifted to the right 
as conpared to the DHEA-S curve. This indicates that peripheral conversion from $D H E A-S$ to $\triangle 4-A$ might be enhanced. The linear increase of the relative plasma $T$ values and the non-linear trend of the $\Delta 4-A$ changes also suggest an enhanced peripheral conversion from $\Delta 4-A$ to $T$, assuming that the hepatic clearance is equally affected (i.e. decreased) for both hormones. This hypothesis is supported by the work of Pratt and Longcope (1978), who reported an increased $P_{B}$ of $\triangle 4-A$ after $A C T H$ administration in women. Since the $P_{B}$ of $T$ is derived from conversion of this hormone to an important part, an increase in $P_{B}$ of $\triangle 4-A$ may lead to a concomitant increase in plasma $T$ levels during exercise.

A decrease of the adrenal secretion rate seems unlikely because, during exercise plasma ACTH concentrations continued to rise. A remarkable finding in the present investigation is the difference in plasma androgen content between trained and untrained subjects during exercise at comparable workloads. This suggests an enhanced pituitary-adrenal responsiveness in the trained subjects. Unlike in untrained subjects, the plasma $A C T H, \triangle 4-A$ and DHEA-S concentrations were already increased at lower workloads. This idea corroborates the data of Frenk1 and co-investigators (1975) who showed in rats a greater responsiveness of the hypothallamo-pituitary-adrenal system after physical training. In addition Chandra and co-investigators (1978b) showed higher activities of steroid synthesizing enzymes in the adrenal cortex of trained as compared to untrained rats. Both the relatively higher ACTH levels and the greater capacity of the adrenal cortex to synthesize steroid homones are responsible for the increased output of these hormones during physical exercise.

\subsubsection{Exercise induced changes in the MCR of estradial}

The fifteen volunteers who participated in study $V a$ and $V b$ were young women with apparently normal menstrual cycles and no evidence of endocrine disorders. Except for the subjects 1225 and 1226 (study $V b$ ), who used oral contraceptives, all subjects were in the follicular phase of their menstrual cycles at the time of the experiment as evidenced by BBT and plasma hormone concentrations. We confirmed that an infusion time of $120 \mathrm{~min}$ after a priming dose (one third of the total dose) is sufficient to reach a steady state for the ${ }^{3} \mathrm{H}_{2} \mathrm{E}_{2}$ concentration in blood plasma (Tait, 1963; Longcope et al, 1968; Poortman, 1974). Therefore, the mean of the two MCR 
values as determined after 120 and 135 min was used as the resting or basal value of the MCR. The mean basal value for all sujects participating in both clearance studies was found to be $1254 \mathrm{l} /$ day (range 669-1765 1/day). or $870.8 \mathrm{~m}^{\mathrm{m}} \mathrm{min}^{-1}$, which is in agreement with the data reported by other investigators (Longcope et al, 1968; Hembree et al, 1969; Longcope and Tait, 1971; Longcope and Williams, 1974; Baird and Fraser, 1974; Gurpide, 1975).

Physical exercise induced a pronounced and highly significant decrease in the MCR of $E_{2}$, especially at the highest workloads. The decrease in MCR is probably caused by a reduction in hepatic blood flow because Rowell and co-investigators (1964) demonstrated that hepatic blood flow and consequently hepatic clearance is inversely related to the physical work intensity. The diminished MCR may explain the exercise induced rise in plasma $E_{2}$ concentration as found in the present study and by other investigators (Jurkowski et al, 1978; Bonen et al, 1979; Bonen et al, 1981; Schmitt et a), 1981). However, theoretically it may be possible that other factors such as an enhanced ovarian production and/or peripheral conversion from androgens might al so play a role. The results of the present study indicate that an enhanced ovarian $E_{2}$ production is not very likely, because the plasma LH concentration decreased significantly. However, peripheral conversion from androgens might be involved. The latter is supported by the work of Pratt and Longcope (1978). They showed a considerable increase in production rate of both $\triangle 4-A$ and estrogens after $A C T H$ administration in men and women. They also measured greatly enhanced $(20-25 \%)$ contributions of these hormones to circulating estradiol.

Additional support for the idea that peripheral conversion might play a role is given by the following findings: In male runners the plasma $E_{2}$ concentration was found to increase with 30 to $80 \%$ after a marathon rum (Schmitt et al; unpublished results from our own laboratory). Since in men, plasma $E_{2}$ arises almost completely from peripheral conversion of $A$ and $T$ (for example in skeletal muscle) it is tempting to speculate that this mechanism might play an even more important role during exercise, when muscle blood flow is greatly enhanced.

The results as reported in study Vb clearly demonstrate that the MCR of $E_{2}$ is still significantly diminished at the end of the recovery period of 30 min at $25 \% \mathrm{~V}_{2}$ max. This abservation, however, has to be interpreted with 
care. Because of the often reported hemodilution after physical exercise (Astrand and Rodahi, 1977, Hollmann and Hettinger, 1981) it is possible that the steady state between infusion rate and disappearance rate of the tracer is not reached, in other words the infusion rate may be too low. This means that one of the basic presumptions for the MCR calculation (i.e. the steady-state condition) does not hold. Hemodilution may also partly explain the finding in study III that the $E_{2}$ concentration falls rapidly after the exercise-test.

In conclusion, the present clearance experiments showed that even short-term physical exercise is able to induce a marked decrease in the MCR of $E_{2}$. This observation is in keeping with the findings of study I, II and III and ather investigations showing a mean increase in plasma $E_{2}$ concentrations of about $60 \%$. However, based upon the increased plasma $\triangle 4-A$ levels and evidence from literature it may be that beside the diminished MCR, other factors are responsible for the enhanced plasma $E_{2}$ levels.

\subsection{GENERAL DISCUSSION}

In summary the findings in the present investigation demonstrate that prolonged physical exercise is able to introduce significant increments in absolute plasma $E_{2}, P, T, P R L$ and $A C T H$ levels in trained and untrained women irrespective of the phase of the menstrual cycle. In the trained runners physical exercise was also able to provoke marked increments in absolute plasma, $\triangle 4-A$ and DHEA-S levels. When the absolute values were expressed as a percentage of the baseline walue, it was shown that also in the untrained women the plasma $\Delta 4-A$ concentration was increased by exercise.

The LH levels were markedly decreased during exercise, whereas this was much less the case with FSH. In a separate study it was shown that physical exercise provokes marked changes in the past-exercise pulsatile patterns of $L H, F S H$ and $E_{2}$ as compared to the pre-exercise period. However, wide interindividual variations in this clearance pattern was observed.

With respect to the present investigation two questions have still to be answered: 
- what causes the exercise-induced changes in plasma-homone concentration. - which factors might be responsible for the reported increase in menstrual cycle disturbances in women athletes.

Factors causing exercise-induced changes in plasma hormone levels.

An increase in plasma sex homone levels might be caused by an enhanced glandular secretion rate, a decreased MCR and enhanced peripheral conwersion rate from pre-hormones. From our results it is likely that the secretion rate of the ovary is not affected by exercise. This is deduced from the decreased plasma L.H levels. However, it is well recognized that a definite prove for this statement is lacking, because we are not informed of the sensitivity of the theca and granulosa cells for circulating LH under these circumstances. Based upon the investigations of Rowell and co-investigators (1964), however, we assume that the blood flow through this region is greatly reduced.

In study $V$ we were able to show a pronounced decrease of the MCR of $E_{2}$ during submaximal and maximal bicyle ergometer work. These results strongly suggest that a decreased MCR also plays a doninant role in the increase of $\triangle 4-A, P$ and $T$, because these steroids are cleared in splanchnic tissue to a large extent. For DHEA-S this mechanism is less likely, due to its tight binding to plasma albumin, which causes a very slow turn-over rate. Based upon the increase in plasma DHEA-S and ACTH levels during exercise in the trained runners we assume that the adrenal cortex is involved in the production of androgens during exercise. This increases the pool of precursor homones for conversion to $T$ and $E_{2}$ (Pratt and Longcope, 1978). We assume that the exercising skeletal muscles are heavily involved in this process. This assumption is based upon the observations that the blood flow through this tissue increases 10-20 fold during exercise as compared to the situation at rest. However, this hypothesis has to be proved in future investigations. The exercise-induced increments in plasma PRL levels are partly explained by the enhanced $E_{2}$ levels, which have been shown to sensitize the pituitary to prolactin releasing factors (Williams, 1981). 
Possible factors responsible for exercise-induced menstrual cycle disturbances.

Menstrual cycle disturbances may originate at various levels. In the first place the disturbance may originate at a level above the hypothalamo-pituitary system. This is clearly substantiated in an investigation of Fries and colleagues (1974) who showed that pronounced psychollogical stress was more frequent in women with secondary amenorrhea than in their agematched controls. It is without doubt that competitive running can be considered to be stressfull. Whether a laboratory experiment provokes the same feelings is not easy to prove. In the present investigation the plasma ACTH and PRL levels at rest were not elevated (except for one case). Hence it is unlikely that this mechanism piays a role in the observed exerciseinduced decrements of plasma LH.

The second level at which the menstrual cycle disturbances may occur is the hypothalamo-pituitary axis. We have witnessed a marked decrease in plasma LH levels during exercise, which might be caused by an enhanced level of endogenous opiates (Carr et a1, 1981), $E_{2}$ and PRL. Endogenous opiates diminish the $\mathbb{L H}$ pulsatile secretion from the pituitary (Ropert et al, 1980; Mcarthur et al, 1980; Blankstein et al, 1981; Grosman et al, 1982). These authors also showed that the LH response to naloxone is mediated by the serum $E_{2}$ levels, the greater response being reached at higher $E_{2}$ levels.

Excessive PRL does alter the menstrual cycle probably by suppressing GnRH secretion (Mcneilly, 1980). The PRL secretion during exercise is most likely to be modulated by an increase in plasma $E_{2}$ and TRH levels as suggested by the increase in TSH levels (Galbo et al, 1977). Another possibility of suppression of pituitary gonadotropin secretion is suggested by Kalkami and co-investigators (1977) who showed in ovariectomized rats a significant suppressed FSH response to GnRH-stimulation after $T$ administration. The greatly enhanced plasma $T$ levels as found in the present investiglation are likely to induce the same phenomenon. This is suggested by the increased LH/FSH ratio after exercise in 4 out of 7 subjects participating in study III.

The third level at which menstrual cycle disturbances may originate is the ovary. McNatty (1974) suggested that plasma PRL levels above 0.6 IU. $1^{-1}$ should be responsible for disturbances in follicular maturation. In the 
present investigation have shown that physical exercise is able to provoke increments in plasma PRL levels both in trained and untrained women. These sometimes exceeded the critical levels indicated by McNatty by a factor 2 or 3 . The menstrual cycle disturbances in women athletes as described in literature (Baker et al, 1981) are likely to be caused by a complex mechanism acting on the hypothalamo-pituitary axis. It will probably depend on the pre-training endocrine status of the individual whether she will experience menstrual cycle disturbances. Fron our results it becomes apparant that the exercise-induced changes in endocrine rilitieu will wane for several hours after the exercise before returning to normal. If the exercise frequency and/or duration is too high or too long, a nomal follicular development is hampered. Therefore it is tempting to speculate that especially the post-exercise period is very important to study in future research. 
CHAPTER V1

6.I SUMMARY AND CONCLUSIONS.

The homonal response to standardized physical exercise in trained and untratned women in relation to the follicular and/or luteal phases of their menstrual cycle was the subject of the present investigation. The aim of the study was:

- to evaluate the influence of the phase of the menstrual cycle on maximal physical working capacity (MPWC) and related physiological parameters.

- to collect detalled information about the plasma sex hormone and gonadotropin responses in highly, moderately and untrained women in order to provide some insight into the passible cause of the often described menstrual cycle disturbances in women athletes.

- to differentiate between changes in degradation rate (measured as the metabolic clearance rate) and an enhanced ovarian secretion rate as a passible cause of the exercise-induced increments in sex homone levels.

The first two objectives were hoped to be solved by serial measurements of plasma hornomes of ovarian, mixed ovarian and adrenal, and adrenal origin during exercise. The related gonadotropins, adrenocorticotropic homone (ACTH) and prolactin (PRL) were al so measured.

The thind objective was hoped to be solved by measurement of the MCR of $E_{2}$ during exercise.

In chapter I, a brief review is given of recent investigations concerning exercise-induced changes in plasma hormone concentrations in women.

In chapter II, the literature about hormonal events, which take place during the nomal menstrual cycle is reviewed. This chapter is included to provide the reader with some information about the complex relationship between phase of the menstrual cycle, follicular maturation, sex hormone synthesis as well as blood production and degradation of these hormones. Al so included in this chapter is a short review of the literature about adrenal steroidogenesis, especially the androgens, in women.

In chapter III the experimental set-up and the purposes of the different studies are described. Fourty seven healthy women, with normal menstrual cycles, walunteered in 5 separate studies $(I-V)$. The effects of the 
phase of the menstrual cycle on MPHC and homonal responses to exercise were imwestigated in study I-III. In study I a group of 13 untrained women volunteered. The exercise test consisted of an increnental bicycle ergometer ride $160 \% 102_{2}$ max for $15 \mathrm{~min}$, followed by an increase of $10 \% \mathrm{TO}_{2}$ max each 15 min until the subject had to give up). In study II 6 highly trained marathon runners volunteered. The exercise test consisted of a treadmill run for $75 \mathrm{~min}$ (60\% $70_{2} \max$ for $15 \mathrm{~min}$, followed by 60 min at $85 \% 60_{2}$ max). In study III 8 previously untrained women were retested after a three nonth endurance training program.

In these three studies each subject performed twice in the menstrual cycle; once in the follicular and once in the luteal phase. Each exercise bout started between 8.30 and $9.30 \mathrm{a.m}$., and was preceded by a $30 \mathrm{~min}$ period of rest. Blood sampling accured every $15 \mathrm{mim}$, through an indwelling venous catheter. The first two samples were obtained $15 \mathrm{~min}$ (15 min after the insertion of the catheter) and just before the start of the exercise. In each blood sample plasma glucose and lactate were measured to evaluate the metabolic responses to exercise in relation to the phase of the menstrual cycle. Additionally, estradiol-17B $\left(E_{2}\right)$, progesterane $(P)$, testosterone $(T)$, androstenedione $(\triangle 4-A)$, dehydroepiandrosterone sul fate (DHEA-S), Iuteinizing hormone (LH), follicle stimulating homone (FSH), prolactin (PRL) and andrenocorticotropic hormone (ACTH) were measured in each plasma sample by radio-immuno-assy (RIA), whereas the free $E_{2}$ and $T$ fractions before and after exercise were determined using a centrifugal ultrafiltration technique.

A11 data were presented as absolute and relative values (hormonal concentration values only) versus time or workload. Glucose, lactate and all homonal data, including the percentual changes, were anallyzed wth a two-way ANOVA (exercise versus phase). Intergroup comparisons (study I versus II; study III: the pre-versus post-training values) were conducted with al multi-way ANOVA. Differences in MPUC between the follicular and Tuteal phases of the menstrual cycle and the pre-and post-exercise values of the free steroid fraction were evaluated for statistical significance with a multiple paired T-test.

The results of these three studies showed: 
- no influence of the phase of the menstrual cycle on MPWC.

- no clear influence of the phase of the menstrual cycle on blood lactate and glucose response to exercise.

- a pronounced difference in blood glucose response to exercise between the highly trained marathon runners and the untrained women (study I and II). At all workloads the blood glucose concentration was more elevated in the highly trained group as compared to the untrained group.

- a pronounced exercise-induced increase in absolute plasma E2, P, PRL and ACTH concentration in the follicular and luteal phases of the menstrual cycle in all groups. The relative increments in plasma PRL and ACTH were more pronounced in the highly trained subjects as compared to the untrained subjects (study I and II). In the untrained subjects the workload had to exceed $70 \% \mathrm{VO}_{2}$ max to provoke increments in plasma PRL and ACTH concentrations, whereas in the trained subjects also the lowest workloads were able to produce such changes.

- an exercise induced increase in plasma $T, \triangle 4-A$ and DHEA-S concentration in the highlly trained runners (study II). These changes even occurred at the lowest workloads.

- an exercise-induced increase in relative plasma $T$ and $\Delta 4-A$, but not in DHEA-S concentration, in the untrained group (study I).

- a lower absolute plasma $T, \triangle 4-A$ and DHEA-S concentration at rest in the highly trained versus untrained or moderately trained women. The relative increments in plasma $T$ and $\triangle 4-A$ concentration, however, were more pronounced in the marathon runners as compared to the untrained women.

- a pronounced decrease in relative plasma LH concentration in the untrained (study I) and highly trained (study II) subjects. The relative FSH concentration decreased only in the untrained group.

- an exercise-induced increase in the free $T$ fraction in both the untrained and highly trained group. The free $E_{2}$ fraction after exercise was slightly decreased (untrained women, study I) or did not differ significantly (study (I) from the pre-exercise values. The mean free $E_{2}$ fraction at rest was lower in the trained than in the untrained group.

- a significantly lower absolute plasma ACTH concentration at rest after a three months training period. However, the relative increments during exercise were statistically not different between the pre- and post-training tests (study III). 
- physical exercise provoked a significant increase in plasna $T$ concentrations after a three month training program, whereas the plasma concentrations of this homone were not statistically significant increased in the untrained situation.

In study IV the gonadotropin and $\mathrm{E}_{2}$ secretion patterns in the two hours after exercise were compared with those in the two hours before exercise in 7 women in the follicular phase of their menstrual cycle. The exercise protocol, was identical to that of study $\mathbb{1}$ and $11 \mathrm{I}$. Blood sampling occured every $15 \mathrm{~min}$ during the whole period.

Although the responses were strikingly different between the individuals, the results showed a marked influence of physical exercise on the secretion pattern of $L H, F S H$ and $E_{2}$. For the whole group a significant post-exercise increase in mean LH levels could be observed which was accompanied by a concomittant rise in pulse frequency, pulse amplitude and pulse increment. In 4 subjects the LH/FSH ratio was increased after exercise, whereas it was decreased in one subject. In the other two subjects this ratio was about the same in the post-exercise period as compared to the pre-exercise periad.

The influence of short-term submaximal and maxima? bicyle ergoneter work on the metabolic clearance rate (MCR) of $E_{2}$ was evaluated in study Va and $\mathrm{Vb}$. For this purpose 15 young wonen volunteered in the follicular phase of their menstrual cycle. In study $V a$ the influence of submaximal and naximal $170 \% \mathrm{~V}_{2}$ max for 10 min followed by $100 \% 0_{2}$ max till the subject was exerted) bicycle ergometer work an the MCR of $E_{2}$ was investigated in 9 physical education students. In study $\mathrm{Vb}$ the influence of a $10 \mathrm{~min} 70 \%$ Vo ${ }_{2}$ max load, followed by a $30 \mathrm{~min} 25 \% \mathrm{~V}_{2}$ max load an the MCR of $E_{2}$ was evaluated in 6 womem with different levels of physical fitness.

The results showed an exercise-induced pronounced decrease (up to 80\%) in MCR of $E_{2}$, which was inversely related to the workload. At the end of the recovery period (study $V b$ ) the MCR of $E_{2}$ was still well bellow the base-line values.

The findings of the present investigation indicate that physical exercise is able to induce marked elevations in plasma $E_{2}, P, \triangle 4-A$ and $T$ levels. These elevations may be attributed to a decrease in MCR. Since the plasma LH concentrations decreased with exercise, an enhanced ovarian secretion rate is not likely to contribute to the increments in plasma sex 
homones. However, an enhanced adrenal secretion rate is most likely to be involved, especially in the highly trained subjects, since the plasma DHEA-S concentration rose in accordance with exercise.

The results of the present investigation also showed that physical exercise is able to induce marked elevations of plasma PRL levels in trained and untrained women, although the relative increments were greater in the former group. The dysregulation of the nomal pulsatile secretion pattern of the gonadotropins as shown in study IV of the present investigation may ariginate from the enhanced $P R L, E_{2}$, and/or $T$ (especially free T) levels, which may inhibit gonadotropin releasing hormone (GnRH) (by means of PRL) and/or ganadotropin (by means of $E_{2}$ and T) secretion patterns.

\subsection{SAMENYATTING EN CONCLUSIES}

Het is de vrouw silechts sinds enige jaren toegestaan on deel te nemen aan zulke zware sportieve belastingen als marathon lopen en lange afstand ski-loop wedstrijden. Tot die tijd werd (voornamelijk door de mam) gedacht, dat zulke belastingen schadelijk zouden zijn voor het vrouwelijk organisme, alhoewel bewijzen voor dit idee ontbraken. Ten gevolge van deze voaroordelen ontbraken tot voor kort gegevens over de specifiek vrouwelijke (hormonale) reacties op fysieke belasting.

De huidige toename in trainingsarbeid en intensiteit van de sportende vrouw veroorzaakte echter een nieuwe, meer wetenschappelijke, belangstelling voor de hormonale veranderingen welke optreden tijdens lichamelijke inspanning. Deze belangstelling werd mede gewekt door de grotere incidentie van stoornissen in de menstruele cyclus bij sportvrouwen vergeleken met niet aan sport deelnemiende vrouwen. Tevens kreeg de vraag of de fase van de cyclus van invloed is op het prestatievermogen hernieuwde aandacht.

Door het nog geringe aantal onderzoekingen op dit gebied en de ingewikkelde regelsystemen waaraan de menstruele cyclus onderworpen is, bleek het niet goed mogelijk te zijn een goede hypothese voor de oarzaak van de cyclusstoornissen op te stellen.

Het huidige onderzoek wil dan ook een bijdrage leveren aan een verbetering van onze inzichten in de homonale veranderingen bij de vroliw tijdens fysieke inspanning in de follicuiatre en luteale fase van de menstruele 
cyclus. Hierbij werd getracht een antwoord te vinden op de volgende vragen:

- Wat is de invioed van de fase van de menstruele cyclus op het fysieke prestatievemogen;

- Welke mechanismen zijn verantwoordelijk voor de in de literatuur gemelde veranderingen in geslachtshornoonconcentraties tijdens fysieke inspanning.

Aangezien zware lichamelijke inspanning tevens invloed heeft op de periode erna, werd de additionele vraag gesteld of fysieke inspanning een effect heeft op hormoonconcentraties, met name de gonadotropinen (LH en FSH) en oestradiol $\left(E_{2}\right)$, in de twee uur na beeindiging van de arbeid.

Om deze vragen te kunnen beantwoorden werd een groep van 47 vrouwelijke proefpersonen, met een varierende mate van getraindheid, aan een of meerdere inspanningsproeven onderworpen. De vrijwilligsters participeerden in vijf verschillende series experimenten.

De invloed van de fase van de menstruele cyclus op het maximale fysieke prestatievermogen en de hormonale veranderingen $t . g . v$. fysieke inspanning werd onderzocht in de experimenten I-III. In experinent IV werd de invloed van fysieke belasting op het secretiepatroon van $L H, F S H$ en $E_{2}$ gedurende de twee uur volgend op de inspanning vergeleken met het patroon gedurende twee uur voorafgaand aan de belasting.

In experiment $V$ werd de afbraksnelheid van $E_{2}$, uitgedrukt als de metabole klaringssnelheid (metabolic clearance rate $=$ MCR) gemeten tijdens inspanning.

Teneinde de lezer enig inzicht te werschaffen in de processen welke ten grandslag liggen aan de cyclische variaties in plasma geslachtshormoonconcentraties gedurende de menstruele cyclus wordt hiervan een beschrijving gegeven in hoofdstuk 2. Speciale aandacht wordt besteed aan de normale follikel rijping en de daarbij plaats vindende veranderingen in hormoonsecretie, terwijl vervolgens wordt ingegaan op het belang van het pulsatiele secretiepatroon van de gonadotropinen. Tevens wordt in dit hoofdstuk aan dacht besteed aan de afbraaksnelheid, conversie en transport van de verschillende geslachtshormonen. Aangezien de bijnier bij de vrouw een belangrijke bijdrage levert aan de plasma androgenenspiegel werd hieraan tenslotte een korte beschrijving gewijd. Dit werd mede gedaan in verband met de cyclusstoornissen ten gevolge van hyperprolactinemie, al of niet gepaard gaande met een verhoogde dehydroepiandrosteronsulfaat (DHEA-S) spiegel. 
Naar aanlefing van de in dit hoofistuk beschreven complexe interacties tussen de verschlllende geslachtshomonen van ovariele en adrenale corsprong alsmede de regulatie van hun synthese door middel van de trope homonen, werd het moodzakelijk geacht de volgende homonen woor en tijdens inspanning in thet plasma te bepalen: cestradial $\left(E_{2}\right)$, progesteron $(P)$, luteiniseringshormoon (LH), follikel stimulerend hormoon (FSH), testosteron (T), androstendion $(\triangle 4-A)$, dehydroepiandrasteronsulfaat (DHEA-S), prolactine (PRL) en adrenocorticotroop hormoon (ACTH).

In hoofdstuk III wordt de samenstelling van de groepen van proefpersomen, de gebruikte methodes en de statistische analyse nader witteen gezet.

In onderzoek I participeerden 19 vrijwilligers, warvan er 6 afvielen om witeenlopende redenen. De bellasting bestond wit een opklimende fietsergometertest ( $60 \% \mathrm{VO}_{2}$ max gedurende $15 \mathrm{~min}$, warna de belasting iedere 15 min werd verhoogd met $10 \% \mathrm{VO}_{2}$ max totdat de proefpersoon moest opgeven).

In onderzoek II participeerden 6 zeer goed getrainde marathonloopsters. De belasting bestand uit een tredmolentest $\left(60 \% \mathrm{v}_{2}\right.$ max, gedurende 15 min, gevolgd door $60 \mathrm{mim}$ met een belasting wan $\pm 85 \% \mathrm{vo}_{2}$ max). De hellingshoek werd op $0^{\circ}$ gehouden.

In onderzoek III werden 8 aanvankelijk ongetrainde wrowwen voor en na de periode van drie maanden duurtraining (3-4 keer per week) belast waarbij gebruik gemaakt werd van hetzelfde protocol als in studie $I$.

Alle proefpersonen welke in deze drie studies participeerden, ondergingen dezelfide belastingstest in de folliculaire en luteale fase van hun menstruelle cyclus, respectievelijk 7-10 en 20-26 dagen na de eerste dag van de menstruatie. Elk experiment wand "s achtends plaats tussen 8.30 en 9.30 uur. De inspanningsproeven werden vooraf gegaan door een rustperiode van 30 min. Bloed werd afgenomen 15 min voor de inspanning en vervolgens elke 15 min (aan het einde van elke belastingsstap).

In het bloedplasma werden het glucose en melkzuur gehalte bepald, alsmede de calculatie van $E_{2}, P, T, \triangle 4-A$, DHEA-S, LH, FSH, PRL en ACTH. Voorts werden de percentages $u r i j E_{2}$ en $T$ voor de inspanning vergeleken met die erna. Alle inspanningshomoonwaarden werden gecorrigeerd voor henoconcentratie door middel wan de totaal-eiwit methode. De hormoonwaarden werden weergegeven als absolute en relatieve (procentuele) waarden alls functie van tijd en/of belastingsintensiteit. 
Veranderingen in relatieve en absolute plasma concentraties vam glucow se, melkzuur en de verschillende homonen tijdens inspanning, verschlllen in reacties tussen de fasen van de menstruele cyclus, alsmede verschillen tussen de groepen werden getoetst op statistische significantie door middel van een tweeweg variatie analyse voor vergelijking tussen groepen. De verschillen in fysiek prestatievermogen, uitgedrukt in watts, tussen de fasen van de menstruele cyclus en de veranderingen in vioj $E_{2}$ en $T$ werden getoetst met een multipel-gepaarde T-test.

De belangrijkste resultaten van deze onderzoeken kunnen als volgt samengevat worden:

- er was geen aantoonbaar verschil in fysiek prestatievernogen tussen de folliculaire en luteale fase. Tevens was de plasma melkzur en glucose reactie niet duidelijk verschillend tussen deze twee fasen in de menstruele cyclus.

- de relatieve plasma LH concentraties daalden in alle gevalien tijdens Inspanning, terwijl de relative FSH concentratie daalde (onderzoek 1 . ongetrainden)) of onveranderd bleef (anderzoek 11, getrainden).

- de absolute plasma concentraties van $E_{2}, P$, PRL en ACTH stegen significant tijdens inspanning. Terwijl de relatieve veranderingen in $E_{2}$ en $P$ concentraties tijdens inspanning niet aantoonbaar verschilden tussen de ongetrainde (onderzoek I) en zeer goed getrainde (onderzoek II) groep, bleken de relatieve PRL en ACTH concentraties in de laatste groep meer toe te nemen. Bij de angetrainden was de toename in plasma PRL en ACTH concentratie slecht significant alls de arbeidsintensiteit bovem de $70 \%$ v02max kwam.

- de absolute $T, \Delta 4-A$ en DHEA-S concentratie namen tijidens inspanning alleen toe bij de zeer goed getrainden. Indiem de plasmaconcentraties uitgedrukt werden als relatieve veranderingen, bleken de $T$ en $\Delta 4-A$ concentraties ook in de ongetrainden toe te nemen. Deze toename was reeds sigmificant bij een arbeidsintensiteit van $60 \% \mathrm{NO}_{2}$ max.

- de absolute plasma $T, \triangle 4-A$ en DHEA-S concentraties in rust waren in de ongetrainde groep hager dan in de zeer goed getrainde groep.

- het vrije percentage $T$ was zowel in de getrainde als in de ongetrainde groep gestegen na inspanning, de wrije $\mathbb{E}_{2}$ concentratie bleef onweranderd (onderzoek I en II) na inspanning.

- na een relatief korte trainingsperiode (onderzoek III) kon een signifi- 
cante stijging van de plasma $T$ concentraties tijdens inspanning geconstateerd worden, terwijl de rustwaarden niet verschilden (folliculaire fase) of na training waren gedaald (1uteale fase). De absolute ACTH spiegels in rust en tijdens inspanning waren gedald na de trainingsperiade.

In onderzoek $I V$ werd het secretiepatroon van $L H, F S H$ en $E_{2}$ in de twee wur na fysieke ïnspanning vergeleken met dat in de twee uur ervoor in 7 ongetrainde vrouwen in de folliculalre fase van hun menstruele cyclus. Het belastingsprotocol was identiek aan dat van onderzoek I.

De resultaten van dit onderzoek, dat opgevat moet worden als een pilotstudie, leverden een zeer gevarieerd beeld op hetgeen de statistische analyse bemoellijkte. Nochthans bleek dat wooral het LH secretiepatroon na inspanning duidelijk veranderd was; de gemiddelde LH concentratie was in deze periode verhoogd vergeleken met de periode voor inspanning. De $L H$ pulsen waren na inspaming eveneens verhoogd. Dit had tot gevolg dat de LH/FSH ratio bij 4 proefpersonen in de gehele periode na de inspanning verhoogd was ten opzichte van de twee uur erwoor. Bij de andere proefpersonen trad een daling op $(1 x)$ ofwel bleven de verhoudingen gelijk.

In onderzoek $V$ werd de MCR van $E_{2}$ bepaald teneinde een inzicht te krijgen in een van de mogel $\uparrow j k e$ oorzaken van de door inspanning geinduceerde stijging in steroid hormoon concentaties. Hiertoe werden 15 vrijwilligsters onderzocht in de folliculaüre fase van hun menstruele cyclus. Gebruik werd gemaakt wan de continue infusie-techniek, waarbij het radioactieve isotoop $\left({ }^{3}-E_{2}\right)$ werd geinfundeerd met behulp van een infusiepomp. De resultaten toonden een daling van de MCR tijdens inspanning, de mate hiervan was ungekeerd evenredig met de intensiteit van de arbeid.

Samenvattend kan geste1d worden, dat de stijging in steroid hormoon concentraties tijdens inspanning in de eerste plaats toegeschreven moet worden aan een daling van de MCR. Al hoewel een toename van ovartele secretie theoretisch tot de mogelijkheden behoort lijkt dit onaannemelijk gezien de daling van de plasma LH concentratie.

Gezien de significante stijging van de plasma DHEA-S concentratie in de zeer goed getrainde groep wordt een toegenomen androgenen secretie van de bijnierschors aannemelijk geacht.

Het gestoorde secretfepatroon van LH en FSH vindt mogelijk zijn oorzaak 
in reming van de hypothalaam-hypofysaire as door PRL, $E_{2}$ en mogelijk T. De abservatie dat in getrainden bij eenzelfde relatieve belastingsintensiteit een relatief grotere toename van PRL en ACTH in plasma wordt gevonden dan in ongetrainden leidt tot de hypothese dat de hypofyse gevoeliger reageert op fysieke stress. Of dit echter zal leiden tot stoornissen in de menstruele cyclus, zal waarschijnlijke mede afhankelijk zijn wan het intrinsieke reactiepatroon van de wrouw in kwestie, daar in dit onderzoek is aangetoond dat in een aantal ongetrainde vrouwen de plasma PRL. en androgenen spiegels wrijwel even sterk stegen als in de getrainde groep. 


\section{RERERECIS}

Abreham, G.E.

Ovarian and adrenal contribution to peripheral androgens during the rienstrual cycle.

J. C11n. Endocrinol. Hetab. 39:340-346, 1974.

Abraham, G.E. and Z.H. Chamakjlan.

Serun sterold levels during the menstrul cycle in a bilaterally adrenalectonized wonen *

J. Clin. Endocrinol. Metab. 37: 582-587, 1973.

Aedo, A. -R. Pedersen, P.H., Pederson, S.C., and E. Diczfalusy. Ovarian sterold secretion in normally menstruating women $I$. The contribution of the deweloping follicle.

Acta Endacrinol. 95: 212-221, 1980.

Aedo, A. -R., Pedersen, P. H*, Pedersen, E. and E. Diczfalusy.

Ovarlan sterold secretion in normally menstruating women II. The

contribution of the corpus luteum.

Acta Badocrino1. 95: 222-231, 1980.

Ahlborg, G. and P. Felig.

Substrate utilization during prolonged exercise preceded by ingestion of glucose.

An. J. Phystoll. 233, E18:8-E194, 1977.

Apter, D., Vinikka, L. and R. Vhiko.

Hormonal patterns of adolescent menstrual cycles.

J. Clin. Endocrinol. Metab. 47: 944-954, 1978.

Auletta, F.

How does the demise of the corpus luteum affect reproduction?

Contemp. Ob/Gyn. 17: 153-166, 1981 .

Astrand, P. -0 . and $\mathbb{K}$. Rodahl.

Textbook of workphyslology.

McGraw-Hill, New York, 1977.

Backstrom, C.T., McNe111y, A.S., Leask, R.M. and D.T. Baird.

Pulsatile secretion of LH, FSH, prolactin, oestradiol and and progesterone durling the human menstrual cycle.

Ciln. Endocrinol. 17: 29-42, 1982.

Batrd, D.T., Uno, A. and J.C. Melby.

Adrenal sectetion of androgens and estrogeiss.

J. Endocrinol. 45: 135-141, 1969.

Baird, D.T. and I.S. Fraser.

Concentration of oestrone and oestradiol at follicular flutd and ovartan venous blood in women.

Clin. Endocrino1. 4: 259-266, 1975. 
Baird, D.T., Baker, T. G, Mckatty, R.P. and P. Heal.

Relationship between the secretion of the corpus lutew and the length of the follicular phase of the ovarian cycle.

J. Reprod. Fert. 45: $511-619,1975$.

Baker, E.R., Mathur, R.S., Kirk, R.F. and H.O. Williamson.

Fenale runers and secondary amenorrhea: correlation th age, parity, milleage, and plasma hormonal and sex-hormone-binding globulin

concentrations.

Feril. Steril. 36: 183-187, 1981.

Baker, E.R., Mathur, R.S*, Kirk, P.F., Landgrebe, S.C., Moody, L. O. and H. O. Williamson.

Plasma gonadotropins, prolactin, and steroid hormone concentrations in

female runners immediately after a long-distance run.

Fert. Ster. 38: 38-41, 1982 .

Bardin, C.W. and M.B. Lipsett.

Testosterone and androstenedione blood production rates in normal momen and women with ldjopathic hirsutism or polycystic ovaries.

J. Clin. Invest . 46: 891-902, 1967 .

Berg, A. and J. Keul.

Physiological and metabolic responses of female athletes during laboratory and field exercise.

In: Women and sport. Series on Med. Sport. 14: 125-140, Karger, Basel,

1981.

Binkhorst, R. A. and R. van Leeuwen.

A rapid method for the deternination of aeroblc capacity.

Int. Z. angew. Physiol. elnschl. Arbeldsphysiol. 19:459-467, 1963.

Bird, C.E., Murphy, J., Boriomand, K, Finnls, W., Dressel, D. and A.t. Clark.

Dehydroepiandrosterone: Kinetics of metabolism in normal men and women.

J. Clin. Endocrinol. Metab. 47: 818-823, 1978.

Bonen, A., Haynes, F.J., Watson-Wright, W. Sopper, M.M*, Pierce, G. N*, Low, F.W and T.E. Graham.

Effects of the menstrual cycle on metabolic responses to exercise.

J. App1. Physiol.: Resp. Enwiron. Exercise Physlo1. (In press).

Bonen, A*, Belcastro, A.N., Ling, W.Y. and A.A. Simpson.

Profiles of selected hormones during menstruml cycles of teenage athletes.

J. App1. Physiol.: Resplrat. Environ. Exere1se Physiol. 50: 545-551, 1981.

Boyden, T.W., Pamenter, R.W, Stanforth, P., Rotkis, T. and J.H. Wilmore. Evidence for alld thyroidal fmpatrment in women undergoing endurance training. J. Clin. Endocrinol. Metab. 53: 53-56, 1982 . 
Brisgon, G, Re, De Carufel, D., Brault, J., Volle, M.A., Awdet, A., Desharnals, Mand $C$. Lefrancois.

Chrculating 4 -androgen levels and blcycle exercise in trained young men. BLoch. Texere. IWb. Ed. J. Poortmang, G. Misset. Univ. Park Press, Baltare, 1981 .

Brisson, G.R.; Volle, M.A., Decareful, D., Desharnals, M. and M. Tanaka . Exercise-indweed dissociation of the blood prolactin response in young women according to thelr sportg habits. Horm. Metab. Res 12: 201-205, 1980.

Brown, Jab.

Chemical method for determination of oestriol, aestrone and oestradiol in hunan urtin.

Hochemistry $60: 185-193,1955$.

Bush, I.E.

Chromatography of steroitds.

Pergamon, New York, 1961.

Cargllle, C.M., Ross, G.T. and T. Yoshimi.

Dafly varlations in plasma follicle stimulating hormone, lutelnizing

hormone and progesterone in the normal menstrual cycle

J. C1In. Endocrtnol. Metab. 29: 12-19, 1969.

Car11, G., Martine111. A., Balid, L., Bonlfazi, M. and C. Lupo di Prlsco. The effect of swiming tralning on homone levels in girls.

J. Sportis Med. 23: 45-50, 1983.

Caron, M.G., Goldsteln, S., Savard, K. and J.M. Marsh.

Proteln kinase stimulation of a reconstituted cholesterol side chain cleavage enzyme system in the bovine corpus luteum.

J. B10.1. Chetn. 250: 5137-5140, 1975.

Carr, D.B., Bullen, B.A., Skrimar, G.A., Arnold, M.A., Rosenblatt, M*, Beitins, I.Z., MartIm, J*B. and J.W. Mcarthur.

Physical conditioning factiltates the exercise-Induced secretion of beta-endorphtn and beta-1ipotropln in women.

N. Engl. J. Med. 305: 560-563, 1981.

Carr, B.R., MacDonald, P.C. and E.R. Slmpson.

The role of 11 poproteins in the regulation of progesterone secretion by the human corpus luteum.

Fert. Ster11. 38:303-311, 1982 .

Cattaneo, S., Forti, G., Fioreli1, G., Barbleri, U. and M. Serio. A rapld radioumunoassay for determination of dehydroeplandrosterone sulfate in human plasma.

Clin. Endocrinol. 4: 505-510, 1975.

Chalny, G. B., and M.S. Kanungo.

Effects of estradiol and testosterone on the activity of pyruvate kinase of the cardiac and skeletal muscle as a function of age and sex.

Bloch. B1ophys. Acta 540: 65-72, 1979. 
Chandra, A.M., Patra, P.B., Chatterjee, P. and C. Deb.

Adrenocortical activity in female rats following long-term exposure to

treadinill rumning.

Endokrinologie $72: 239-242,1978$.

Chandra, A.M., Patra, P.B., Chatterjee, P. and C. Deb.

Effect of long-term treadmill running on gonadal activity in female rats.

Endokrinologie 72: 299-303, 1978.

Channing, C.P.

Steriodgenesis and morphology of human ovarian cell types in tissue

culture.

J. Endoctinol. 45:297-308, 1969.

Channing, C.P. and A. Tsafriri.

Mechanisms of luteinlzing hormone and follicle stimulating hormone on the ovary in vitro.

Metabol. 26: 413-468, 1977 .

Collins, D.C., Robinson, H.D., Howard, C.M. and J.R.R. Preedy.

Metabolism of arterial plasma estrogens by the splanchnic organs of the dog in vivo.

J. Clin. Invest. 49: 2324-2335, 1970 .

Cost111, D.L., Coyle, E., Dalsy, G., Evans, W., Fink, W. and D. Hoopes. Effects of elevated plasma FFA and insulin on muscle glycogen usage during exercise.

J. App 1. Physiol. 43: 695-699, 1977.

Cuming, D.E., Strich, G., Brunsting, L., Greenberg, L., Rles, A.L., Yen, S.S.C. and R. Webar.

Acute exercise-related endocrine changes in women runners and non-rumners. Fert. Ster11. 36: 421-425, 1981 .

Dale, E., Gerlach, D. H. and A.ll. Wilhite.

Menstrual dysfunction in distance runners.

obstet. Gynecol. 54: 47-53, 1979.

Dalsky, G.

Effect of progesterone level on substrate utillzation during endurance runnting.

Ph. D. dissertation, Brigham University, Provo, Utah, 1982.

David, R. and W.D. Drucker.

Plasma DHEA-S in hypathalamic pitultary dysfunction.

Adrenal Androgens. Symp. Sienna 7-9th October, 1979.

Delforge, J.P., Thomas, K.T., Roux, F., Carnelro de Sequira, J. and J. Ferin.

Time relationships between gramulosa cell growth and luteinization, and plasma lutelnizating homone discharge in human.

Fert. Steril. 23: 1-11, 1972. 
DI Zerega, G. S., Woxol.c, H.Z. and G. D. Hodgen.

Intercycle gerum folldcle-stimilating hormone elevations: significance in rectultrent and election of the dominant follicle and assessment of corpus 1ute un norkalcy.

J. C1.1n. End. Metab. $50(6): 1046-1049,1980$.

Dhowekl, W. F., Headley, S. and E. Radnanska "

Effects of danazol on puldatile gonadotropin patterns and on serum entradiol levels in mormilly cycling women.

Fert. Ster. 39:49-55, 1983.

Domilnquez, 0.V., S.A. Valencla, and A.C. Loza.

On the role of sterold sulfates in hormone biasynthesis.

J. Sterold Blochern. 6: 301-304, 1975.

Doollttle, T.L. and J. Engebretsen.

Performance varlation durfing the menstrual cycle.

St. Spts. Med. Phys. Fitness 12:54-58, 1972.

Drinkwater, B.L.

Physlological responses of women to exercise.

Exerc. Spart Scl. Rev. 1: 125-153, 1973.

Drucker, W.D. and R.R. David.

Dehydroeplandrosterone sulfate (DHAS) in mormals and patients with hyperprolactinerda.

In: Adrenal androgens, Ed. A.R. Genazzanl, J.H.H. Thijssen and P.K.

S11terl. Raven Press, New York, 1980.

Dunn, J.F., NA.sula, B. C. and D. Rodbard.

Transport of sterold hormones: binding of ZI endogemous steriuds to both testosterone-binding globulin and corticosterold-binding globulin in human plasma.

J. Clin. Endocrinol. Metab. 53:56-68, 1981.

Ehara, Y., Stler, T., Van den Berg, G., Sinha, X.N. and S.S.C. Yen. Circulating prolactin levels during the menstrual cycle: eposodic release and diurnal vartation.

Am. J. Obst. Gynecol. 117: 962-1966, 1973.

Fachinett, F., Inaud1, P. and A.R. Genazzl.

Adrenal response to ACTH in hyperprolactinemic amenorrhea: effect of bromocryptine treatment.

Adrenal. Androgens (ed. A.R. Genazzi). Raven Press, New York, pp. 95-101, 1980.

Paiman, C., Winter, J.S.D. and F.I. Reyes.

Pattarns of gonadotrophins and gonadal sterolds throughout 11 fe.

C11n. Obst. Gynaeco1. 3: 467-483, 1976.

Falcht, C.B., Johnson, T.S., Mart1n, B.J., Sparks, K.E. and W.W. Wagner. Secondary anenorrhea in athletes. Lancet $2: 1145-1146,1978$. 
Forest, M. G.

Age-related response of plasma testosterone, $\$ 4$-androstenedione, and cortisol to adrenocorticotrophin in infants, children and adults.

J. Clin. Endocrinoll. Hetab. 47:931-937, 1978 .

Fraioll, F., Morett, C., Paolucci, E., Allcicco, E., Crescenzi, E.F. and G. Fortunio.

Physical exerclse stimulates marked concomtetant release of -endorphin and adrenocorticotropic hormone (ACTH) in peripheral blood in man.

Experienta $36: 987-989,1980$.

Frenkl, R., Csalay, L. and G. Csakvary.

Further experimental results concerning the relationship of muscular exercise and adrenal function.

Endokrinologie $66: 285-291,1975$.

Fries, H., Nillius, S.J. and F. Petterson.

Epldemiology of secondary amenor rhea.

An. J. Obst. Gynecol. 118: 473-479, 1974.

Frisch, R.E., Canick, J.A. and D. Tulchinsky.

Human fatty marrow aromatizes androgen to estrogen. J. Clin. Endocrinol. Metab. $51: 394-396,1980$.

Frisch, R.E., Gotz-Welbergen, A.V., MacArthur, J.W., Albright, T. Witschi, J., Bullen, B., Brinholz, J., Deed, R.B., and H. Hermann.

Deliayed menarche and amenorchea of college athletes in relation to age of onset of training.

JAMA 246: $1559-1563,1981$.

Fritz, M.A. and Li. Speroff.

The Endocrinology of the menstrual cycle: the interaction of folliculogenesls and neuroendocrine mechandsms.

Fert. Ster. 38: 509-528, 1982 .

Galbo, H., fummer, L, Peterson, I.B., Christensen, N.J., and N. Bie. Thyroid and testicular hormone responses to graded and prolonged exercise in man.

Europ. J. App1. Physio1. 36: 101-106, 1977.

Galbo, H., Christensen, $N_{*} J_{*}$, and J.J. Holst.

Glucose-induced decrease in glucagon and epinephrine responses to exercise in man.

J. Appl. Physiol.: Resp. Environ. Exerc. Phystol. 42: 525-530, 1977.

Gorski, J., Stankiewlcz, P., Bryrka, R., and K. Kiczka.

The effect of estradioll on carbohydrate utilization during prolonged exercise in rats.

Acta Physiol. Pol. 27: 361-367, 1976. 
Grosgtiann, A., Hould, P.J.A., He. Intyre, H., Evans, J., Silverstone, T."

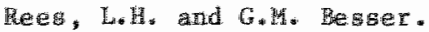

Oplate medication of amenorhoea in hyper prolactinaemia and in weight-loss related amenorthoted.

C11n. Endoctina1. 17:379-388, 1982.

Goodsman, A.L.", Descalz1, C.D., Johnson, D. and G.D. Hodgon.

Composte pattern of clrculating LH, FSH, estradiol and progesterone during the menatrual cycle in cynologus monkeys.

Proc. Soc. Exp. Blo1. Med. 155: 155:479-481, 1977.

Gurplde, E.

Tracer methods in hormone tesearch.

Monogr. Eadocrinol, vo1. 8. Sprlnger Verlag, Berlin, 1975.

Hall-Jurkowskd, J.E., Jones, N.L., Toews, C. and J.R. Sutton.

Effects of menstrual cycle on blood lactate, $\mathrm{O}_{2}$ dellvery, and performance during exercise.

J. App1. phygio1. $51: 1493-1499,1981$.

Harmond, G.L., HLker, J.A*, Jones, L.A. and P.K. Silteri.

Estination of the percentage of free sterold in undiluted serum by centrifugal ultraflitration dialysis.

J. Bitol. Cherm. 255: 5023-5026, 1980 .

Marris, D. V.

The female athlete: strength, endurance and performance.

In: Burke, Toward and understanding of human performance. Wilcox Press, Ithaca, 1977 .

Hembree, W.C., Bardin, C.W. and M.B. Lipsett.

A study of estrogen metabolic clearance rates and transfer factors.

J. Clin. Invest. 48: 1809-1819, 1969.

H11ler, S.G., van den Boogaard, A.M.J., Relchert, L.E. and E.V. van Hall. Intraovarian sex sterold hormone interactions and the regulation of fallicular maturation: aromatization of androgens by human granulosa cells in vitro.

J. Clin. Endocrino1. Metab. 50:640-647, 1980 .

Hohlweg, $W_{*}$ and $K$. Junknan.

Die homonale-nervose Regulterung der Funktion des hypophysen

Vorder lappens.

Kitr. wochechr. 1: $32-323,1932$.

HoLlanders, J.G.M.

Hyperandrogenisme blj de vrouw.

Thes 1s, Rotterdan, 1981.

Hollmann, W. and Th. Hettinger.

Sportmedizin-Arbelts- und Trainingsgrundlagen.

Schat tanerverlag, Stuttgart, 1981 . 
Horton, R. and J. F. Tait.

Androstenedione production and interconverzlon rates messured in peripheral blood and studies on the possible site of 1 ts conversion to testosterone. J. Clin. Invest. $45: 301-312,1966$.

Jaffe, R., Yuen, B., Keye, W., and A. Midgley.

Physiologic and pathologic profiles in circulating human prolactin.

An. J. Obst. Gynecol. 117: 757-773, 1973.

Jong de, F.M.

Secretion and production of androgens.

Androgenen en ant1-androgenen, Int. Symp. Organon, Oss, 1982.

Judd, H.L and S.S.C. Yen.

Serum androstenedione and testosterome levels during the menstrual cycle. J. Clin. Endocrinol. 36: 475-481, 1973.

Judd, S.J., Rakoff, J.S. and S..S.C. Yen.

Inhibition of gonadotropin and prolactin release by dopamin: Effect of endogenous estradiol levels.

J. Clin. Endocrinol. Metab. 117: 494-498, 1978*

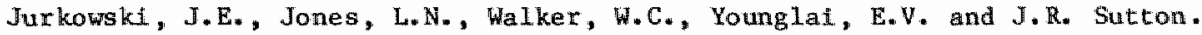
Ovarian hormoinal repsonses to exerclse. J. Appl. Physiol.: Resplrat.

Environ. Exercise Physiol. 44: 109-114, 1978.

Karsch, F.J., Welck, R.F., Butler, W.R., Dierschke, D.J., Krey, L.C., Weiss, G., Hotchkiss, J., Yamajl, T. and $\mathbb{R}$. Knobil.

Induced LH surges in the Rhesus monkey: strength-duration characteristics of the estrogen stimulus.

Endocrino1. 92:1740-1747, 1973.

Karsch, F.J. and G.P. Sutton.

An intra-ovarian site for the luteolytle actlon of estrogen in the rhesus monkey.

Endocrinol. 98: 553-559, 1976 .

Kato, T., and R. Horton.

Studies of testosterone binding globulin. J. Clin. Endorcrinol. Metab. 28: $1160-1165,1968$.

Keil, E. Scheibe, J. and A. Borner.

Der Einflus eines extremen Ausdauerlaufes auf den Ostradiol-, Testosteromund Kortisolspiegel tin Blut bel Fraven.

Med. Sport. 19: 373-375, 1979.

Kirschner, M.A. and J.B. Jacobs.

Combined ovarian and adrenal veln catheterization to determine the site(s) of androgen overproduction in hirsute women.

J. Clin. Endocrino1. 33: 199-209, 1971 .

Kirschner, M.A. and C.W. Bardin.

Andragen production and metabolism in normal and virlitized women. Metabolism 21: 199-209, 1972 . 
Kaus, B.J. and H. Woacto

Frat und sport.

Thueme Ver1ag, stuttgart, 1961 .

Krnob11, 1 .

On the contral of gonadotropla secretion in the thesus monkey.

Ree. Prog: Horm. Reis. 30: 1-46, 1974 .

Knobi1, E.

The neuroendocrine control of the menstrual cycle.

Rec. Progr. Horm. Res. 36: 53-818, 1980.

Kotenman, S.G. and B.M. Sherman.

Further studles of gonadotrophin and estradlol secretion during the pre-ovulatry phase of the menstrual cycle.

J. Clin. Endocrinol. Metab. 36: 1205-1209, 1973 .

Kulpers, H.

Varfability of physiological responses to exercise.

Thesis, Hastricht, 1983.

Kulkarn1, P.N., Slmpson, A.A. and W.H. Moger.

Modulation of pitultary respongiveness to LHRH by androgens in ovariectomized fiemale rats.

Can. J. Phys1o1. Pharmacol. 55: 188-192, 1977.

Kuoppasalril, K., Naveri, H., Harkonen, M. and H. Adlercreutz.

Plasma cortisol, androstenedione, testosterone and luteinizing hormone in running exercise of different intensities.

Scan. J. Clin. Invest. 40: 411-418, 1980.

Kuoppasalmi, K., Naveri, H., Kosunen, K., Harkonen, M. and H. Adlercreutz. Plasma serold levels in muscular exercise.

Blochemestry of exercisie IV-B (Eds.J. Poortmans, G. Nisset).

University Park Press, Baltimore, 1981.

Lake Polan M, and H.R. Behrman *

Prolactin-stimulated ovartan androgen metabolisn.

Am. J. Obstet. Gyneco1. 139: 487-491, 1981.

Lata, G.F., Hu, H.K., Bagshew, G. and R.F. Tucker.

Equilibrium and kinetic characteristics of sterold interactions with human plasma sex gterold binding protein.

Arch. Blochen. Btophys . 199(1): 20-227, 1980 .

Lenton, E.A., Cooke I.D., Sampron G.A. and L. Sexton.

Destradtol secretion in men and pre-menopausal women.

Clin. Endocrinol. 9: 37-47, 1978 .

Lenton, E. A., Brook L.M., Sobowale O. and I.D. Cooke.

Prolactin concentrations in normal menstrual cycles and conception cycles. Clin. Endocrinol. 10: 383-391, 1979. 
Leyendecker, G., Wardlaw, S. and Wocke.

Experimental studies on the endocrine regulaton dirlug the pre-oviatory phase of the human menstrual cycle. Acta Endocrinol. 71 : 160-178, 1972.

Lin, M. T*, Estergreen, $V_{1}$. and G.E. Moss.

In vivo metabolites of ( $\left.{ }^{14} \mathrm{C}\right)$ progesterone fin bovine muscle and adpose tissue.

Sterolds 32: $547-561,1978$.

Little, B., Billiar, R.B., Rahman, S.S., Johnson, W.A., Takaokia, Y. azd R. J. White.

In vivo aspects of progesterone distribution and metabolisth.

Ars. I. Obstet. Gynecol. 123: 527-534, 1975.

Lobo, R.A., Kletzky O.A., Kaptein E.M. and U. Goebelsmann.

Prolactin modulation of dehydro-epiandrosterone sulfate secretion.

Am. J. Obstet. Gyneco1. 138: 632-636, 1980.

Longcope, C., and K. I. H. WLLlams.

The metabolusm of estrogens in normal women after pulse injectlons of 3 H-estradiol and 3 H-estrone.

J. Clin. Endocrinol. Metab. 38: 602-607, 1974a

Longcope, C.L., Pratt, J.H., Schneider, S.H. and S.E. Fineberg*

The in vivo metabolisn of androgens by muscle and adipose tissue of nomal men. Sterotds, 28: 521-533, 1976.

Longcope, C., Pratt, J.H., Schmelder, S.H. and S.E. Fineberg.

In vivo studies on the metabolism of estrogens by muscle and adpose tissue of normale males. Gin. Endocrinol. Metab. 43: 1134-1145, 1976.

Longcope, C., Pratt, J.H., Schnetder, S.H. and S. E. Fineberg. Aronatization of androgens by muscle and adipose tissue in vivo. J. Clin. Endocrinol. Metab. 46: 146-156, 1978.

Longcope, C., Layne, D.S. and J.F. Tait.

Wetabolic clearance rates and interconversions of estrone and 178-estradiol. in normal males and females.

J.Clin. Invest. 47: 93-106, 1968 .

Lutter, J.M., and S. Cushman *

Menstrual patterns in female runners. Phys. sports Med. 10 (9): 60-72, 1982.

MeArthur, J.W., Buller, B.A., Bertins, I.Z., Panago, M., Badger, T.M. "and A. K1 banski.

Hypothalamic amenorrhea in runners of normal body composition. Endocrin.

Res. Comm. 7: 13-25, 1980 .

MeNatty, K.P.

Relationship between plasma prolactin and the endrocrine microenvironment of the developing antral follicle. Fert. Ster. 32: 433-438, 1979. 
MeNatty, K.P. and R. S. Sayers.

Relationship betwen the endoctine enviroment within the cratian follicle and the bubsequent rate of progesterone secretion by huan grandosa cells in vitro.

J. Endocreno1. $66: 391-400,1975$.

MeNatey, K. P., Batrd, D.T., Bolton A., Chambers P., Corker, C.S. and H. Me Lean.

Concentrations of egtrogenes and androgens in human ovarian plasina and follicular fluld throughout the menstrual cycle.

J. Endocr nol. 71:77-85, 1976.

MeNatty, K. P. and D. T. Balrd.

The relationshtp between FSH, androstemedlone and oestradiol in hurnan folltcular fluld.

J. Endocrinol. 76:527-531, 1978 .

MeNatty, K.P., Makris A., Reinhold V.N., De Crazla C., Osathanondh R. and K.J. Ryan.

Metabolism of androstenedione by human ovarion tissues in vitro with particular reference to reductase and aromatase activity.

Sterolds. 34: 429-443, 1979 .

MeNatty, K.P., Sawers, R.S. and A.S. Mc. Nellly.

A possible role for prolactin in control of steraid sectrion by the thuman Graafian folldele.

Nature $250: 653-655,1974$.

McNe1l1y, A.S. and T. Chard.

Circulating lievels of prolactia during the menstrual cycle.

clin. Endocrinol. 3:105-112, 1974.

MeNeil1y, A. S.

Prolactin and the control of gonadotrophin secretion in the female.

J. Reprod. Fert. 58: 537-549, 1980.

Merimee, T.J., Flneberg, S.E., and J.E. Tyson.

Fluctuations of human growth homone secretion during menstrual cycle:

response to arginine.

Metabol1sm 18: 606-608, 1969.

Metcalf, M. G.

Dehydroepiandrosterone sulfate in plasma: hydrolysis, extraction and rad Lo immunoas say.

Sterolds $28: 311-324,1976$.

Mitha11, G.

Hormone secretion by the human ovary.

Gyneco1. Invest. $1: 5-20,1970$.

Millahn, H.P., and A. Drecoll.

Die zyklusbedingten Schwankungen der körperlichen Leistungsfähigkeit der prau.

Med. Sport 5: 129-134, 1968. 
Moll, G.W., and R.L. Rosenfleld.

Testosterone binding and free plasma androgen concentrations under physiological conditions: characterization by flow-dialysis technique.

3. Gin. Endocrinol. Metab. 49: 730-737, 1979.

Moll, G.W., Rosenfleld, R.L. and J.H. Melke.

Estradiol-testosterone binding interactions and free plasma estradiol under physiological conditions.

J. Gin. Endocrinol. Metab. 52: 868-874, 1980.

Moon, Y.S., Tsung, B.K., Simpson, C. and D. I. Armstrong*

17- Bestradiol biosynthesis in cultures granulosa thecal celis of human

owartan follicles: stimulation by follicle stimulating hormone.

J. Clin. Endocrinol. Metab. 47: 263-267, 1978.

Monroe, S., Jaffe, R. and A.R. M1dgley.

Regulation of human gonadotrophins XII. Increase in serum gonadotropins in response to estradiol.

J. Clin. Endocrinol.Met. $34: 342-347,1972$.

Moretti, C., Cappa M., Paolucci D., Fabbri A., Santoro C., Fraioli F. and

A. Isidori.

Pitultary Responses to physical exercise: sex differences.

In: Med. Sport. Ed: E.Jok1, vol. 14 pp. 180-186. Karger, Base1, 1981 .

Morrow, P.G., Marshall, W.P., Kilm, H.J., and R. Kalkhoff.

Metabolic response to starvation. II. Effects of sex sterold administration to prem and post-menopausial women.

Metabolism. 30: 274-278, 1981 .

Moult, P.J.A., Rees, L.H. and G.M. Besser.

Pulsatile gonadotrophin secretion in hyperprolactlatem anemorrhoe and the respons to bromocriptine therapy.

Clin. Endocrinol. 16: 153-162, 1982 .

Miller-Limroth, W. and E. Lohaus.

Die Schwankungen der Leistungsfäigkeit innerhalb des Menstruationszyclus bei trainierten und untrainierten Frauen.

Sportartz, Sportmed. 14: 23-29, 1963.

Nelson, D. H.

The adrenal cortex: physlologlcal function and disease.

Major problems in intern." med. voll. XVIIL. Saunders, Philadelphta, 1980.

Ni11Lus, S. and L. Wide.

Effects of oestrogenen on serum levels of LH and FSH.

Actia Endocrinol. 65: 583-594, 1970.

N1111us, S. and L. Wide.

Induction of a mid-cycle peak of LH In young women by exogenous oestrad101-178.

J. Obst. Gynaeco1. 78: 822-827, 1971 . 
One jes, D.A.

The phatracologic control of adrenal steroldogenests.

Litie Sc. 26: 2023-2035, 1980 .

Apstad, F.K. and A. Aakvaag.

Decreased serum levels of oestradiol, teatosterone and prolactin during prolonged physical strain and sleep deprivation, and the influence of a high calory diet.

Eur: J. Appl. Physto1. 49: 343-348, 1982.

Pahlke, U., and H-P Siltka.

Menstruatlonszyklus und sportiche lelstungstähigelt trainlerter

spottlehretinnen.

Med. Sport 17: 123-126, 1977 .

Parker, L. N*, Chang, S* and W. D. Odell.

Adrenal androgens in patients wh chronlc marked ellevation of prolactin. C11in. Endocrinol. 8: 1-5, 1978.

Pearlman, W.H., Crepy, O. and M. Murphy.

Testosterone-binding levels in the serwn of women during the nomal menstrual cycle, pregnancy and the postpartun period.

J. C11n. Endocrinol. Metab. 27: 1012-1020, 1967.

De Peretti, E. and M.G. Forest.

Pattern of plasma dehydroeplandrosterone sulfate levels in humans from birth to adulthood.

J. Clin. Endocrinol Metab: $572-578,1978$.

Pesquies, P.C., Morville R., Guezennec C.Y. and B.D. Serrurler.

Effects of prolonged physical exercise on blood concentrations of adrenal and testcular androgens.

In: Int. Serles Sp. Sict. Wolume 11 B. Bloch. Exerc. IV B; Ed. J. Poortmans, G. Nisset, University Park Press, Baltimore, 1981.

Poortman, J., Thijssen, J.H.H. and F. Schwarz. Androgen production and conversion to estrogens in normal post-menopausal women and in selected breast cancer patients.

J. Clin. Endocrinol.Metab. 37: 101-109, 1973.

Poortman, I.

Sex hormones and mammary cancer

Thes 1s, Utrecht, 1974 .

Pratt, J.H. and C. Longcope.

Effects of adrenocorticotropin on production rates and metabolic clearance rates of testosterone and estradiol.

J. Clin. Endocrinol. Metab. 47: 307-314, 1978.

Prior, J.C., K. Cameron, B.H. Yuen, J. Thomas.

Menstrual cycle changes wt marathon tralning: Anovulation and short

1 uteri. phase.

Can. J. Appl. Sport Sc1. 7: 173-177, 1982. 
Prior, J.C.

Endocrine "conditioning" with endurance training a preilminary review. Car. J. Appl. Sport. Scl. 7:3, 148-157, 1982.

Reinke, U., Ansah, B., and K.D. Volgt.

Effect of the menstrual cycle on carbohydrate and lipid metabolism in normal females.

Acta Endocrino1. 69: 762-768, 1972.

Ropert, J.F., Quigley, M.E. and S.S.C. Yen.

Endogenous oprates modulate pulsatile luteinizing hormone relaese in hunan. J. C11n. Endocrinol. Metab. 52: 583-585, 1981 .

Rowe11, L., Blackman, J. and R. Bruce.

Indocyantine green clearance and estimated hepatic blood flow during mild to maximal exercise in upright man.

J. Clin. Invest. 43:1677-1690, 1964.

Santen, R.J. and C.H. Bardin.

Eplsodic luteinizing hormone secretion in man. Pulse analyses, clinical

interpretation, physiological mechanism.

J. Cin. Invest. Metab. 36:55-63, 1973.

Sarris, $W_{*}$ and F. Wilkending.

On some non-parametric tests of predicted order.

Biometr. 3: $339-345,1977$.

Schmitt, W.M., Kindermann, W., Schnabe1, A., and G. Biro.

Metabolism und homonelle Regulation bef Marathonlaufern under besonderer Berucksicht 1 gung von Lebensalter, Tralningszustand und Geschlecht *

Dtsch. Z. Sportmed. 32: 1-7, 1981.

Schoene, R*B., Robertson, H.T., PLerson, D.J. and A.P. Peterson.

Respiratory drives and exercise in the menstrual cycles of athletic and no-athletic women.

J. App1. Physio1.: Resp. Environ. Exerc. Physiol. 50: 1300-1305, 1981.

Schwanitz R., Goretzlehmer G. and 0 . Hamann.

Der Elnfluss der Menstruationzyklus und verschiedener hormonaler

Kontrazeptiva auf Parameter des Kohlenhydratstofwechsels bei

Husdaue rbelastung.

Med. Sport 19: $366-369,1973$.

Shangold, M., Freeman, R., Thysen, B., and M.t. Gatz.

The Relationshlp between long distance running, plasma progesterone, and luteal phase length.

Fert11. Ster11. 31: 130-133, 1979.

Shaw, R.W., Butt, W.R., London, D.R. and J.C. Marshall.

varlation in response to synthetic lutelnizing hormone-relleaslng hormone (LH-RH) at different phases of the same menstrual cycle in normal wonen. J. Obst. Gynaecol. 81:632-639, 1974 . 
Shatw', 跳. Wh.

Oestrogen modulation of gonadotrophin release.

Proc. Whal Soc. Wed. 68: 73-75, 1975 .

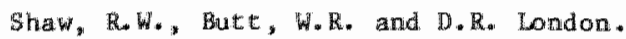

The effect of progesterone on FSH and LH response to LHRH in nomal women. Cl1a. Endoctino1. 4: 543-550, 1975.

Shav, 跑.

Weuroendocrinology of the menstrual cycle in humans.

Olth. Endocinol. Metab. 7(3): 531-559, 1978.

Speroff, L., and D. B. Redwine.

Exercise and mertisul function.

Phys. Sport Med. 5 (8): 42-45, 1980.

Stephenson, L.A., Kolka, M.A. and J.E. Wllkerson.

Metabolic and therworegulatory responses to exercise during the human

mentrual cycle. Med. Sci. Sports Exercise 14: 270-275, 1982.

Stowffer, R.L., Nuxom, W.E and G.D. Hodgen.

Estrogen inhibition of basal and gonadotropin-stimulated progesterone production by rhesug monkey luteal cells in vitro.

Endocrinol. 101: 1157-1203, 1977.

Sutton, J.R., Coleman, M.J., Casey, J. and L. Lazarus.

Andtogen responses during physical exercise.

Brit. Med. J. 1: $520-522,1973$.

Tagat $z_{,}$G.E., and E. Gurpide.

Hormone secretion by the normal humam ovary.

In: Handbook of physiology, Sect. 7: Endocrnol. Vol. II. Pt. 1. Am. Physiol. Soc. (Eds. R. O. Greep, E.B. Astwood). Willians and Wilkins, Baltimore, pp. $603-613,1973$.

Talt, J.F.

The use of isotoplc sterolds for the measurements of production rates in vivo.

J. Clin. Endocrinol. Metab. 23:1285-1297, 1963.

Tavernett, R.R., Rosenbaum, W. Kelly, W.G.H. Christy, N.P. and M.S.

Rog1nsky.

Widence for the presence in human plasma of an estrogen-binding factor other than albumin: abnormal binding of estradiol in men with hepatic cirrhosis.

J. C1ta. Endocrinol. Metab. 27: 920-931, 1967.

Träger, L.

Sterold hormonen.

Springer-Verlag, Berlin, 1977.

Treloar, A.E., Boynton, R.E., Benn, B.G. and B.W. Brown.

Variation of the human menatrual cycle through reproductive life.

Int. J. Fert. 12:77-126, 1967. 
Vekemans, P., Delvoye, M., Hemite, M.L., and C. Robijn.

Serum prolactin levelis during the menstrul cycle.

J. Clin. Endocrinol. Metab. 44: 989-993, 1977.

Vermeulen, A.

Testosterome in plasma: a physlopathological study. Verhandelingen Kon.

Acad. Geneeskd. Wan Belgle. 35: 95-180, 1973.

Wermewlen, A. and L. Werdonck.

Plasma androgen levels during the menstrual cycle.

Am. J. Gynaeco1. 125: 491-494, 1976.

Vermeulen, A*, Suy, E. and R. Rubens.

Effect of prolactin on plasma DHEA (S) levels.

J. Clin. Endocrinol. Metab. 44: 1222-1226, 1977.

Vermeulen, A. and L. Verdonck.

Studies on the binding of testosterone to human plasma.

Sterolds 11: $609-635,1968$.

Verrievilen, A. and S. Ando.

Prolactin and adrenal androgen secretion.

Clin. Endocrino1. 8: 195-303, 1978.

Vermeulen, A. and S. Ando.

Metabolic clearance rate and interconversion of androgens and the influence of the free androgen fraction.

J. Clin. Endocrinol. Metab. 48: 320-326, 1979.

Verstappen, F.T.J., Kulpers, H. and H.A. Kelzer.

Reproducibility of aeroblc power and related physiologicall varlables in wornen.

In: Women and Sport. Serles on Med. Sport. 14:14: 133-142, 1981.

Verstappen, F.T.J., Hupperts, R.M. and L.H.E.H. Snoeckx.

Effect of training speciflcity on maximal treadmflil and bicycle ergoneter exercise.

Int. J. Sports Med. 3: 43-46, 1982.

VIgersky, R.A., Kono S., Sauer M., Lipsett M.B. and D. Lynn Lorlaux.

Relative Hinding of testosterone and estradiol to

testos terone-es tradlol-binding glabulin.

J. Clin. Endocrinol. Metab. 49: 899-904, 1979.

Vollman, R.F.

The menstrual cycle.

Major problems in obst. gyn. vol. 7 Saunders Phil. London. Toronto, 1977.

Wellis, C.L.

The female athlete, muths abd superstitions put to rest.

In: Burke, Toward an understanding of hurwan performance.

W1 cox Press, Ithaca, 1977. 


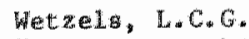

Ultrasonographlical aspects of follicie growth.

Theses dis, Matraticht, 1983.

Wetzel. , L.C.G., Hoogland, H.J. and I. de Haan.

Basal boty terperature as a method of ovulation detection: comparison with ultasonographical find Lngs.

gynacel. Obstet. Invest. 13: 235-240, 1982.

MHLIIIAs; R.H. (Ed)

Textbook of Endocinology (6th Edition).

W. Bi. Saunders, New York, 1981.

Wu, C.H., Motohasht T., Abdel-Rahman H.A., Flickinger G.L. and G. Mikhail. Eree and proteln-bound plasma estradiol-17B dur 1 ing the menstrual cycle. J. Clin. Endocrinol. Metab. 43: 436-445, 1976.

Ven, S. S.C. and C.C. Tgai.

Acute gonadotropin release induced by exogenous estradiol during the add-follicular phase of the menstrual cycle. J. Clin. Endocrino1. Metab. 34: 298-305, 1972.

Yen, S.S.C., Tsai, C.C., Naftolin, F., Vandenberg, G. and L. Ajabor. Pulsatile patterns of gonadotrophin release in subjects with and without ovarlan function.

J. Cl1n. Endacrinol. Metab. 34: 671-676, 1972 .

Yen, S.S.C, Vandenberg, G., Reabr, R. and Y. Ehara.

Varlation of pltultary responsiveness to synthetic LRF during different. phases of the menstrual cycle.

J. Clin. Endocrinol. Metab. 35: 931-934, 1972.

Young, J.R. and R.B. Jaffe.

Strength-duration characteristics of estrogen effects on gonadotropin response to gonadotropin-releasing homone in women. II. Effects of varying concentrations of estradiol.

J. Clin. Endocrinol. Metab. 42: 432-442, 1976. 
Table A.1

Plasma $L H$ concentrations $\left(I U .1^{-1}\right)$ in the two hours before and after exercilse (study IV).

Subject code

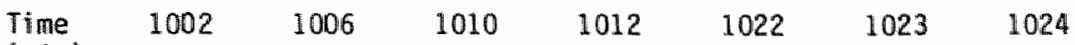

(min)

\begin{tabular}{lrlllllll}
\hline B E & -105 & 5.5 & 4.6 & 5.5 & 5.4 & 7.9 & 7.1 & 6.8 \\
E X & -90 & 5.5 & 5.5 & 5.0 & 5.5 & 9.2 & 5.6 & 6.5 \\
$F$ E & -75 & 5.1 & 5.5 & 6.2 & 7.2 & 8.2 & 6.2 & 7.4 \\
0 R & -60 & 5.0 & 5.0 & 6.7 & 6.7 & 7.2 & 5.6 & 6.0 \\
R C & -45 & 5.0 & 4.2 & 6.3 & 5.9 & 7.1 & 5.2 & 7.8 \\
E I & -30 & 5.0 & 5.0 & 5.9 & 5.5 & 7.6 & 4.1 & 5.1 \\
S & -15 & 6.2 & 4.3 & 6.4 & 7.0 & 8.2 & 5.9 & 4.8 \\
E & 0 & 6.7 & 3.9 & 5.8 & 6.4 & 9.2 & 7.7 & 8.7
\end{tabular}

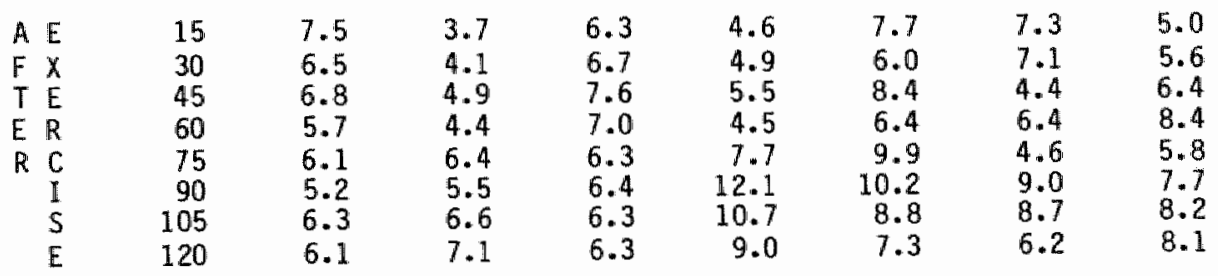


Table A:2

Plasma FSH concentration (IU. $1^{-1}$ ) in the two hours before and after exercise (study IV).

Subject code

$\begin{array}{llllllll}\text { Time } & 1002 & 1006 & 1010 & 1012 & 1022 & 1023 & 1024\end{array}$

\begin{tabular}{lrlllllll}
\hline B E & -105 & 4.4 & 5.4 & 4.7 & 1.9 & 4.7 & 7.4 & 6.0 \\
EX & -90 & 3.8 & 5.4 & 4.7 & 2.2 & 4.1 & 7.0 & 5.8 \\
$F E$ & -75 & 4.5 & 5.7 & 5.3 & 2.2 & 4.2 & 6.6 & 6.2 \\
$0 R$ & -60 & 4.4 & 4.4 & 5.3 & 2.6 & 4.8 & 5.6 & 6.0 \\
$R C$ & -45 & 3.8 & 6.0 & 5.6 & 1.9 & 4.7 & 7.0 & 5.2 \\
E I & -30 & 4.1 & 5.4 & 6.3 & 2.2 & 4.2 & 6.5 & 4.4 \\
$S$ & -15 & 4.3 & 6.8 & 6.0 & 2.5 & 4.9 & 6.8 & 4.2 \\
E & 0 & 5.0 & 5.4 & 6.1 & 2.7 & 6.0 & 7.0 & 7.8
\end{tabular}

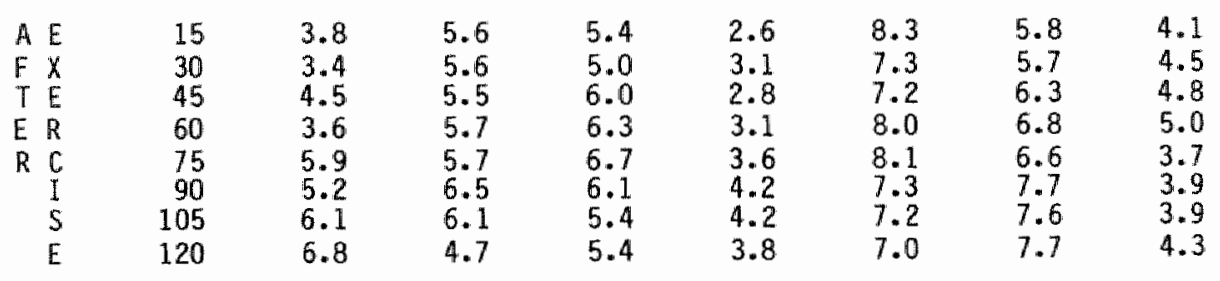


Table A.3

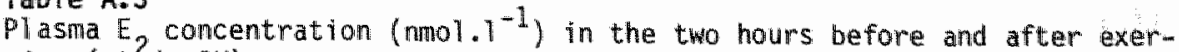
cise (sthdy IV).

Subject code

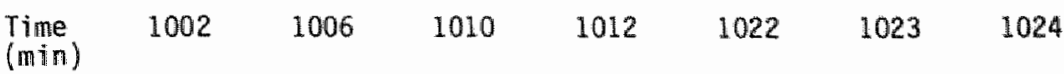

\begin{tabular}{lrlllllll}
\hline B E & -105 & 0.08 & 0.19 & 0.23 & 0.6 & 0.14 & 0.07 & 0.33 \\
EX & -90 & 0.06 & 0.17 & 0.32 & 0.69 & 0.14 & 0.05 & 0.29 \\
$F E$ & -75 & 0.07 & 0.17 & 0.42 & 0.64 & 0.12 & 0.08 & 0.32 \\
$0 R$ & -60 & 0.07 & 0.13 & 0.48 & 0.64 & 0.11 & 0.10 & 0.27 \\
R C & -45 & 0.07 & 0.18 & 0.43 & 0.57 & 0.13 & 0.09 & 0.30 \\
E I & -30 & 0.08 & 0.18 & 0.22 & 0.62 & 0.12 & 0.10 & 0.30 \\
S & -15 & 0.08 & 0.22 & 0.23 & 0.63 & 0.15 & 0.10 & 0.33 \\
E & 0 & 0.08 & 0.19 & 0.30 & 0.65 & 0.15 & 0.10 & 0.33
\end{tabular}

\begin{tabular}{|c|c|c|c|c|c|c|c|c|}
\hline$A E$ & 15 & 0.10 & 0.22 & 0.24 & 0.88 & 0.17 & 0.16 & 0.57 \\
\hline$F \bar{X}$ & 30 & 0.09 & 0.25 & 0.28 & 0.74 & 0.17 & 0.14 & 0.36 \\
\hline$T E$ & 45 & 0.08 & 0.18 & 0.30 & 0.71 & 0.16 & 0.13 & 0.37 \\
\hline$E R$ & 60 & 0.05 & 0.20 & 0.25 & 0.57 & 0.14 & 0.10 & 0.35 \\
\hline $\mathrm{C}$ & $\begin{array}{l}75 \\
90\end{array}$ & $\begin{array}{l}0.10 \\
0.09\end{array}$ & $\begin{array}{l}0.22 \\
0.20\end{array}$ & $\begin{array}{l}0.23 \\
0.24\end{array}$ & $\begin{array}{l}0.58 \\
0.59\end{array}$ & $\begin{array}{l}0.14 \\
0.14\end{array}$ & $\begin{array}{l}0.10 \\
0.11\end{array}$ & $\begin{array}{l}0.32 \\
0.34\end{array}$ \\
\hline 5 & 105 & 0.10 & 0.19 & 0.22 & 0.61 & 0.14 & 0.11 & 0.32 \\
\hline 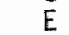 & 120 & 0.11 & 0.21 & 0.24 & 0.60 & 0.15 & 0.10 & 0.30 \\
\hline
\end{tabular}


NAWOORD

Het onderzoek wat aan dit proefschrift ten grondslag ligt, is begonnen binnen de groep medische fysiologie van de Rijksuniversiteit te Utrecht (hoofd Prof. Dr. P.A. Blersteker), waarna het, zilj het in andere vom, bij de capaciteltsgroep fysiologie van de Rijksuniwersiteit te Limburg werd voortgezet.

Velen zijn in meer of mindere mate betrokken geweest bij dit onderzoek en hen wil ik wan harte danken woor hun medewerking.

Enkele personen wil the graag bij name noemen, ondat zonder hun medewerking het proefschrift niet of nawelijks tot stand was gekomem.

- Prof.Dr. R.S. Reneman, Prof.Dr. P.d. Brombacher en Prof.Dr. J. de Haan.

Beste Rob, Paul en Jelte, jullie hebben, elk op geheel eigen wijze, en met veel geduld, gezorgd dat mijn gedachten enigszins ordelijk op papier kwarten, waarvoor ik jullie hartelijk dank.

- Dr. Jan Poortman.

Beste Jan, ik ben je weel dank verschuldigd voor je begeleiding tijdens mijn eerste wankele schreden op het pad der wetenschap. Tewens ben ik je zeer erkentelijk voor de manier, warop je het proefschrift wan kritische kanttekeningen voorzag.

- Drs. Bert Bunnik

Beste Bert, voor de kundige en vriendschappelijke wijze warop je de "clearance" experimenten mede hebt opgezet, ben ik je zeer dankbaar. Ik hoop, dat onze wetenschappelijke wegen zich in de toekomst veelvuldig kruisen.

- Alle medewerkers van het fysiologisch laboratorium te utrecht dank ik voor de ondersteuning in de initiele fase van het onderzoek.

- Dr. Arno Gijjssen en Harrie Jansen.

Beste Arno, beste Harrie, ilk ben jullie veel dank verschuldigd voor de ombaatzuchtige wijze waarop jullie in een perfode, toen het onderzoek hier stagneerde, mij hebben ondersteund.

- De medewerkers(sters) van het klinisch chemisch laboratorium van het Sint-Annadal Ziekenhuis dank ik hartelijk voor de nauwgezette wijze waarop zij de bepalingen hebben verricht. 
- Lucien Habets

Beste Lucien, je punctuele manier van werken en je inzet hebben voor dit onderzoek veel betekend, warvoor mijn dank.

- Drs. Eugene Janssen, Adje Hennissen, Peter Geurten, Gerrit van Kranenburg en Ed. Beckers.

Beste Eugene, Adje, Peter, Gerrit en Ed. Ik dank jullie hartelijk voor de manier warop jullie het vele werk dat dit onderzoek met zich meebracht hebben werricht. Vooral $j i j$ Ed was voor mij in de latste maanden onmisbaar.

- Drs. Otto varn Soest.

Beste otto, het begin van dit onderzoek was niet altijd aven gemakkeijjk. Niettemin bedank ik je voor de hulp bij de experimenten en hoop, dat jij voldoende wetenschappelijke ingangen zult vinden voor je eigen promotie.

- Dr. Arend Bonen, Dalhousie University, Halifax, Canada.

Beste Arend, het was voor mij een gelukkige onstandigheid je enige jaren geleden te ontmoeten. De hieruit voortvloeiende samenwerking is deels in dit proefschrift vastgelegd, waarvoor ik je dank.

- Marion de Vrede en Marie Louise Coenen.

Beste Marion, beste Marie Lovise, ik ben jullie zeer erkentelijk roor de werkelijk fantastische manier warop jullie mijn gepriegel hebben weten on te zetten tot een leesbare tekst.

- Mijn referenten Prof.Dr. J.H.H. Thijssen en Dr. J.L.H. Evers.

Beste Jos, beste Hans, ik ben me ervan bewust dat ik het jullie niet makkelijk heb gemaakt. Enerzijds kwam dit door het onderwerp, wat vaak onverwachte en moeilijk te interpreteren gegevens opleverde, anderzijds door het chronische tijdgebrek warin ik verkeerde, wardoor ongecorrigleerde teksten in jullie handen kwamen. Noor jullie geduld en opmerkingen mijn hartelijke dank.

- Alle proefpersonen.

Dit onderzoek was onmogelijk geweest zonder de fantastische inzet vam de proefpersonen. De belasting was voor hen warschijnlijk groter als voar alle andere medewerkers aan dit proefschrift, ik kan hen daarvoor danook niet genoeg bedanken.

- Drs. Alex Volovics en Drs. Arno Muijtjens ben ik veel dank verschuldigd voor de statistische verwerking van de gegevens. 
- Michel Janssen en Piet Zinken dank ik heel hartelijk voor de vele malen dat zij mij uit de "computer put" hebben gehaald. Zonder hun hulp was ik warschijnlijk nu nog bezig geweest.

- Het "hardloopcentrum Nijbroek" in de personen Peter en Fia Groen dank ik hartelijk voor de kleding en schoenen, die zij ons konden leveren.

- Nike International in de persoon van Jos Hemens dank ik voor de schoenen, welke er mede toe hebben bijgedragen dat een van belangrijkste problemen, de weel voorkomende blessures, nu hopelijk tot het verleden behoren.

- Ten slotte moet ik vooral $I 1 j a$, Danielle en Imo bedanken voor hum geduld, liefde en toewijding die zij voor mij hebben getoond.

Lieve Ilja, je hebt letterlijk aan de wieg gestaan van de idee voor dit onderzoek. Dat de uitwerking ervan za'n allesoverheersende stempel op ons leven zou drukken, hebben we niet kunnen voorzien. Dat je nochthans in staat was, mij hierin volledig te steunen, stemt mij tot grote dankbaarheid. Vanaf nu ligt er een nieuwe weg voor ons. 
Hans Keizer werd in 1940 geboren in Medemblik. Wa het behalen van het einddiploma HBS-B (1959) werd de diensplicht vervuld. Van 1962 tot en met 1966 volgde hij de opleiding tot Leraar Lichamelijk opwoeding. In deze functie was hij tot en met 1969 werkzaam in de gemeenten Haamememeer en Leiden. In $1969 \mathrm{ging}$ hij Geneeskunde studeren aan de Rijksuniversiteit te Utrecht, terwijl hij tevens deels part-time, deels full-time werkzaam was als wetenschappelijk ambtenaar aan het fysiologisch laboratorium van dezelfde universiteit. In zijn studieperiode was hij tevens werkzam als universitair sportieider en bondscoach voor het midden- en lange afstand lopen bij de Koninkiijke Nederlandse Atletiek Unie. Van 1975 tot 1980 was hij eveneens als part-time docent fysiologie verbonden aan de Academie voor Lichamelijke Oproeding te Amsterdam. Na in 1977 het artsexamen te hebben afgelegd, was hij tot februari 1980 als wetenschappelijk medewerker verbonden aan het fysiologisch laboratoriun te Utrecht. Vanaf deze laatste datum is hij als wetenschappelijk medewerker, later als hoofdmedewerker, werkaam bij de Capaciteitsgroep Fysiologie van de Rijksuniversiteit te Limburg. 